LA-UR- 93-650
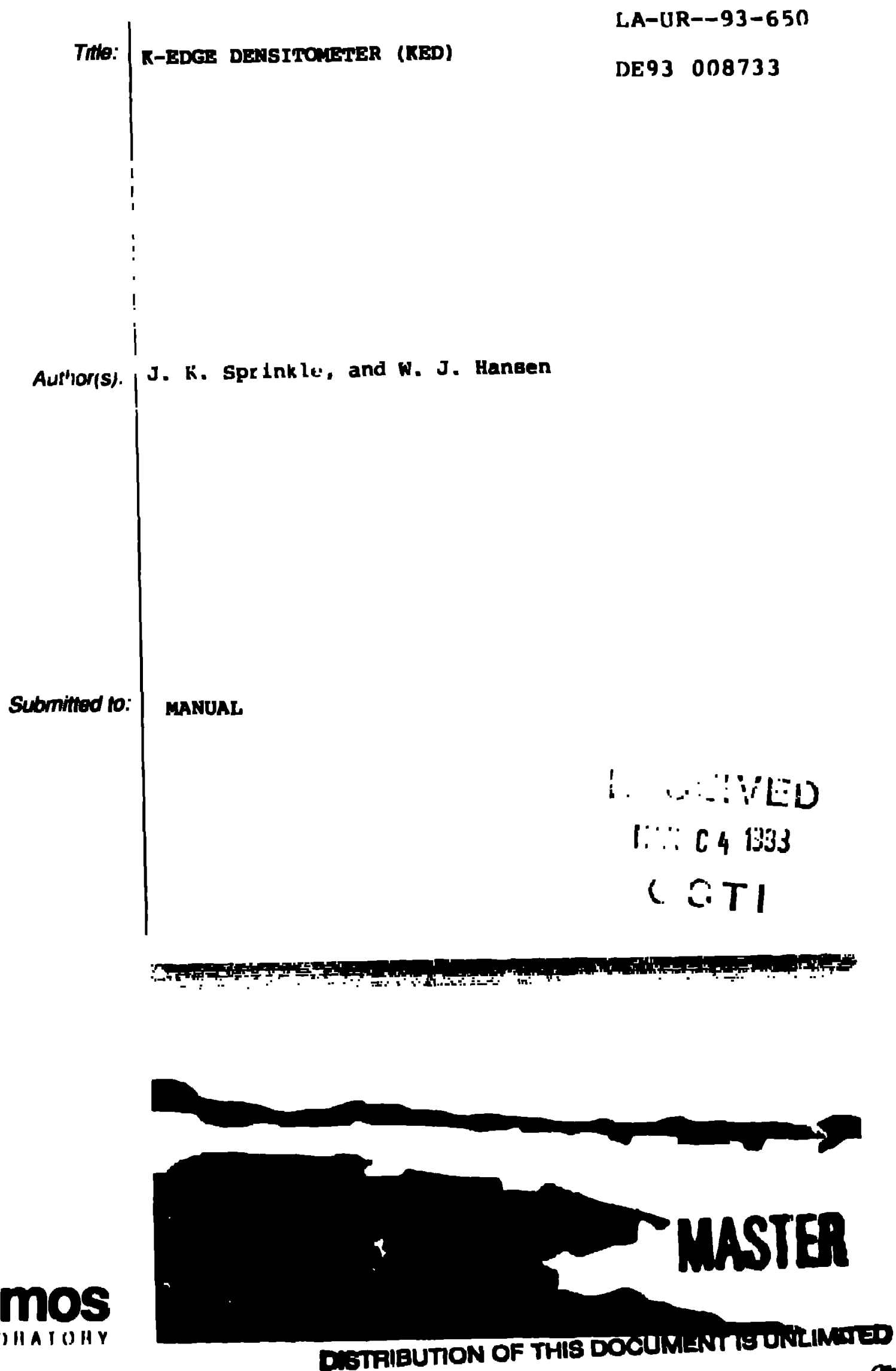

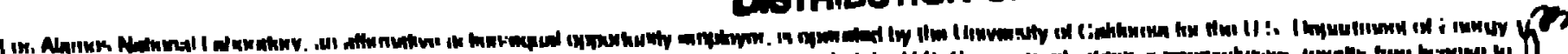

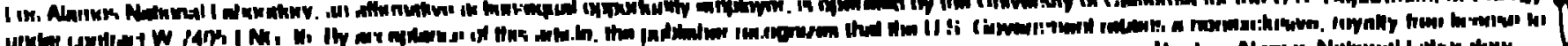

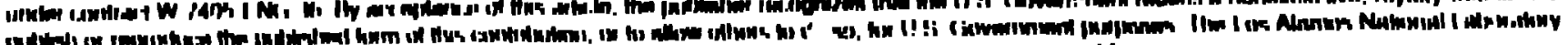

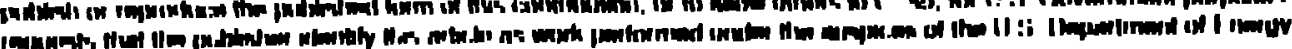




\title{
K-EDGE DENSITOMETER \\ (KED)
}

\author{
User Manual
}

\section{James K. Sprinkle Jr. and Walter J. Hansen \\ Los Alamos National Laboratory \\ Los Alamos, NM 87544}

February 11, 1993

\section{IMK 'LAIMER}

\begin{abstract}
This repurt was prepareal as an nccount of work spunsured hy an mgenty of the I Inileal Sinten

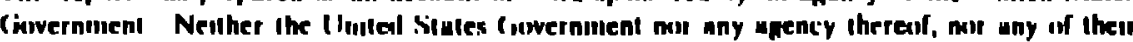

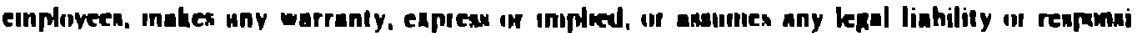

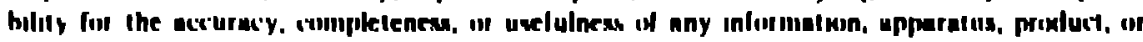

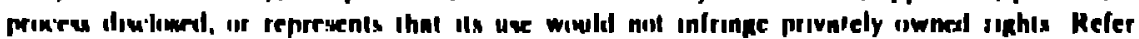

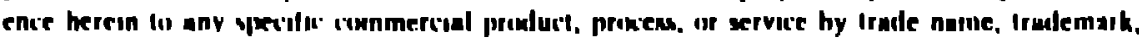

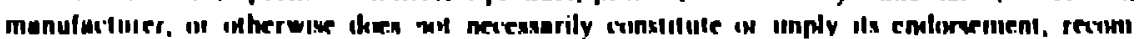

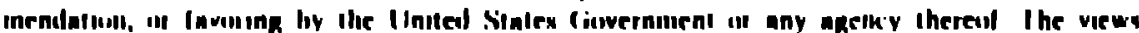

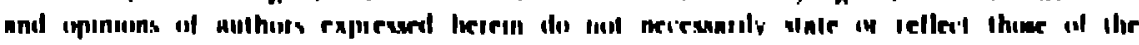

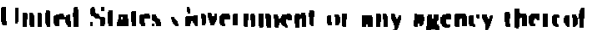




\section{TABLE OF CONTENTS}

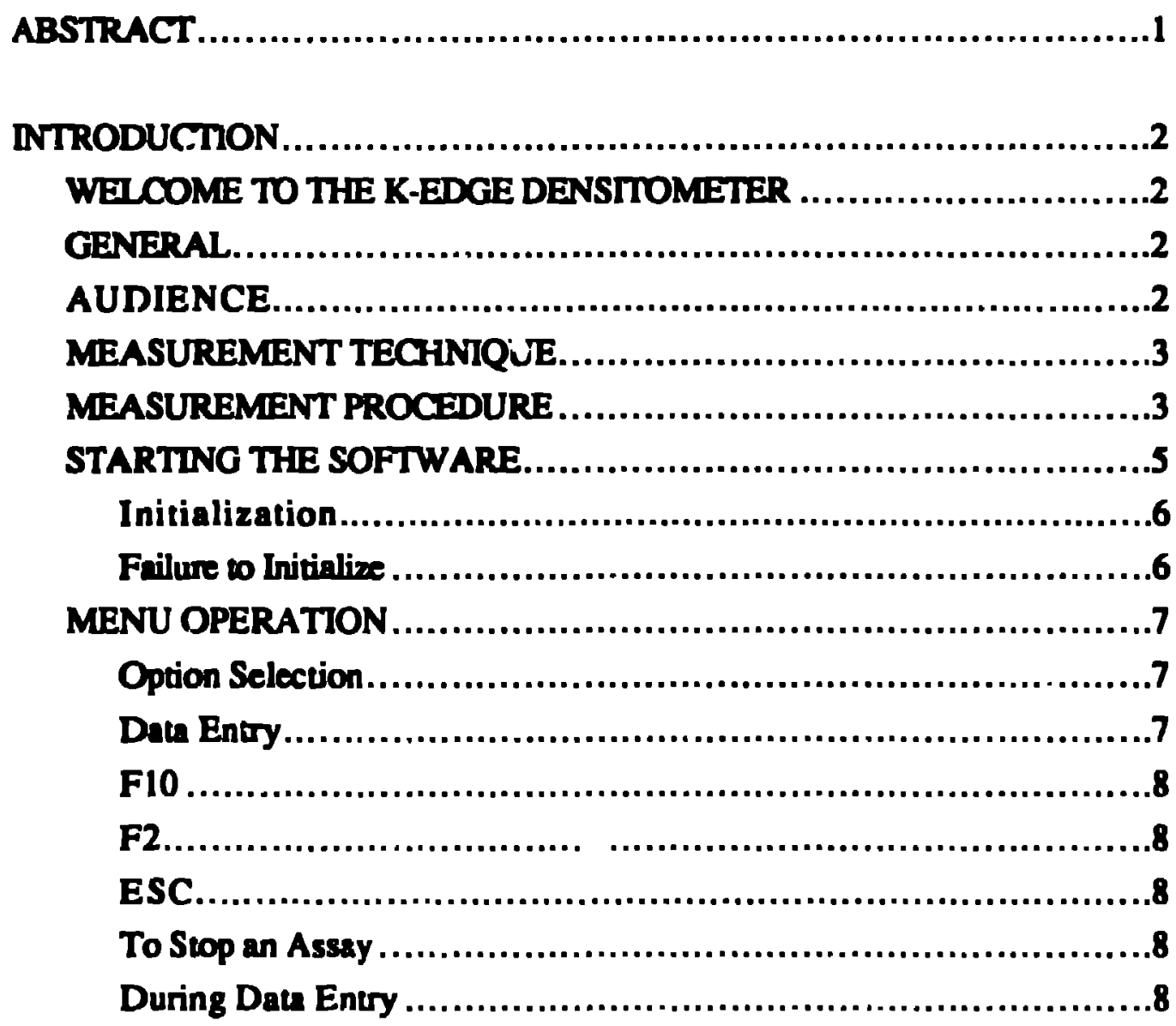

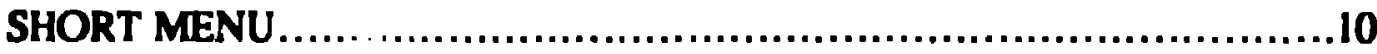

USING THE SHORT MENU .......................................10

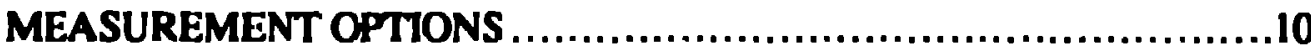

To Stop a Measurement ..........................................11

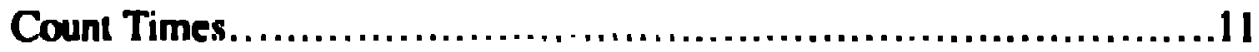

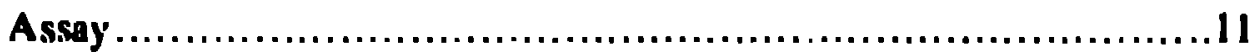

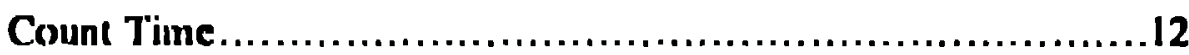

Measurement Results File ..................................... 12

Spectral Data File Name ...................................13

Display Juring Acquisition ..................................13

Sample I'rintout (Normal (Output) ............................14

I song Printoul ...........................................

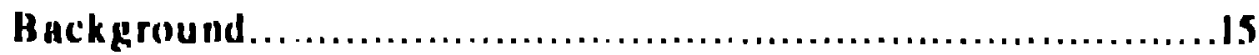

Recommendal linequency .................................16 


\section{TABLE OF CONTENTS}

(cont.)

Count Time. .16

Measurement Results File

Waming Limit ..................................................17

Spectral Data File Name ..........................................17

Display During Acquisition .....................................17

Sample Printout (Normal) ....................................18

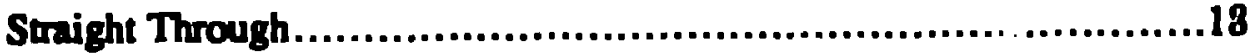

Recommended Frequency........................................19

Count Time...... .................................................19

Measurement Results File .........................................19

Warning Limits ..................................................20

Spectrol Data File Name .........................................20

Sample Printout (Normal) .....................................21

MC-Bias ........................................................21

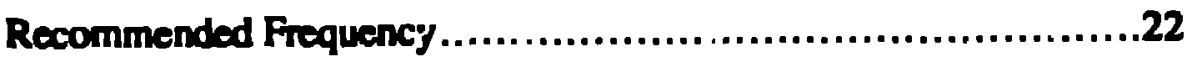

Count Time...................................................22

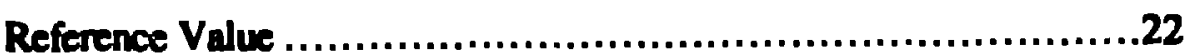

Historical Standard Deviation....................................23

Waming and Action Limits .................................23

Spectral Data File Narre ......................................23

Sample Printout ............................................24

MC-Precision ......................................................

Recommended Frequency.....................................25

Count Time........................................................

Number of Runs .................................................

Warning and Action Limits ...............................26

Spectral Duta lïle Nnme ....................................26

Sample Printout (Nommal) ....................................27

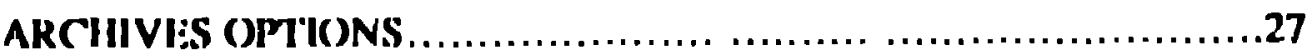

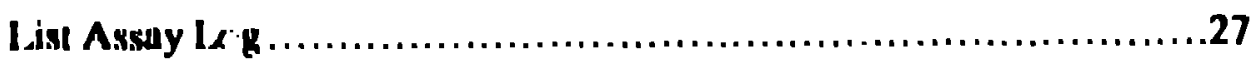

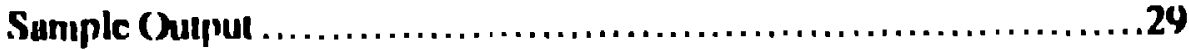

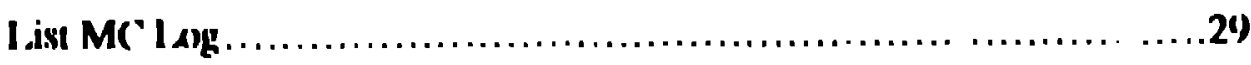

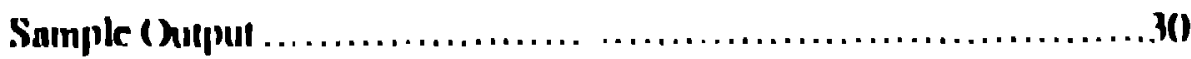




\section{TABLE OF CONTENTS}

(cont.)

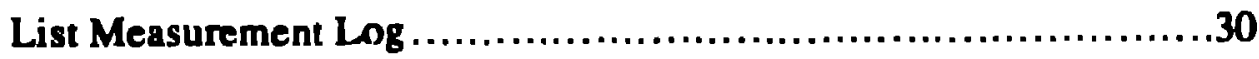

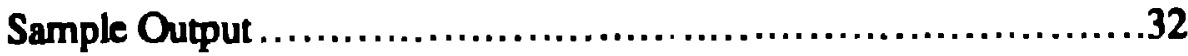

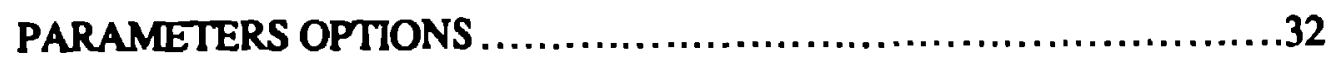

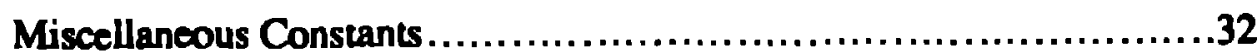

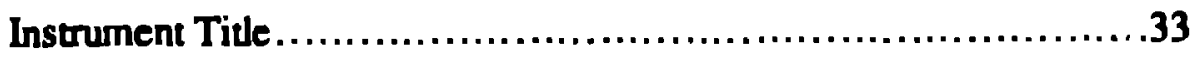

Frint Level..........................................................

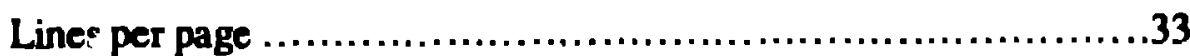

Write Spectral Data to Disk...........................................

Automatic Background ...........................................34

Autom_tric Straight-Through ......................................34

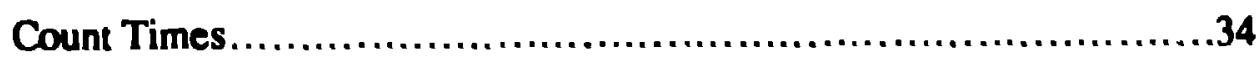

MENU/EXTT OPTIONS ...................................................

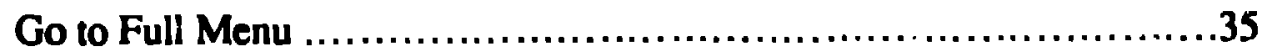

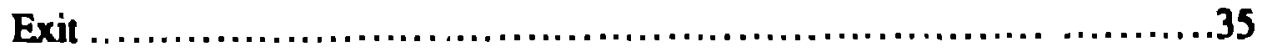

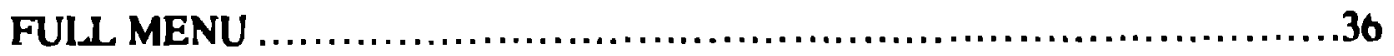

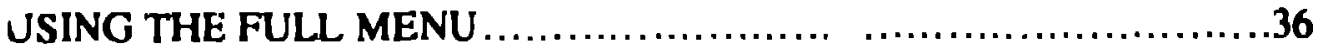

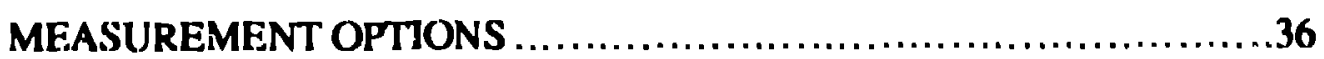

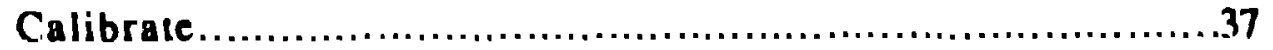

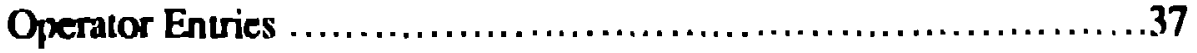

Count Times and Number of Cycles..................................

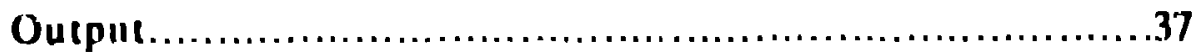

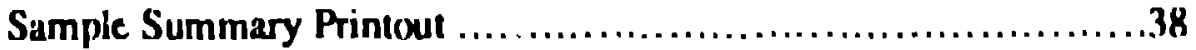

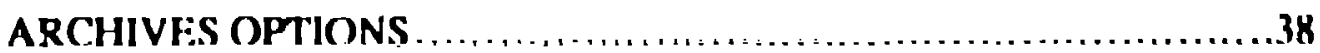

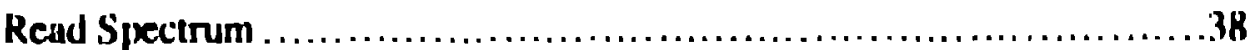

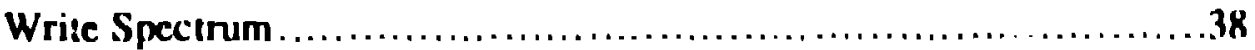

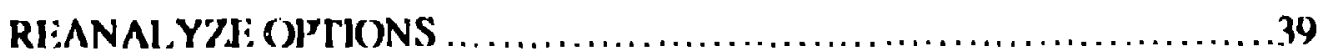

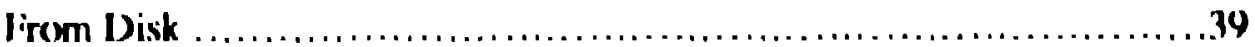

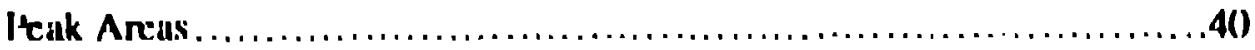

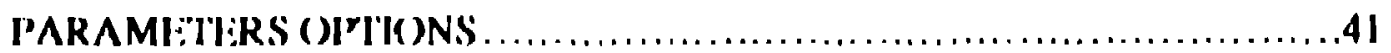

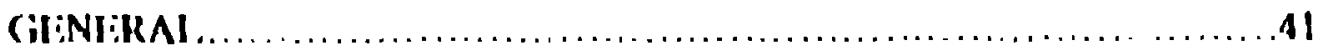

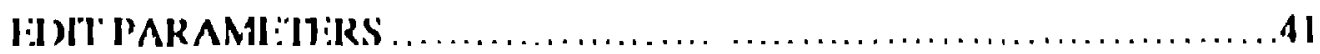




\section{TABLE OF CONTENTS}

(cont.)

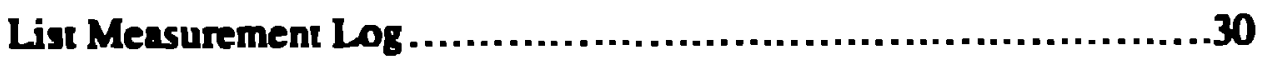

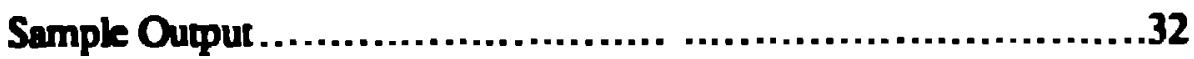

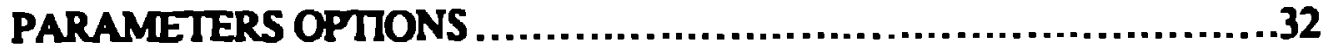

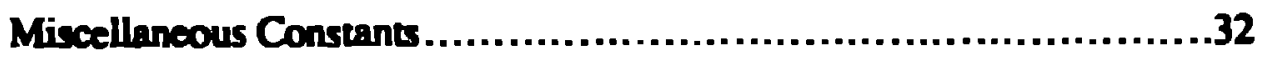

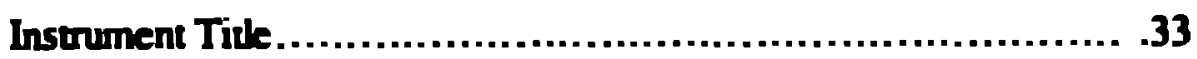

Frint Level. .........................................................

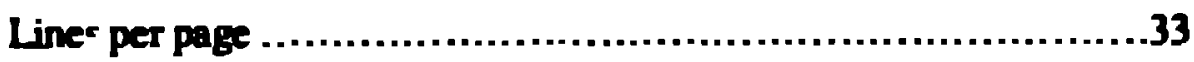

Write Spectral Date to Disk............................................33

Automatic Background ..............................................34

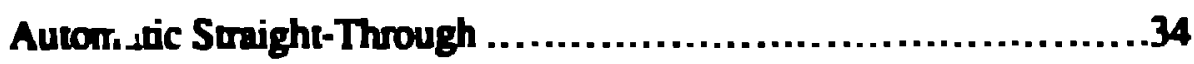

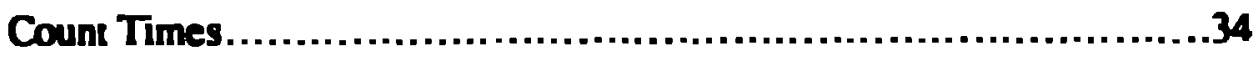

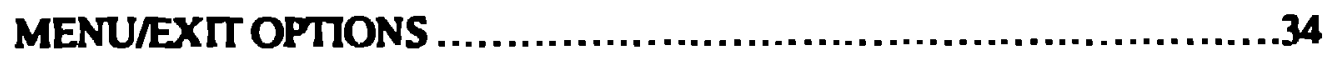

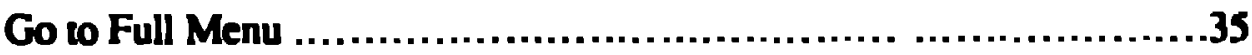

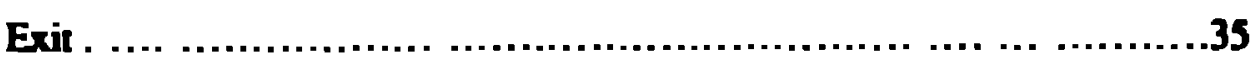

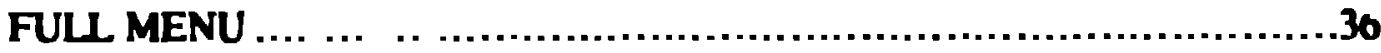

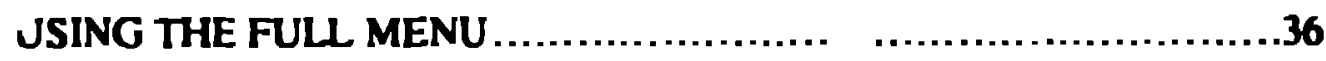

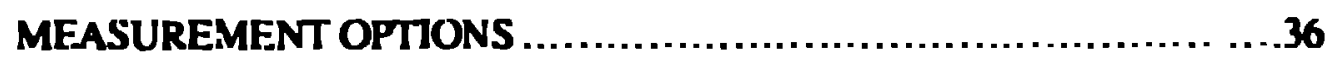

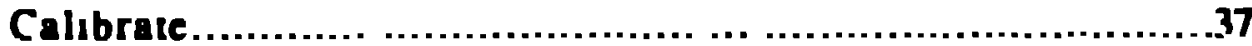

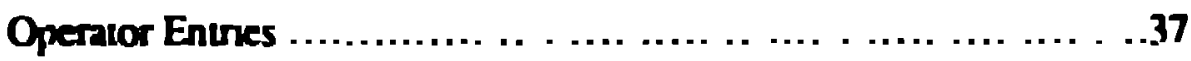

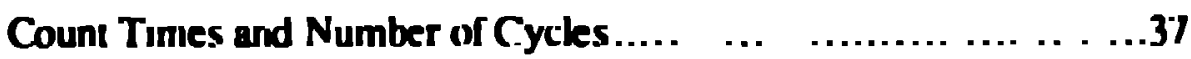

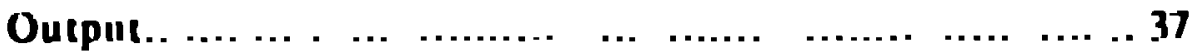

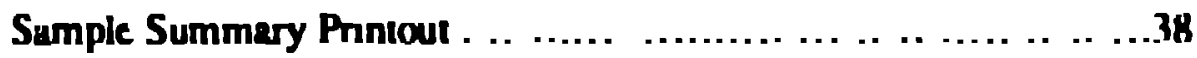

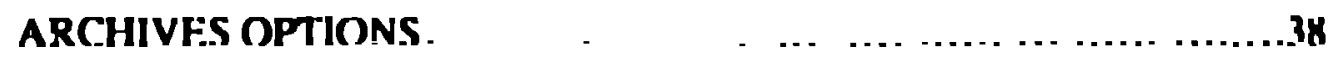

$\begin{array}{lllllllllllll}\text { Read Spectrum . } & \ldots & \ldots & \ldots & . & \ldots & \ldots & \ldots & \ldots & \ldots & \ldots & \ldots & . .\end{array}$

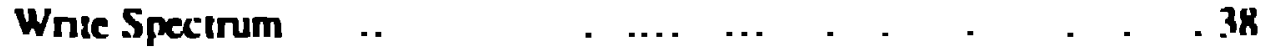

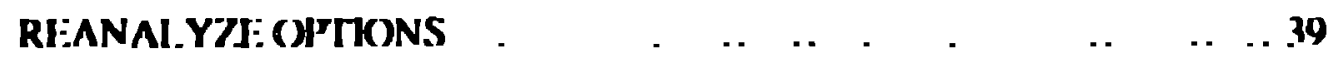

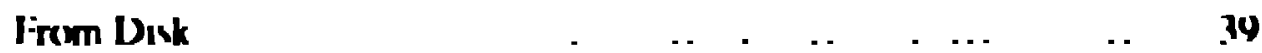

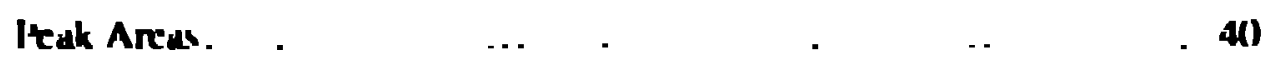

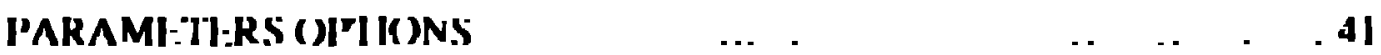

GiTIRAL.

IJ) PARAMII.II RS H 


\section{TABLE OF CONTENTS}

(cont.)

Peak Region Summation.........................................62

Background Determination ..........................................62

Energy Calibration ...............................................63

FWHM Determination ...............................................63

K-EDGE DENSITOMETRY ........................................64

EXTRAPOLATION TO THE EDGE...................................69

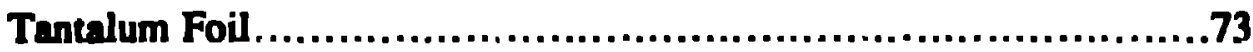

Rate-Loss Source Considerations .................................73

AARON'S BUIIBLE TEST FOR ASSA YS ............................74

MC-PRECISION TESTS ...........................................75

Chi-Square Test..................................................75

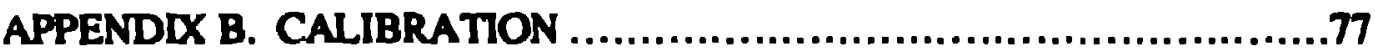

INTRODUCTION ......................................................77

DATA ACQUISITION ..............................................77

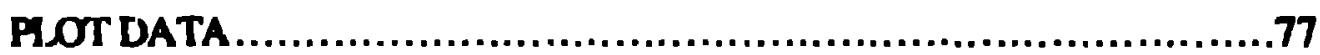

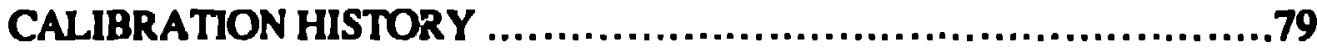

APPENDIX C. TROUBLE SHOOTING .................................82

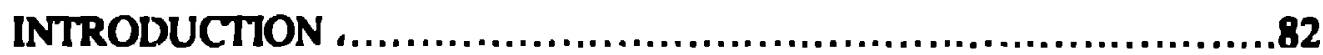

MULTICHANNEL. ANALYZER ....................................82

COMPUTER.............................................................

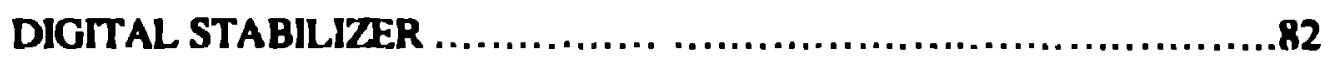

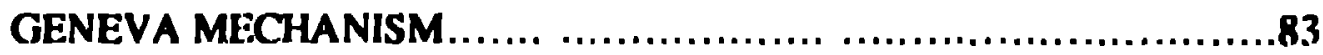

MEASURFD STANDARD DEVIATTON FXCEEDS EXPFC.TED

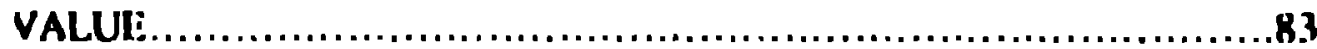

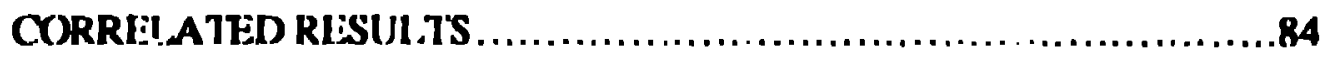

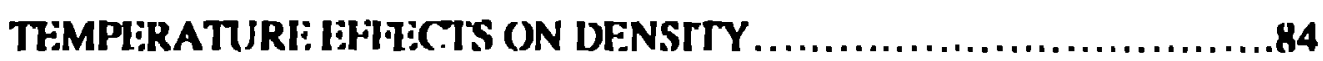

DIACINOSTIC. SOITWARE: ..................................84

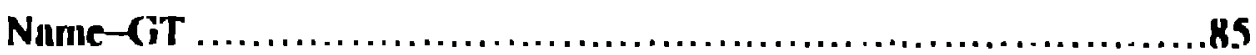

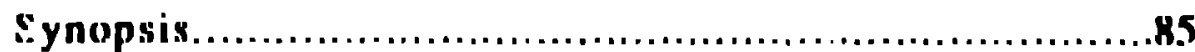

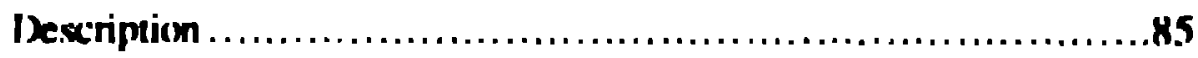

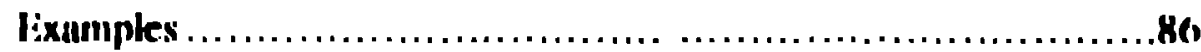




\section{TABLE OF CONTENTS}

(cont.)

Name-DST ...................................................86

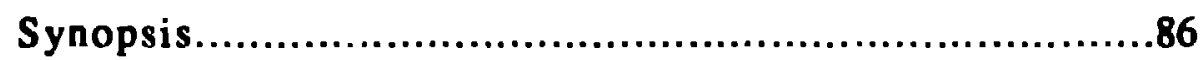

Description ...................................................86

Examples ...................................................87

ERROR MESSAGES $\ldots \ldots \ldots \ldots \ldots \ldots \ldots \ldots \ldots \ldots \ldots \ldots \ldots \ldots \ldots \ldots \ldots \ldots$

APPENDIX D. DOS COMMANDS ..................................98

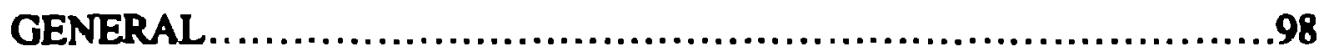

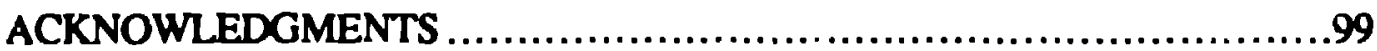

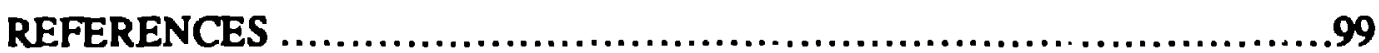

Previous Manuals for this System...................................100

Othcr Installations of Similar Instruments ..............................100 


\title{
K-EDGE DENSITOMETER (KED) \\ USER MANUAL
}

by

James K. Sprinkle Jr. and W: iter J. Hansen

\begin{abstract}
In 1979, a K-edge densitometer (KED) was installed by the Safeguards Assay group from Los Alamos National Laboratory in the PNC reprocessing plant at Tokai-mura, Japan. It uses an active nondestructive assay technique, KED, to measure the plutonium concentration of the product solution. The measurement uncertainty of an assay depends on the count time chosen, but can be $0.5 \%$ or better. The computer hardware and software were upgraded in 1992. This manual describes the operation of the instrument, with an emphasis on the user interface to the software.
\end{abstract}


WELCOME TO THE K-EDGE DENSITOMETER

GENERAL
In this chapter, you will learn

- how this manual is organized,

- the measurement principles of the densitometer,

- how to start up the system, and

- guidelines for the menti operation.

This document describes the operation of the K-edge densitoneter (KED). Other related manuals are the KED Hardware Manual, the KED Software Manual and manuals for the commercially available components and modules. Additional information, including the results of measurement campaigns and performance evaluations, is in the references.

This manual is divided into three parts:

- The first part (Chaps. 1 and 2) introduces you to the KED, provides an overview of the features, and rells you how to get started. The options in the short menu will be discussed. This includes how to request a measurement and how to print out the instrument's activity logs. It is written for the operators who use the instrument rouinely.

- The second part (Chaps. 3 and 4) explains the options in the full menu. This part is intended for the instrument supervisor: the operator who is to be the resident expert. It discusses the availatle advanced options, which may require more knowledge for proper use. For example, you will learn to print and edit the parameter file and the calibration Option.

- The third part (Chaps. 5 and 6) contains the analysis physics and instrument settings. You will leam about calibration procedures and trouble shooting. It is intended to be a resource of additional information.

- There might be a README.KED file on the computer. This updates the documentation after the user manual has gone to print. 
MEASUREMENT TECHNIQUE

MEASURFMENT PROCEDURE
The KED measures the concentration of plutonium solutions. It provides precise assays of solutions from $50 \mathrm{~g} / \mathrm{L}$ to $500 \mathrm{~g} /$. The result is independent of the quantity of other elements in the solution, but the method requires that there be no suspended solids or bubbles. Two results are computed. They are equivalent for the typical product solutions from the Tokai-mura plant. The "extrapolated" result is better if there are large concentrations of other nuclear materials. such as $100 \mathrm{~g} / \mathrm{L}$ of uranium.

The KED instrument measures plutonium concentration by monitoring the transmissions of two gamma rays that bracket the plutonium $\mathrm{K}$-absorption edge. This is possible because in general the gemma-ray transmission through a fixed sample increases as the gamma-ray energy increases. However, when the increasing gamma-ray energy passes an absortion edfe, the transmission abruptly decreases. The energy of these absorption edges is specific to each element.

Selenium-75 provides a gamma ray of $121.1 \mathrm{keV}$ and ${ }^{57} \mathrm{Co}$ provides a gamma ray of $122.1 \mathrm{keV}$; these bracket the plutonium K-edge at $121.7 \mathrm{keV}$.

The KED uses a peak fitting process with response functions to determine the intensities of the desired gamma rays. Selfcalibration of the response function parameters is performed during the measurements with no sample present.

A ${ }^{109} \mathrm{Cd}$ source fixed to the detector head is user" 7onitor the effects of deadtime and pileup in the electrct in. . The Appendix describes the measurement physics and equations in more detail. Figure 1 is a line drawing of the measurement geometry.

An assay consists of two independent concentration measurements. The results must be consistent or else the sample is checked for bubbles and then measured a third time. Each concentration measurement requires the use of two gammaray transmissicn sources. Therefor an assay consists of either four or six data acquisitions. The self-diagnostics that the KED performs on each measurement are described in the appendix. 


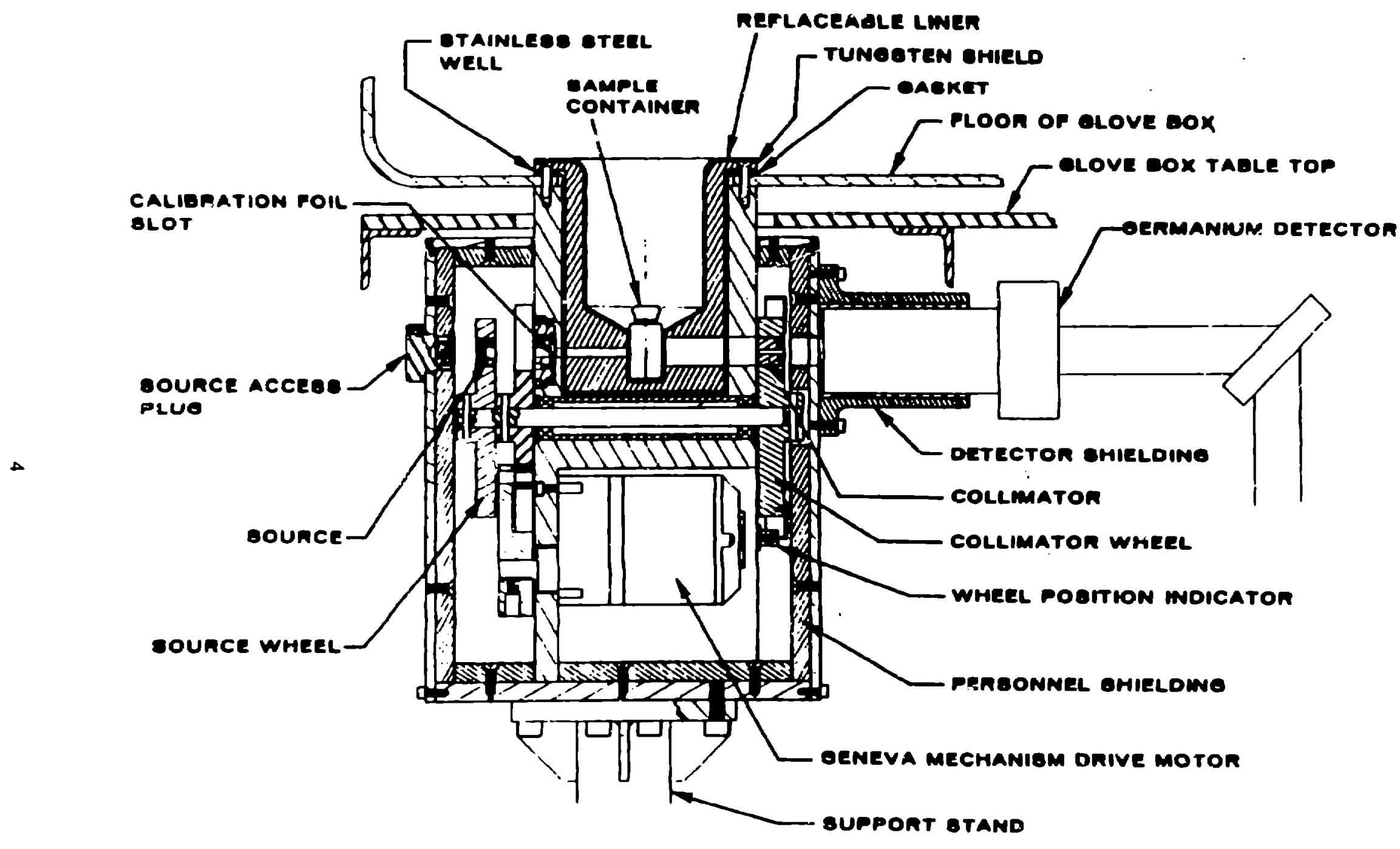

Fig 1. A !ne drawing (cross-section) of the Kedge Densilometer illustrales the measurement geometry. Important mecharical componenss such as the transmission source, sample container, and high-resolution detector are labeled. 
MEAsURement PROCEduRe (cont.)
STARTING THE SOFTWARE
On a periodic basis, the intensity of the transmission sources is measured with no sample in the assay position. These "stright-through" measurements yield net peak areas that are used as the denominator in the transmission calculations.

The straight-through measurements may be chosen to occur automatically each day at 00:00 hours or by operator request.

Additional periodic messurements are made to verify proper instrument response. These may be performed without a sample, or with stable, well-known items.

To recover from system halts or other severe problems, use the ctrl-alt-delete combination, or power the computer off for $10 \mathrm{~s}$ and then on again. The procedure to turn on the power is in the KED Hardware Manual.

The computer will automatically start the KED software when it is powered up. The start-up process takes 1 or $2 \mathrm{~min}$. If the computer is not running the software, the KED woftware can be stared by typing

\section{CONTOKAI[ENTER] \\ KED(ENTER],}

The first screen on the CRT will be the one shown below.

LOS ALAMOS NATIONAL LABORATORY

K-edge Densitometer at Toka1-murz, Japan

Version 1.00

Release November 9,1992

\author{
Enter date (MM/DD/YY) $11 / 09 / 92$ \\ Fint.er time (HH:MM:SS) 12:25:58
}

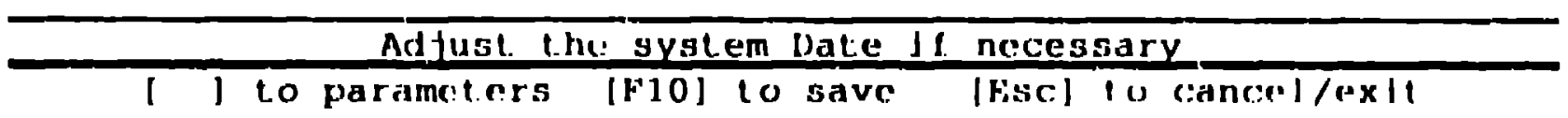


STARTING THE SOFTWARE (cont.)

Initialization

Failure To Initialize
The date and time can be adjusted if necessary. When the date and time are correct, push the F10 key. The computer will then initialize the Canberra S100 MCA.

If the initialization of the computer-MCA communications is not successful, the operator is presented with the following red dialng box:

\section{ERROR}

\section{MCA not responding}

Continue without MCA operations

Retry MCA connection

Abort KED software

Switch MCA Board number from $1 \rightarrow 2$

If the MCA cannot be initialized,

first, toy a software reser: type ctrl-alt-delete. This will cause the system to reset the devices on the computer back plane and then restart the computer operating system.

second, try a hardware reset: power down the computer, wait $10 \mathrm{~s}$, and power up the computer.

third, make sure the $S-100$ is configured correctly and seated in the back plane slot conrectly.

The last choice, switching the MCA board number, is not used on this implementation. The KED uses MCA board no. 1 .

The program tries to initialize the printer, an error messuge appears if the printer is off or off-line.

If the data bases are not found, the software will create them and provide a waming message.

If the initialization ss successful, the KIII) shon menu will the displayed, as shotin below. All noutine operations can be 
Failure To Initialize

(cont.) selected from this menu. The options in the short menu will be discussed in Chap. 2.

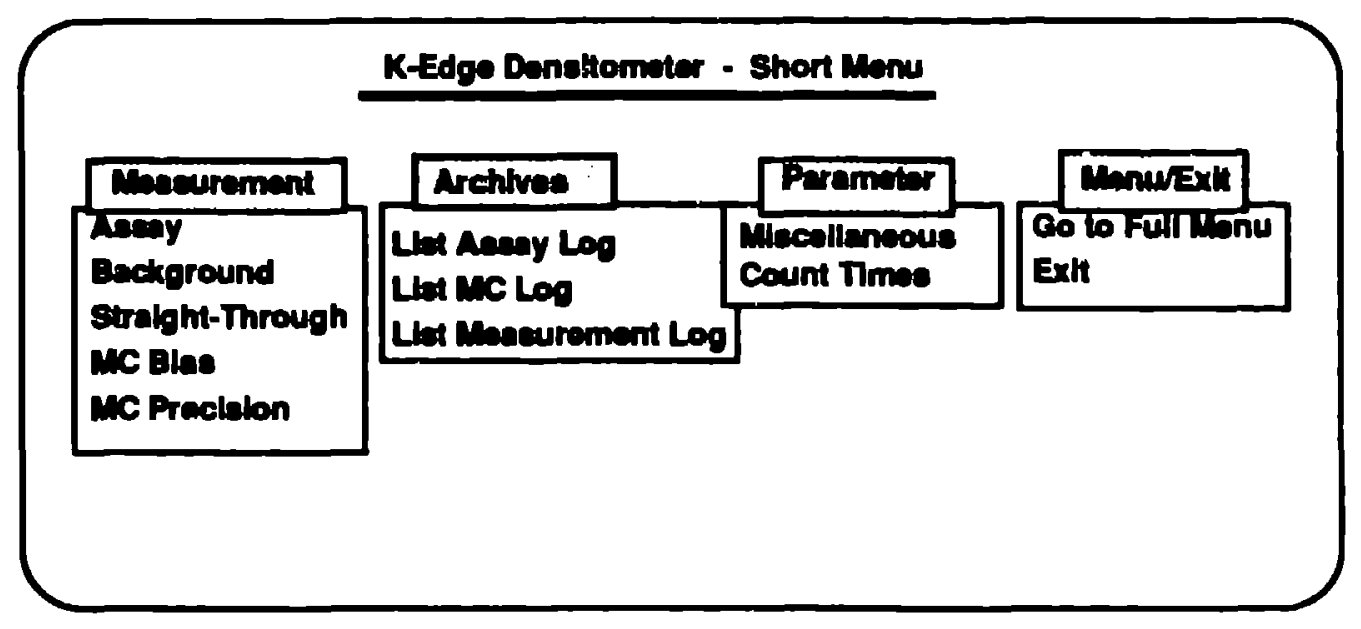

MENU OPLRATION

Option Selection

Data Entry
All other options of the KED system will be discussed in Chap. 3.

The shor KED menu is a pull-down-window format with four headings. The headings can be selected by pressing the "left" or "right" arrow key.

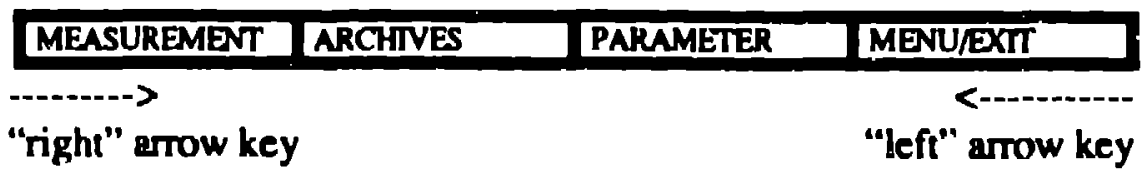

Under each heading there are several options that may be selected by using the "up" und "down" arrow keys to move the cursor to the desired option and pressing ENTTER to activate the selected option.

Selecting an option displays a dialog box with the possible actions for the option. Defaults are built in with many of the inputs; a default response, if one is available, is listal in the blunk after the question. The operator can moxlify the inputs. 
Date Entry

(cont.)

F 10

$\mathbf{F} 2$

ESC

To Stop an Assay

Duriag Data Fintry
The operator may correct a response by using the "up" or "down" arrow key. The "home" key will bring the cursor to the top of the box; the "end" key will bring the cursor to the bottom of the box. Once the cursor is at the incorrect response, the operator can correct the response.

When all the entries in the dialog box are correct, press F10 to have the computer accept the entries.

The $\mathbf{F} 2$ function key is used to show the acceptable inputs of the highlighted entry. The "up" and "down" arrow keys can move the cursor to the desired input. The ENTER key will enter the input into the highlighted entry.

The operator can recover from incorrectly selected options with the ESC key. It will return the operator to the main menu so the operator may select an option.

During the data acquisition, pressing ESC will bring up the following dialog box:

\section{Assay suspended}

Quit

Quit with Analysis

Resume Measurement

Moving the cursor to the appropriate option will enable the operator to quit or resume the assay.

During dittu entry, the ESC key will bring up the following dialog hox: 
Durlng Data Ensry (cont.)
Warning

$\because$ ESC2 is normally used

to cancel all changes

Resume editing

Cancel changes

Save changes \& exit form

Moving the cursor to the appropriate option will enable the operator to quit or cancel changes. 
USING THE SHORT MENU In this chapter you will leam about

- Measureinents

- Archives

- Parameters

- Menu/Exit

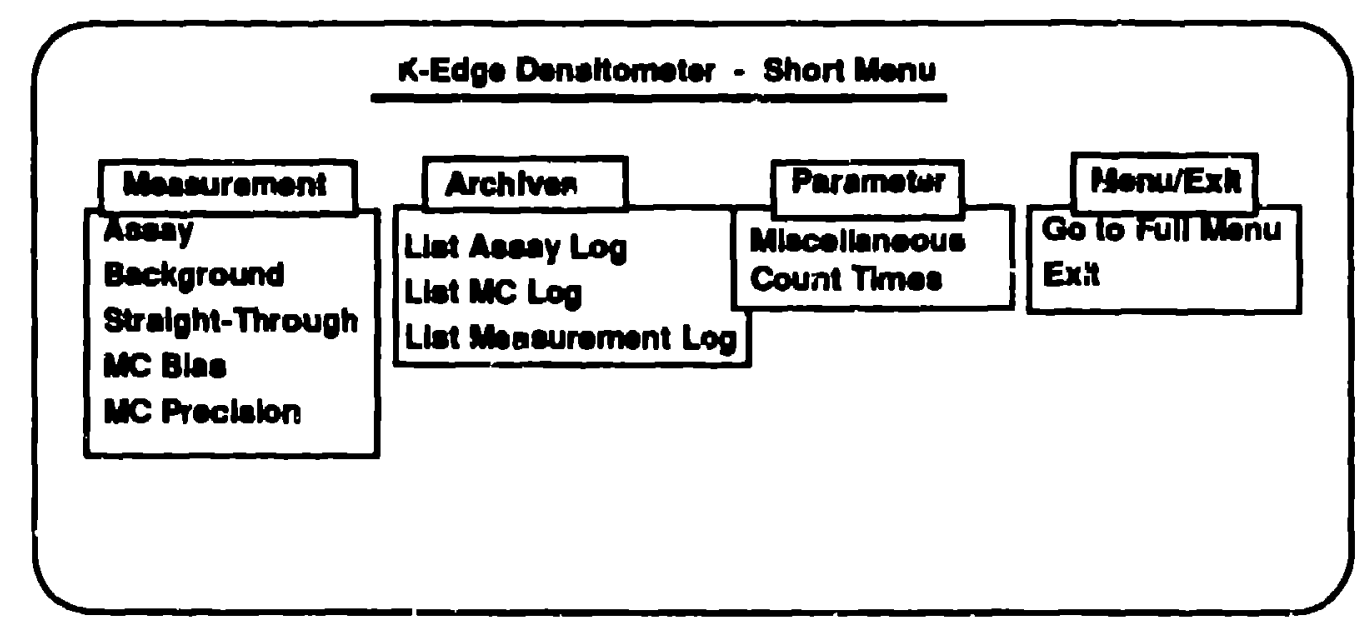

The short menu has four headings. These will be discussed in the next four sections.

MEASUREMENT ARCHIVES PARAMETER MINIJEXXT

MEASURFMENT OPTIONS
Five types of measurements can be made with the K-edge. densitometer under the short menu. These will be discussed in the next five subsections.

\section{MEASUREMENT}

Assay

Background

Straight-Through

MC Bias

MC Precision 
To Stop a Measurement
During any data acquisition, pressing ESC will bring up the following dialog box:

\section{Assay suspended}

Quit

Quit with Analysis

Resume Measurement
Count Times
After moving the cursor to the appropriate choice (Quit, Quit with Analysis, or Resume Measurement), pressing creturn> will cause the selection to be activated

The precision of a computed result is dependent on the precisions of all of the measurements used to compute the result. Therefore, the ccunt times used for the assay, straight-through, and background measurements all affect the precision of the assay. Better precision can be obtained with longer count times, up to a limit of $-1,3 \%$.

Count times for the straight-through and background runs are used for each assay that follows them until those measurement types are repeated. This causes the results that share straight-through data to be correlated. Background effects and correlations are usually negligible for the Tokaimure product solutions $(>2(x) g /)$.

Count times for the different measurement types are set in the parameter file. They can be changed in the edit option under the parameter heading in the full menu.

The Assay Option is used for the measurement of samples with an unknown plutonium concentration. Selecting the Assay Option displays the following dialog box: 
Assay

(cont.)

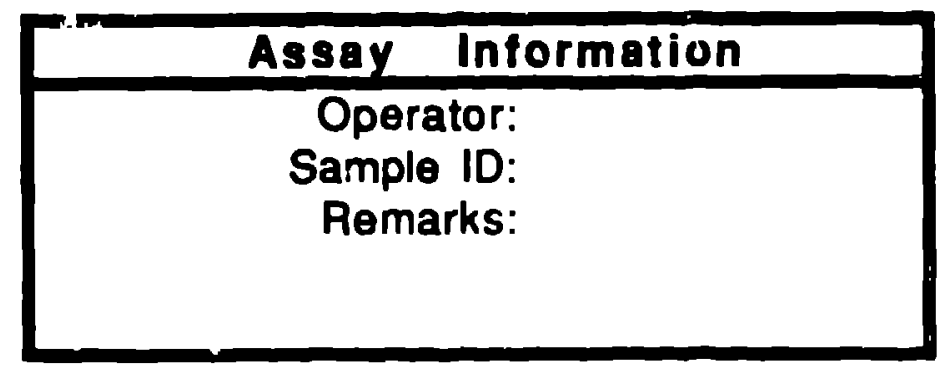

The user enters the operator and the sample identification. Up to 16 characters are allowed for the operator ID and up to 32 characters are allowed for the sample ID. The first eight characters of the sample ID are used to create the liile name when spectral data are written to a disk file. Up to $4 i$ characters are allowed for the remarks. If the information is not correct in any field, the user may use the arrow keys and the (delete) key and type the information again. When the information is correct, press F10 to proceed. Next, the software will ask the operator if the sample is in place, ready for measurement.

Count Ther. It is recommended that the assay count time be shorter than the straight-through count time, unless the straight-through measurement is repeated before each assay. This will realuce the magnitude of the correlations between different assay iesults. The count til..e can be changed under the PARAMETERS Option (See page 33, the Count 'Time Option under the PARAMETERS Option in the chapter on the Shor Meiuu.)

Measurement Results Fille. All results (peak areas, errors, etc.) from all measurements are automatically stored in the fik

\section{KI:() D)B.DAT}

This file is to be distinguished from the raw clatta files that are discussed later. 
Spectral Data File Name. If the Write Data to disk feature is selected (in the Default Option under the Parameter heading), two data files are written for each assay. The file name convention for sach assay is

xxxxxxxx.Snn 75 Se source

xxxxxxxx.Cnn ${ }^{57}$ Co source

where $\times \times x \times \times \times x \times=$ first eight characters of the sample identification and

$\boldsymbol{r}=$ run number of assay.

The run number is automatically increased in increments of one to prevent overwriting previous data files with the same file name, for up to 99 files. The software will not check all outut devices, this automatic increment will be applied to the first output device, which is expected to be the primary archive on the hard disk. If the Write Data to disk is selected, the hard copy printout will show the names of files written successfully to disk.

Dhplay During Acquialiton. While a measurement is in progress, the template that is seen on the computer display indicates the preset count time and the time remaining for that data acquisition. Some measurements require multiple data acquisitions. After the acquisition is finished, the display indicates which calculation is underway or if the printing to hard copy is active. 


\section{Sample Printout (Nornal Output)}

Toka1-mura K-Edge Densitomete=

Sanple ID: erpty

Operator: Janes

Remark: let us try another output format

Stralght-Through Date: 92.08.01

L1ve time $(\mathrm{Se}-75)$ a $60 \mathrm{~s}$

\author{
NSB \\ IAEA \\ Meagurement TYpo: ASSAY \\ Measurement Date: 92.08 .30 \\ Constants F1le Date: 90.01 .01 \\ Live time $(\mathrm{Co}-57)=60 \mathrm{~s}$
}

\footnotetext{
Sumbary of Results
}

Pu concentiation $(\mathrm{g} / \mathrm{ml})$

Analysis method tested: Simple

\begin{tabular}{llc} 
Cycle & Siruple Method & Extrapolation \\
\hline 1 & $226.61624+/-2.85414$ & $226.88812+/-2.83475$ \\
2 & $228.32866+/-2.76485$ & $228.47076+/-2.74880$ \\
& & \\
Average & $227.55555+/-2.00600$ & $227.55555 . /-2.00000$ \\
Z1 & 0.90 & 0.89
\end{tabular}

Agsay OptIC PASSED ---

The redium printout will also include the net peak areas from exch cycle, the disk filenames, and a header. The header includes the sample ID, the operator, the measurement dnte, and the count times. 


\section{Sample Printout (Normal Output) (cont.)}

Toka1-mura K-Edge Densttometer

Sample ID: 123456789012

Operator: NAGANO

Remarks :

Straight-Through Date: 92.08.01

Data Files: 12345678.S01

12345678.C01

a: \subdtrec $\backslash 12345678.501$

a: \subdtrec $\backslash 12345678 . C 01$

b: \oct $92 \backslash$ subdirectory $\backslash 12345678.501$

b: loct $92 \backslash$ subdi rec cory $\backslash 12345678$. C01

Live time $(s a-75)=300 s$
NSB

IAEA

Measurement Type: ASSAY Measurement Date: 92.08 .30

Constants File Date: 90.01 .01

Live time $(\mathrm{Co}-57)=288 \mathrm{~s}$

$\begin{array}{rlrrr}\text { Energy } & \text { Isotope } & \text { Net Peak Area } & \text { Normal1zed Area } \\ 88.036 & \text { Cd-109 } & 158540.0+/- & 408.98 & 1.00000+/-0.00258 \\ 121.115 & \text { Se-75 } & 44929.0+/- & 231.99 & 0.28339+/-0.00164 \\ 136.000 & \text { Se-75 } & 163945.0+/- & 416.05 & 1.03409+/-0.00374 \\ & & & \text { Normal1zeo Area } \\ \text { Energy } & \text { Isotope } & \text { Net Peak Area } & -0.000 \\ -98.036 & \text { Cd-109 } & 150773.0+/- & 398.40 & 1.00000+/-0.00264 \\ 122.060 & \text { Co-57 } & 909976.0+/- & 969.54 & 6.03540+/-0.01720\end{array}$

\begin{tabular}{lllll} 
& & Simple & \multicolumn{1}{c}{ Extrapolated } \\
Calibration constant $(c c / g)$ & $6.12345+/-$ & 0.12345 & $6.12345+/-$ & 0.12345 \\
Sample concentration $(g / 1)$ & $1.11+1 /-1.49$ & 1.06 & $+/-$ & 1.42
\end{tabular}

Long Printout. The long printout is intended for diagnostic reponts or troubleshooting. It prints the intermediate values from the calculations and the results of each diagnostic test.

Background

A background measurement is done with no sumple in the measurement position and with both transmission sources in the shielded position. 'The background is computed for all of the peuks used in the instnument: the 88.036, the 121.115, 
Background

(cont.)

the 122.060, the 136.000, and the 279.528-keV gamma peaks. It also checks for a weak plutonium signal, using the $59.5-\mathrm{keV}$ gamma ray from ${ }^{241} \mathrm{Am}$ and the $129.29-\mathrm{keV}$ gamma ray from ${ }^{239} \mathrm{Pu}$. A low background is important for assays of low-plutonium concentrations, but not for solutions of $>150 \mathrm{~g} / \mathrm{L}$. Selecting the Background Option displays the following dialog box:

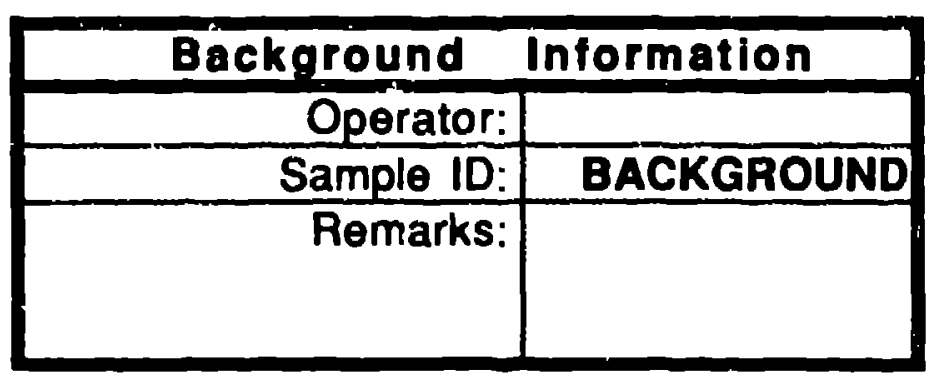

The user enters the operator identification as requested and any comments desired urider Remarks. If the information is not correct, use the arrow keys and the [delete] key and type the information again. When the information is correct, press F10 to proceed. Next, the softwire will ask the operator to verify that the sample measurement chamber is empty: ready for the background measurement.

Recommended Frequency. This measurement technique is relatively insensitive to background. A background measurement should be done every 2-3 days, if solutions of low concentration $(<150 \mathrm{~g} / \mathrm{L})$ are to be measured.

Count Time. This measurement technique is relatively insensitive to background, but very short count times for the background measurement will affect the precision of the following assays. A minimum of $300 \mathrm{~s}$ is recommended for each background measurement. 
Measurement Results File. All results (peak areas, errors, etc.) from all measurements are automatically stored in the file

\section{KED_DBDAT}

This file is to be distinguished from the raw data files that are discussed later.

Waraing Limit. The background count rates at selected gamma-ray energies are checked against a warning limih, which is stored in the parameter file. if a limit is exceeded, the corresponding waming message is printed in each assay that follows the background measurement. If this happens, the source of the background signal should be removed. The warning will remain in effect until the background measurement is repeated without failing the diagnostic test.

Spectral Data File Name. If the Write Data To Disk feature is selected (in the Default Option under the Parameter heading), the file name will be of the form

\section{BCYYMMDD.Bnn}

$$
\text { where } \begin{aligned}
Y Y & =\text { year, } \\
M M & =\text { month, } \\
D D & =\text { day of the month, and } \\
\text { nn } & =\text { run number. }
\end{aligned}
$$

Display during Acquisition. While a measurement is in progress, the template that is seen $\rightarrow$ the computer display indicates the preset count time and the time remaining for that data acquisition. 
Sample Printout (Normal)

Toka1-mura K-Edge Densitaneter

Operator: Sprinkle

Remarks: This is the operator's remarks.

Data Files: None

Live time (Blank) $=60 \mathrm{~s}$
NSB

IAEA

Measurement TYpe: BACKGROUND

Measurement Date: 92.09.30

Constants File Date: 92.09.28
Straight Through
Backgiound Option PASSED ---

The medium printout will also include the net peak areas. The long printout will also include the results of the diagnostic tests.

A straight-through measurement is done with no sample in the chamber and with a data acquisition from both transmission sources. The results will be combined with the measurement results fom succeeding samples to compute the sample transmissions for each. The 88.035-keV gamma ray is again used to normalize the other gamma-ray intensities to correct for dead time and pileup effects. Selecting the Straight-Through Option displays the following dialog box:

\begin{tabular}{|r|r|}
\hline \multicolumn{2}{|c|}{ Straight-Through Information } \\
\hline Operator: & \\
\hline Sample ID: & Straight-Through \\
\hline Remarks: & \\
& \\
\hline
\end{tabular}


Straight Through (cont.)
The user enters the operator identification as requested and any comments desired under Remarks. If the information is not correct, use the arrow keys and the [delete] key, and type the information again. When the information is correct, press F10 to proceed. Next, the software will ask the operator to verify that the sample measurement chamber is empty. ready for the straight-through measurement.

Recomeneded Frequency. A straight-through measurement is required at regular intervals. The maximum time allowed between straight-through measurements is adjusted in the parameter file. The frequency of straight-through runs is daily or weekly. The software has the capability to automatically initiate a straight-through measurement each day at 00:00 hours. This allows long count times when the instrument is normally idle.

Cownt These. The precision of the straight-through measurement is more important than the frequency with which it is done. Results from the straight-through are used for each assay that follows them until the Straight-Through Option is repeated successfully. Therefore the results that share straight-through data are correlated. Each straight-through measurement should be run for a long time so that its statistical precision does not contribute significantly to the statistical precision of the transmission measurement used to compute. an assay result. The straight-through run should be conducted for at least 1000 to $2000 \mathrm{~s}$ for both sources.

Count times for straight-through runs are set in the parameter file. They can be changed in the Edit Parameter Option.

Measuremeat Resuls filk. All results (peak areas, errors, etc.) from all measurements are automatically stored in the file

KIED_DB.DAT

This file is to be distinguished from the nuw data files, which are discussed later. 
Warning Linits. The normalized count rates from the 121.1-keV gamma ray ( 75 Se source) and the 122.1-keV gamma ray ( $57 \mathrm{Co}$ source) are compared to the rates obtained in the jrevious Straight-Through measurement, with a correction for the half-life decays. If the rates are consistent, the limit is passed. If the rates are not consistent, a warning is printed that specifies the offending source, and successive measurements will include a repetition of that waming. Now that the ${ }^{109} \mathrm{Cd}$ will affect both transmission source normalized rates. After any new source is installed, ${ }^{109} \mathrm{Cd},{ }^{75} \mathrm{Se}$, or ${ }^{57} \mathrm{Co}$, two successive straight-through measurements will reset the expected value and confirm it.

Spectral Data Flle Nane. If the Write Data To Disk feature is selected (in the Default Option under the Parameter heading), the file name will be of the form

STYYMMDD.Cnn

STYYMMDD.Snn

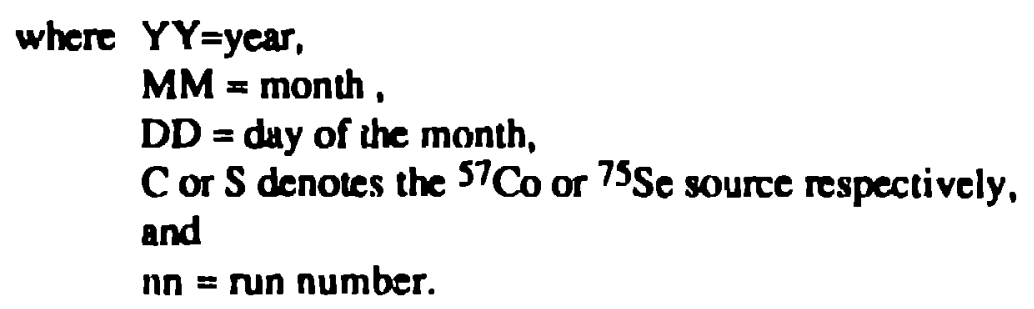




\section{Sample Printout (Normal)}

NSB

IAEA

Measurement Type: STRAIGHT-THROUGH

Operator: M1111e Measurement Date: 92.09.30

Renarks:

Constants File Date: 92.09.28

Data Files: None

Live time $(\mathrm{Se}-75)=60 \mathrm{~s}$

Live time $(\mathrm{Co}-57)=60 \mathrm{~s}$

--- Stralght-Through Option PASSED ---

MC-Bing 
MC-Bias

(cont.)
The operator must select one of the sample ID's that have been previously set up in the parameter file. Use of the F2 button will suggest what choices are available.

After the measurement, the assay result is compared with a reference value stored in the parameter file. The same result (simple or exumpolated) is used for this test as has been selected for the bubble test. (See the Assay Criterion parameters in Chap. 4 - EDIT PARAMETEKS.) The difference between the assay result and the reference value (in units of the historical standard deviation of the measurement) is compared to warning and action limits. If the waming limits are not passed, subseguluent assays are accompanied by a waming in the results. If the action limits are not passed, further use of the Assay Option is not allowed until the MCBias Option is executed successfully. A negative value for the historical standard deviation will turn this test off. Five reference values are stored in the parameters, each with a sample ID.

Recommeaded Fre rency. An MC-Bias measurement is required at regular tervals with the maximum time allowed between bias runs being set in the parameter file. A single MC-Bies measurement of one of the reference items is recommended to be done weekly during perionds of heavy use of the densitomeirt. otherwise we recommend that a single MC--Bias measurement proceck any sample measurements after the densitometer has been idle.

Count Time. The count times are stored in the parameter filc. They can be changod using the PARAMETER Option. The count times should be similar to those used for mutine assays.

Reference Value. The assay result of an MC-Bias sumple may not be the snme as its actual plutemium content hecaluse the sample geconetry is different from that of a solution. 'Iherefire, the foil sinuuld te incusured very precisely after every calibration und the reference value in the parameter file should le upelated. (twer a period of time ( $x$ 'veril years) the equivalent vilue of the fioil muy be hnown. 'Ihe 
Refereace Value. (cont.)

measurement result will be directly affected by a change in the calibration constant. Both foils should be checked this way.

Historical Standard Devintion. The historical standard cleviation of the foil data is determined by examining results obtained over extended periods of time. It should include all contributions that affect the assay with the exception of variations in sample depth and sample-vial variations. This precision will vary slowly with time as the transmission sources decay.

Waraing and Action Llmits. The difference between the MC-Bias assay result and the foil reference value, in units of the historical standard deviation, is compared against waming and action limits, assuming normal distribution. These limits can be adjusted in the parameter file under the Measurement Control Option.

\begin{tabular}{|c|c|}
\hline Limit & Probability of Not Exceeding \\
Limit
\end{tabular}

This test is sensitive to how well the historical standard deviation is known. If the proposed standard deviation does nox include all long term and systematic errors, this test will fuil more often than suggested by the lable. An error of 3 (4)\% in the historical standard deviation can change the results froun the 4.0 level (o) the 3.0 level.

Spertral Date File Name. If the raw data are written II disk, the tile name will be of the fom 


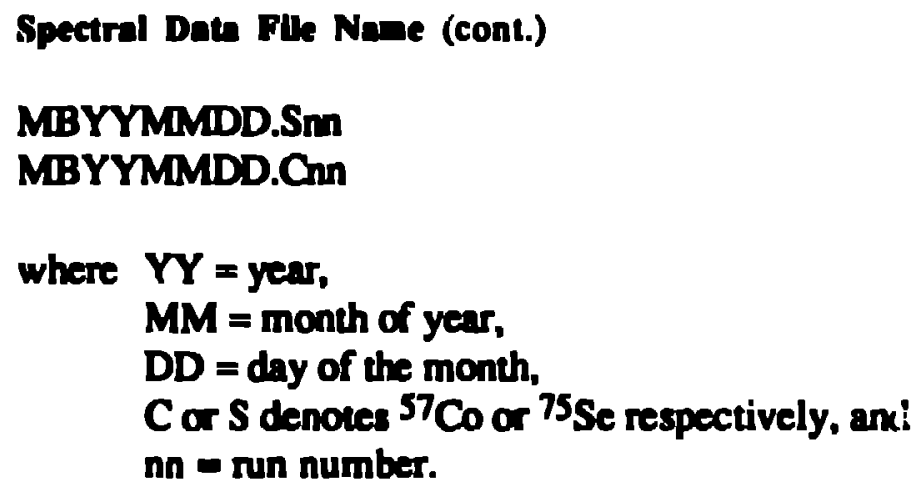

Sample Printoul. The printout is the same as that used for in ASSAY, except that the Measurement Type is MC-Bias, and a message is printed at the very end of the printout stating whether the MC-Bias run PASSED or FAILED.

Toka1-mura K-Edge Densitameter

NSB

IASA

Sanple ID: Ta_7_7

Measurement Type: MC-BIAS

Operator: Walt Measurement Date: 92.08.30

Remark8: <up to 40 characters allowed> Stralght-Through Date: 92.08.01 Constant.d File Date: 90.01.01 Data Files: None Live time $(\mathrm{Se}-75)=500 \mathrm{~s}$ I.tve t.Ime $(C .0-57)=650 \mathrm{~s}$

stmple

Caltbraiton constant (cc/q)

Sample eoncentiat ton (N'A)

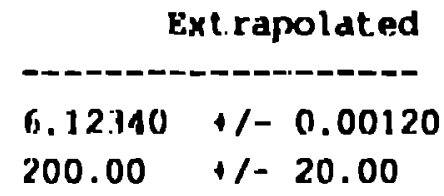

M:-M1as Teat

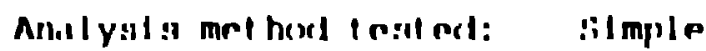

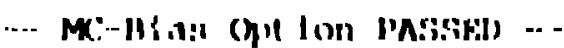

The medium printout will inclukte the net peuk areas. It will also inclisk the ineasured result, the exprected result, und the histcric'nl stumblund devintion. 
Sample Printout (cont.)

If the MC-Bias test fails the WARNDNG or ERROR limit, a message stating the test information is printed. The LONG PRINTOUT is for diagnostic purposes. It includes the measured and expected values of all diagnostic tests.

A measurement control-precision run is dcie regularly as a part of the measurement control program. This measurement can be done with any sample or an empty chamber. The measurement consists of multiple runs as specified in the parameter file. The assay results from these runs are analyzed statistically to verify that the random variations observed are consistent with those predicted from counting statistics. The test can fail in two ways. The first mode of failure is when the calculated variance propagated from counting statistics is incorrect. The formulas for these errors have been thoroughly tested, and we do not believe that this potential source of failure is present. The second failure mode will be because of instabilities in the counting electronics. This is indicated when the observed measurement variance from repeated runs is larger than the propagated variance.

Recommended Frequeacy. A measurement control-precision sequence is required at regular intervals with the maxi. mum time allowed between sequences being set in the parameter file. A measurement control-precision run sequence should be carried out monthly. This lest may be tumed off by selecting a negative value for the frequency in the Fdit Parameter Option.

Count Time. The count times for the ${ }^{75} \mathrm{Se}$ and ${ }^{57}$ ( $\mathrm{C}$ (d) dafa acquisitions are set in the parameter file.

Number of Runk. The number of runs is set in the purame ter file. Allowed values will be displayed when the onerator presses the 12 bugtum. The selection is restricted because the limits on the chi-square test ikepend upon the number of cycles. In genernl, a sniall number of shorr count lime 
Number of Ruas (cont.)

measurements can pass the statistical tests more easily. A large number of long count-time measurements is a more stringent test.

Warning and Action Linits. The standard deviation of the replicate measurements is compared to the standard deviation estimated from the counting statistics of a single run. The value of the resulting chi-square/degree of freedom is tested against warning limits at $95 \%$ confidence and action limits at 99\% confidence. These limits are fixed in the software. Failure of the warning limit will cause a warning to be printed for evey succeeding measurement type, until the MC-Precision Option is successfully passed Failure of the action limit will cause the system to not allow assays until the MC-Precision Option is successfully passed or a waming limit level is achieved. This test may be avoided by selecting a negative time for the repetition rate.

Spertral Data File Name. If the raw data are written to disk, the file name will be of the form

MPYYMMDD.Snn MPYYMMDD.Cnn

where $Y Y=$ year, $M M=$ month,

DD = day of the month, and $\mathrm{nn}=$ nun number. 


\section{Sanple Printout (Nornal)}

Toka1-mura R-Edge Densitometer

Sample ID: Ta7_7_7_7_7

Operator: James

Renark:

Stralght-Through Date: 92.08.01

Live time (se-75) $=60 \mathrm{~s}$

\author{
NSB \\ IAEA \\ Masurement Type: MC-PRECISION \\ Measurement Date: 92.08.30 \\ Constants File Date: 90.01.01 \\ Live time $(\mathrm{CO}-57)=60 \mathrm{~s}$
}

MC-Prejision Test Sumbary

Number of measurements: 6

\begin{tabular}{cc} 
Simple & Extrapolated \\
\hline 200.00 & 222.22 \\
1.11 & 1.00 \\
1.00 & 0.99
\end{tabular}

Analysis method tested: Simple

Error limits for Reduced chisquare $>0.11$ and $<3.09$

Warning $11 \mathrm{mits}$ for Reduced chisquare $>0.21$ and $<2.41$.

-- MC-Precision Option PASSED --

\section{ARCIIIVRS OPTIONS}

\begin{tabular}{l} 
Archives \\
List Assay Log \\
\hline List MC. Ins? \\
\hline List Measurement Los?
\end{tabular}

B.Iat Amay I.ne

An archivul file of the inost recent $5(X)$ meusurements is kept on the system disk. When the lile is full, the oldest mea surement is replaxed hy the inewes. measurement. 'Ilse 
Lia Ama Los (cont.) contents can be listed on the operator terminal, printed on the line printer, or written to a file in ASClI format

When this option is selected, the following dialog box is shown:

List MC Log
List entries between two dates
List $n$ entries
List all entries
Return to main menu

After selecting one of these options, another dialog box will be presented where the operetor specifies which output format is desired. The following dialog box will be presented if the operator chooses a date range:

\section{List MC Log}

Range (dates) From: 53.01 .02

To: 92.12 .12

Output to Screen: $Y$

Output to Printer: $N$

Output to File: $\mathbf{N}$

File Name:

The user can select from three output devices. Any combination cian be selected. Fony-three characters are allowed for liik Name of the ASC.II file. 


\section{Sample Output}

Tokai-mura K-Edge De
Type Sample ID
MC-P item
MC-P item
MC-P item
MC-P item
MC-P item
MC-P item
MC-B Ta-7 7
ST Straight-Thr
B Background
MC-P test
MC-P test

MC-P test
Densitometer

\begin{tabular}{|c|c|c|}
\hline Operator & Result & $(g / 1)$ \\
\hline------ & ----- & \\
\hline Jim & 220.40 & 0.90 \\
\hline Jir. & 220.00 & 1.23 \\
\hline Jim & 220.00 & 1.23 \\
\hline Jim & 220.00 & 1.23 \\
\hline Jim & 221.00 & 1.23 \\
\hline $\operatorname{Jim}$ & 220.22 & 1.23 \\
\hline Wilber & 123.45 & $+/-12.34$ \\
\hline Hooter & & \\
\hline Hooter & & \\
\hline $\begin{array}{l}\text { Wilber } \\
\text { Wilber }\end{array}$ & $\begin{array}{l}123.45 \\
123.45\end{array}$ & $\begin{array}{l}+/-12.34 \\
+/-12.34\end{array}$ \\
\hline
\end{tabular}

\begin{tabular}{cccc}
\multicolumn{4}{c}{ Measurement Control Log } \\
E/S & MC & Cycle & Date \\
\hline-- & - & -1 & -1 \\
E & Passed & Average & 92.10 .02 \\
E & Passed & $5 / 5$ & 92.10 .02 \\
E & Passed & $4 / 5$ & 92.10 .02 \\
E & Passed & $3 / 5$ & $92.10 .0 ?$ \\
E & Passed & $1 / 5$ & 92.10 .02 \\
E & Passed & $1 / 5$ & 92.10 .02 \\
S & Falled & $1 / 1$ & 92.09 .30 \\
& Passed & $1 / 1$ & 92.09 .09 \\
& ?? & $1 / 1$ & 92.09 .09 \\
S & Falled & Average & 92.09 .01 \\
S & Failed & $121 / 121$ & 92.09 .01
\end{tabular}

The measurement type of Assay is indicated in the first column. The result printed in the fourth column is from either the simple method or the extrapolated method. The selected method is listed in the fifth collumn under the $E / S$ heading. $E$ indicates the extrapolated-method result was selected.

This option is similar to the List Assay Log Option, but lists only measurement control measurement types: MC-Bias, MC-Precision, Background, and Straight-Through measurements.

When this option is selected, the following dialog box is shown:

List MC Log
List entries between two dates
List $n$ entries
List all entries
Return to main menu

After selecting one of these choices, a dialog box will be presented $s$ ) the operatior can chosose the output formats. 


\section{List MC Log}

(cont.)

\section{List MC Log \\ Range (dates) From: 53.01.02 \\ To: 92.12 .12}

Output to Screen: $Y$

Output to Printer: $\mathbf{N}$

Output to File: $\mathbf{N}$

File Name:

The user can select from three output drvices. Any combination can be selected. Forty-three characters are allowed for File Name if the ASCII file.

\section{Sample Output}

\begin{tabular}{|c|c|c|c|c|c|c|c|c|c|}
\hline Tor & lura K-Edge & & & & & & & Measur & ement Log \\
\hline Type & Sample ID & Operator & Result & $\lg / 1$ & & $E / S$ & Quality & Cycle & Date \\
\hline & 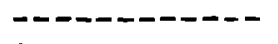 & $---ー--ー-$ & $--\cdots--1$ & --- & $1-1$ & --- & $-----\infty$ & $-----\infty$ & -------- \\
\hline$M C-P$ & Item & $\operatorname{Jim}$ & 220.40 & $+1-$ & 0.90 & $\dot{c}$ & Passed & Average & 92.10 .02 \\
\hline$M C-P$ & 1tem & $\mathrm{Jim}$ & 220.00 & $+1-$ & 1.23 & $\mathbf{E}$ & Passed & $5 / 5$ & 92.10 .02 \\
\hline$M C-P$ & item & $\mathrm{Jim}$ & 220.00 & $+1-$ & 1.23 & $\mathbf{E}$ & Passed & $4 / 5$ & 92.10 .02 \\
\hline MC-P & item & Jim & 220.00 & $+1-$ & 1.23 & $\mathbf{E}$ & Passed & $3 / 5$ & 92.10 .02 \\
\hline$M C-P$ & item & $\mathrm{Jim}$ & 221.00 & $+1-$ & 1.23 & $\mathbf{E}$ & Passed & $2 / 5$ & 92.10 .02 \\
\hline MC-P & item & Jim & 220.22 & $+1-$ & 1.23 & $\mathbf{E}$ & Passed & $1 / 5$ & 92.10 .02 \\
\hline $\mathbf{A}$ & 123456789012 & $\mathrm{Jim}$ & 220.40 & $+/-$ & 0.90 & $\mathbf{E}$ & Passed & Average & 92.10 .01 \\
\hline A & 123456789012 & Jim & 220.00 & $+1-$ & 1.23 & $\mathbf{E}$ & Passed & $3 / 2$ & 92.10 .01 \\
\hline A & 123456789012 & $\mathrm{Jim}$ & 221.00 & $+1-$ & 1.23 & $\mathbf{E}$ & Passed & $2 / 2$ & 92.10 .01 \\
\hline A & 123456789012 & $\mathrm{Jim}$ & 220.22 & $+1-$ & 1.23 & $\boldsymbol{E}$ & Passed & $1 / 2$ & 92.10 .01 \\
\hline$M C-B$ & Ta $7-7$ & wilber & 123.45 & $+1-$ & 12.34 & $\mathbf{S}$ & Falled & $1 / 1$ & 92.09 .30 \\
\hline $\mathbf{S T}$ & St ra $\mathrm{i} g h t-T h r$ & Hooter & & & & & Passed & $1 / 1$ & 92.09 .09 \\
\hline B & Background & llooter & & & & & $? ?$ & $1 / 1$ & 92.09 .09 \\
\hline C & std 001002 & NISHIDA & 6.0000 & $+1-$ & 0.001 & $\mathbf{E}$ & Passed & $2 / 5$ & 92.09 .08 \\
\hline$C$ & std 001002 & NISHIDA & 6.0000 & $+1-$ & 0.001 & $\mathbf{E}$ & Passed & $1 / 5$ & 92.09 .08 \\
\hline$M C-P$ & $\operatorname{test}$ & Wl lber & 123.45 & $+1-$ & 12.34 & $\mathbf{s}$ & ralled & Average & 92.09 .01 \\
\hline$M C-p$ & test & Willerer & 123.45 & $+1-$ & 12.34 & $\mathbf{S}$ & Failnd & $121 / 121$ & 92.09 .01 \\
\hline
\end{tabular}

L.ist Measurement I.ok

This option will allow the user to review all six of the measurement types in seyuential order. When this option is selected, the following dialog box is shown: 
List Messuremeat Log (cont.)

\section{List MC Log}

List entries between two dates

List $n$ entries

List all entries

Return to main menu

After the operator selects one of these options, a dialog box will be presented.

\begin{tabular}{l}
\hline List MC Log \\
\hline Range (dates) From: 53.01 .02 \\
To: 92.12 .12 \\
Output to Scroen: $\mathrm{Y}$ \\
Output to Printer: $\mathrm{N}$ \\
Output to File: $\mathrm{N}$ \\
File Name: \\
\hline
\end{tabular}

The user can select from three output devices. Any combination can be selected. Forty-three characters are allowed for File Name of the ASCII file. 
Sample Output

Toka1-mura K-Edge Dengitometer

Measurement Log

\begin{tabular}{|c|c|c|c|c|c|c|c|c|}
\hline Type & Sample ID & Operator & Result & $(g / 1)$ & $E / S$ & Quality & Cycle & Date \\
\hline---- & - - - - - - - - & -ー-ー-ー- & -ーーーーー & -ーーーーー & -ーー & -ー-ーーーー & ----- & \\
\hline MC-P & 1tem & Jim & 220.40 & 0.90 & $\mathbf{E}$ & Passad & Average & 92.10 .02 \\
\hline MC-P & item & $\mathrm{J} \perp \mathrm{m}$ & 220.00 & 1.23 & $\mathbf{E}$ & Passed & $5 / 5$ & 92.10 .02 \\
\hline$M C-P$ & item & $\mathrm{J} \operatorname{lm}$ & 220.00 & 1.23 & $\mathbf{E}$ & Passed & $4 / 5$ & 92.10 .02 \\
\hline MC-P & item & Jim & 220.00 & 1.23 & $\mathbf{E}$ & Passed & $3 / 5$ & 92.10 .02 \\
\hline$M C-P$ & Item & Jim & 221.00 & 1.23 & $\mathbf{E}$ & Passed & $2 / 5$ & 92.10 .02 \\
\hline MC-P & 1tem & Jim & 220.22 & 1.23 & $\mathbf{E}$ & Passed & $1 / 5$ & 92.10 .02 \\
\hline A & 123456789012 & Jim & 220.40 & 0.90 & $\mathbf{E}$ & Passed & Average & 92.10 .01 \\
\hline $\mathbf{A}$ & 123456789012 & Jim & 220.00 & 1.23 & $\mathbf{E}$ & Passed & $3 / 2$ & 92.10 .01 \\
\hline $\mathbf{A}$ & 123456789012 & Jim & 221.00 & 1.23 & $\mathbf{E}$ & Passed & $2 / 2$ & 92.10 .01 \\
\hline $\mathbf{A}$ & 12.3456789012 & Jim & 220.22 & 1.23 & $\mathbf{E}$ & Passad & $1 / 2$ & 92.10 .01 \\
\hline $\mathbf{M C}-\mathbf{B}$ & Ta_7_7 & Wilber & 123.45 & $+/-12.34$ & $\mathbf{S}$ & Falled & $1 / 1$ & 92.09 .30 \\
\hline ST & straight-Thr & Hooter & & & & Passed & $1 / 1$ & 92.09 .09 \\
\hline $\mathbf{B}$ & Background & Hooter & & & & $? ?$ & $1 / 1$ & 92.09 .09 \\
\hline C & std 001002 & NISHiDA & 6.0000 & 0.001 & $\mathbf{E}$ & Passed & $2 / 5$ & 92.09 .08 \\
\hline C & std 001002 & NISHIDA & 6.0000 & $+/=0.001$ & $\mathbf{E}$ & Passed & $1 / 5$ & 92.09 .08 \\
\hline MC-P & test & Wilber & 123.45 & $+/-12.34$ & $\mathbf{S}$ & Failed & Average & 92.09 .01 \\
\hline$M C-P$ & test & WilbeI & 123.45 & $+/-12.34$ & $\mathbf{S}$ & Failed & $121 / 121$ & 92.09 .01 \\
\hline
\end{tabular}

\section{PARAMETERS OPTIONS}

User adjustable parameters are accessed with the parameters option. The short menu allows access to two subsets of parameters. See Chapter 4, Parameters Options, for information on complete access.

\begin{tabular}{l} 
Parameters \\
\hline Miscellaneous \\
\hline Count Times \\
\hline
\end{tabular}

Miscellaneous Coustants

This option allows the user to change some parameters without a password. These changes are stored in the paraineter file. When this option is selected, the following dialog box is shown: 


\section{Miscellaneous Constants \\ Instrument Tite: Tokai-mura K-edge Densitometer \\ Default Print Level: Normal \\ Lines per page: $\quad 58$ \\ Write Spectral Datn to Disk: $\mathbf{N}$ \\ Directory 1: c:kokgi \\ Directary 2: \\ Directory 3: \\ Directory 4: \\ Automatic Background: \\ Automatic Straight-Through: \\ None \\ Weekly \\ Hour: 22:00 \\ Hour: 23:59}

Instruneat Title. This allows the operator to change the title displayed on the top line of the video terminal display while the software is in use.

Print Level. The printout level can be normal, medium, and long. Any warning or error messages from the diagnostics are printed for all printout levels.

Normal - The normal-level printout consists of a header section and a results section, followed by any diagnostic messages. This will be the most frequently used output.

Medium - The medium-level printout includes the net peak areas in addition to the normal output.

Long - The long-level printout includes the medium printout. In addition, information from all of the diagnostic tests is printed.

Debug - The debug-print level includes channel by channel cutput from the regions used to determine the net peak areas.

Lines per puge. This parameter controls the number of lines per line-printer page. We recommend 58 for a laser writer and 64 for a dot matrix printer.

Write Spectral Data to Disk. If this value is changed to No, no spectral data will be written during any measurement. This is the recommended choice. If this value is 
Write Speetral Data to Diat (cont.)

changed to Yes, the directories specified in the next four lines will be used. There will be a maximum of four copies of each spectral file written to different diskblirectory choices. A blank in any row wiil indicate fewer copies. Please note that writing data $w$ diskette is not a fast process. One file can be written during the measurements, and the multiple copies can be generaced afier all measurements are complete. Only the first diskldirectory is checked for previous use of the filename. If a match is found, the run number is incremented to avoid overwriting the furst file.

Automatic Background. TBD

\section{Antomatic Straight-Through. TBD}

Count Times

If this option is selected, the following dialog box is presented. Use the arrow keys to move to the entry of interest, then type the new count time desired.

$\begin{array}{lllll}\text { Measurement Type } & \begin{array}{l}\text { iount Times in Seconds } \\ \text { Number of } \\ \text { Measurements }\end{array} & \text { No Source } & \text { Co-57 } & \text { S0-75 } \\ \text { Alsay } & 2 & & 500 & 500 \\ \text { Beckground } & 1 & 300 & & \\ \text { Straight-Through } & 1 & & 2000 & 2000 \\ \text { MC-Bias } & 1 & & 300 & 300 \\ \text { MC-Precision } & 15 & 500 & 500 \\ \text { Calibrate } & 10 & 100 & 100\end{array}$

The number of measurements aikd the medusurement types ane listed for information purposses. Neither can be changed in this option.

These coptions allow lie user to switch between the long nind shon menus or (o exit the Kl:D) progrnam. 
MENU/EXIT OPTIONS

(cont.)

Go to Full Meau

Exit
Menu/Exit

Go to Full Menu

Exit

The KED software has two menus: the short menu and the full menu. To go from the shor to the full menu requires selecting this option under the MENU/EXIT heading. Approved operator identification is required for this option to be exercised (Level 1 privilege). When the KED is in the full menu, this option becomes Go to Shor Menu; no password is required to go from the full to the shon menu.

To exit the KED software, use the EXIT Option. Approved operator identification is required for this (level 1 privilege). 
In this chapter you will leam about the options in the full menu. The parameter menu will be discussed in the next chapter.

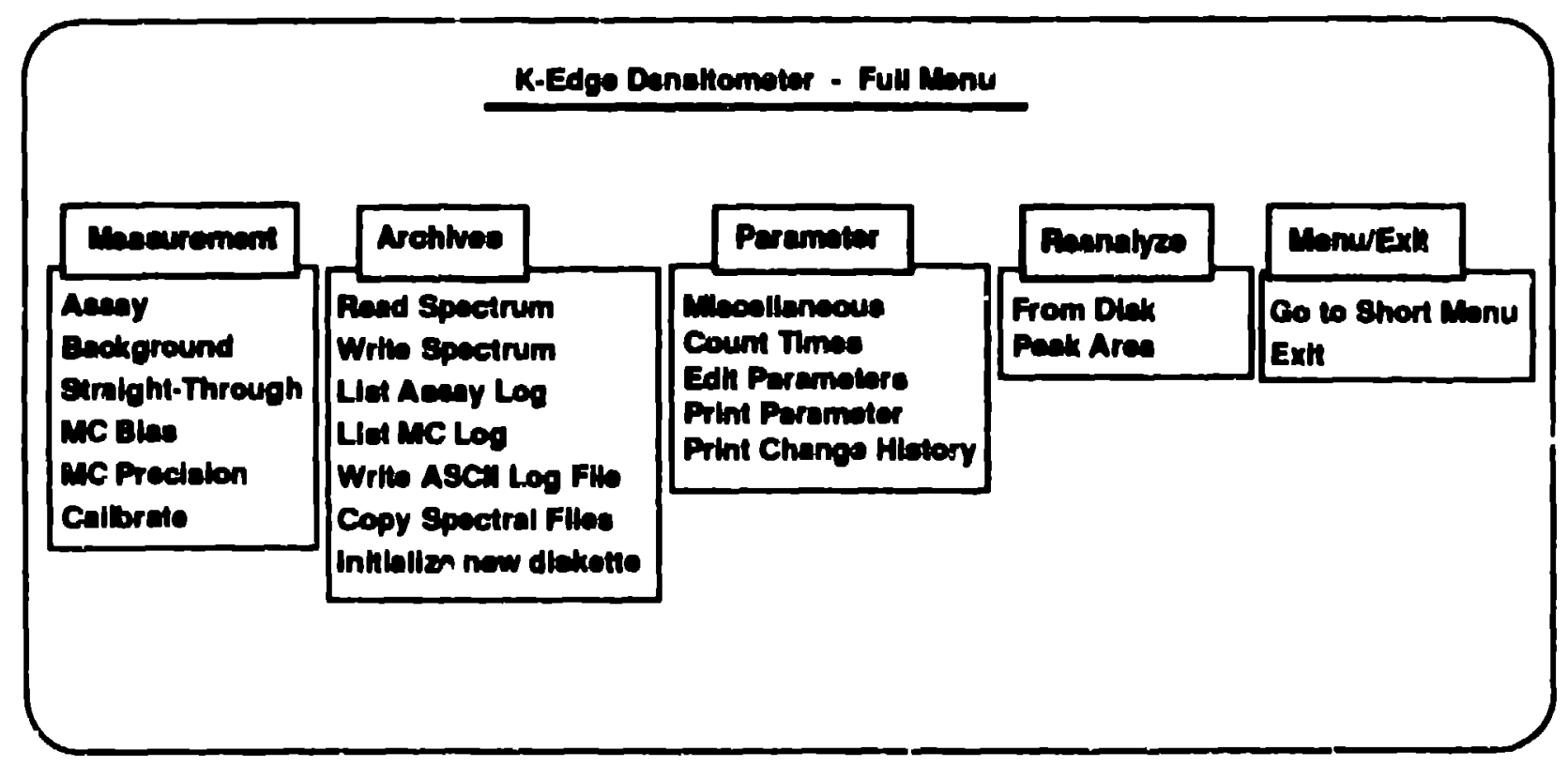

In the full menu. there are five object headings. Amalysis is a new heading nox found in the shon menu. Only options nor discussed in the shor menu will he discussed here. except that the options under the purameter heading will be discussed in Chap. 4.

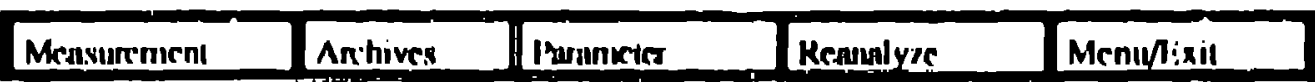

Measurement

Assiny

Bick groumil

Strnighe 'Through

MC' Hiss

MC' Irrecisioul

('alibrate 
MEASUREMENT OPTIONS (cont.)

Callorate
There are six options in the measurement heading, one more than in the shor menu: calibrate.

The Calibration Option is similar to an MC-Precision Option. Repeated measurements are performed on a calibration solution, and the average result (both calibration constants) is printed out at the end of the option. Statistical tests are made on the measurement set.

Operator Eatrlea. In addition to the usual entries, the operator is required to enter the plutonium concentration in grams per liter. If the uncertainty in the concentration is entered for the sigma (sample concenuration), the result will include that in the error estimation.

\begin{tabular}{|r|}
\hline \multicolumn{2}{|c|}{ Colibrate Intormation } \\
\hline Operator: \\
\hline Sample ID: \\
\hline Sample Concentration $(\mathrm{g} / \mathrm{l}):$ \\
\hline sigma(g/1): \\
\hline Remarks: \\
\hline
\end{tabular}

Count Timen and Number of (yclex. We recommend counting long enough $w$ ) that the uncertainty in the calibration constunt is alxout four times less than the uncertuinty in a typical assay. up to $0.1 \%$. The count time can be changod in the PARAMI:IT:R ('ount 'Time Option, the number of cycles can be sel in the PARAMI:I7:R lidil Parumeter Option uncer calibrution constants

(Wutput. The shorn output of the ('alibrate ( potion ouly includes a summonary. 'The realoced chi spuare test cal help lo (ketenmine if the variation in the measurements is Ixcause of counting statistics $(x$ if it has alditional systematic effects.

ite medium output of the ('alibrate ( p)tion moks a printout from ench cycle This printout will inclekle the nommalized

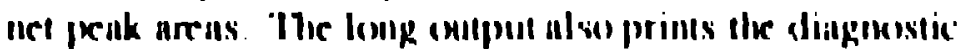
tests for rach cycle. The atroug printeut has mblitional 
Output (cont.)

information and was useful as the program was being written and for the initial testing.

\section{Sample Summary Printout.}

Sample ID: Pufoill

Measurement Type: CALIBRATE

Operator: Jim

Measurement Date: 92.11 .05

Cycle: 5

Remarks: testing tighter FWHM limits

Straight-Through Date: 92.11 .03

Live time $\left(\mathrm{Se}_{e}-75\right)=300 \mathrm{~s}$

Constants File Date: 92.11 .05

Live time $\left(C_{0}-57\right)-300$ s

Callbration Summary

Analysis Method tested: Simple

Number of Measurements: 5

Average Result (cc/g):

\begin{tabular}{l} 
Simple \\
\hline 6.0000 \\
0.0610 \\
1.67
\end{tabular}

\begin{tabular}{l} 
Ext rapolated \\
\hline 6.1000 \\
0.0600 \\
1.66
\end{tabular}

Reduced Chisquare:

\section{ARCHIVES OPTIONS}

Read Spectrum

Wrife ipecerum
This option can be used to recall a spectrum from disk and place it into the S10()-bound memory. The file format is the format specified by Canberry for the $S \mathbf{I O})$. This function is also available under the $S 1(X)$ software. It is of little use unless the user can lox)k at the spectruin. The operator must specify the complete file name including the disk unit. Sec the section on Sprectral I)isplay for directions io whserve the spectrin.

'This option can be used (1) write a specinsm from the $S I(X)$ menury (o) the disk. 'The file fornat is the format specified by ('unlerra for the $S I(X)$. This function is also) availathle under the $S I(X)$ sofiware. The user can use the $S I(X)$ sofit ware of lonk at the specita linter. 'The opernitor must specify the complecte file mame including disk unit. 


\begin{tabular}{|l|}
\hline REANALYZE \\
\hline From Disk \\
\hline Peak Areas \\
\hline
\end{tabular}

The REANALYZE menu contains options to repeat the analysis of recorded spectra.

When this option is selected, the following dialog box is shown:

\begin{tabular}{|r|}
\hline \multicolumn{2}{|c|}{ Analysis from Disk } \\
\hline Operator: \\
\hline Sample ID: \\
\hline Sample Spectral Flles \\
\hline Se-75: \\
\hline Co-57: \\
\hline REMARKS:
\end{tabular}

This option requires the operator to supply the sample file names. The software will search for these files. If the files are nox for' $x d$, the software will indicate which ones need w be entereu correctly. We recommend that the operutor use the REMARKS to specify why the analysis from disk is being done.

The printout of this option is similar to the regular assay; the nanes of the files on which the analysis is hased are included. 
This option allows the operator to determine the peak areas in a single spectrum stored on disk. When this option is requested, the following dialog box will be shown:

\begin{tabular}{|r|l|}
\hline \multicolumn{2}{|c|}{ Analyze Peak Areas } \\
\hline Spectrum file name: & C:I \\
\hline Which source: & Blank \\
\hline Vary FWHM coefficients: & $\mathrm{N}$ \\
\hline
\end{tabular}

In this optici, the program will use the spectrum stored in the memory of the $S 100$ if the entry for the spectrum file name is empty. The operator can select the blank, ${ }^{75} \mathrm{Se}$, or ${ }^{57} \mathrm{Co}$ source peak information and fitting region" with which to analyze the spectrum. The "vary FWHM coefficients" is not used for the summation method of determining the net peak area. If peak fitting is selected for determining the net peak area, then the operator can control whether to vary the FWHM coefficien's. The FWHM parameters may all be allowed to vary, or only the first tem may be allowed to vary, or all FWHM parameters may be fixed. See the Appendix for a discussion of We FWIIM parameter definitions. 
General

In this chapter you will leam these things about the parameter menu:

- How to edit parameters

- How to print parameters, and

- How to print the history of parameter changes.

The parameter file is the key to the KED system.

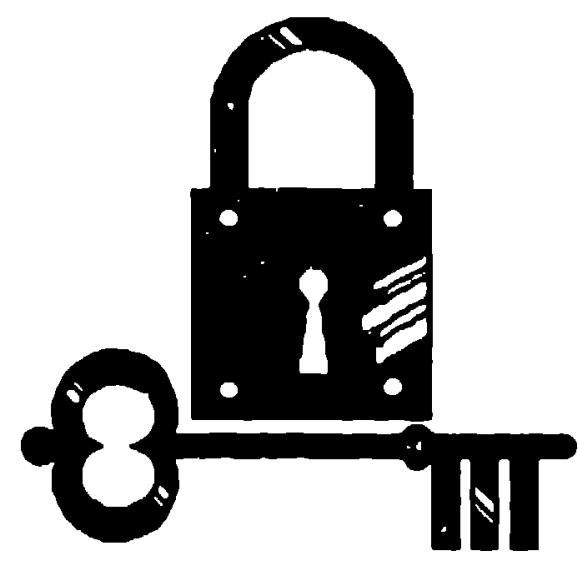

\begin{tabular}{|l|}
\hline Parameters \\
\hline Miscellaneous \\
\hline Count Times \\
\hline Fdit Parameters \\
\hline Print Parameters \\
\hline List Change History \\
\hline
\end{tabular}

Ihe Miscellanauus und Count 'limes (ptions have heen discussed in (hap. 2 as pun of the shorn menu. The other three options are discussed below.

This is the (yption used on moxlify the parameters used in the Klil) analysis and software. When this option is selected. the following dinlog box is shown: 
EDIT PARAMETERS

(cont.)

\begin{tabular}{|l|}
\hline Edlt Which Daramoters? \\
\hline Peak Information \\
\hline Peak Fitting Regions \\
\hline Peak Fitting Constants \\
\hline FWHM \& Cenroids \\
\hline Stabilizer Settings \\
\hline Calibration Constants \\
\hline Assay Test Criterion \\
\hline Measurement Control \\
\hline Operator Passwords \\
\hline Return to Mdin Menu \\
\hline
\end{tabular}

The first two options use a more general format than the other options. They require different values for each transmission source configuration. Three types of transmission source configurations exist:

1. Background or no source,

2. ${ }^{75 g e}$ source, and

3. ${ }^{57}$ Co source.

The information in these two options must be consistent. The - rxe assumes that the region number is consistent bretw-en the Iwu oppions. The oxher options are independent of the transmission source.

Berh the Peak Information Option and the Peak Iritting Regions Optuon list the parameters in spreud-sheet form. Use lise up und down arrows to change berween rows. Use th - tah aml left arnow keys to change between cells. 'To odit ali wher pinumeters, the cursor is moved between entries by fice up and down arrow keys.

Aft:-r the cyeraltor alits purameiers, the program will usk the (yeratox (1) enter a conment. 'The user might indicate, which purameters were changexl. These comments can be reviewed in the l isst ( 'hunge I listory ( pution. 
The peak fitting constants depend on which transmission source in the Geneva mechanism is being used. Different peak fitaing parmeters are allowed to vary for the analysis of each source. When the Peak Information Option is selected, the following dialog box will be shown:

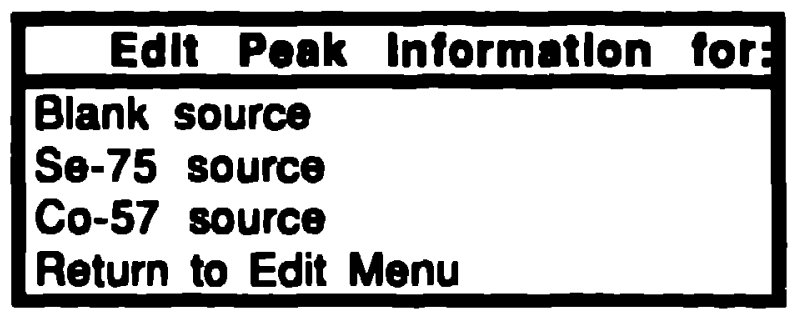

The user selects the type of spectra corresponding to the parmeters to be edited and presses enter. The following dialog box is shown when the ${ }^{57} \mathrm{Co}$ source is selected:

\begin{tabular}{|c|c|c|c|c|c|c|c|}
\hline \multirow[b]{2}{*}{$\begin{array}{l}\text { Inotope } \\
\text { Nume }\end{array}$} & \multirow[b]{2}{*}{$\begin{array}{l}\text { Pack } \\
\text { Enoray }\end{array}$} & \multirow[b]{2}{*}{$\begin{array}{l}\text { Branching } \\
\text { Ratio }\end{array}$} & \multirow[b]{2}{*}{ Aru } & \multicolumn{4}{|c|}{ Peak Information (Co-57 Source) } \\
\hline & & & & $\begin{array}{l}\text { Aren } \\
\text { Sumined } \\
\text { Whin } \mathrm{B} \text {. }\end{array}$ & $\begin{array}{l}\text { Uned } \\
\text { For } \\
\text { Er.try }\end{array}$ & $\begin{array}{l}\text { Uned } \\
\text { For } \\
\text { Eingn, }\end{array}$ & $\begin{array}{l}\text { Und } \\
\text { For } \\
\text { Shrog }\end{array}$ \\
\hline $\begin{array}{ll}1 & \text { Cd. } 109 \\
2 & \text { Co. } 57 \\
3 & \text { Co. } 57\end{array}$ & $\begin{array}{r}88.036 \\
122.060 \\
136.471\end{array}$ & $\begin{array}{l}0.000 E+000 \\
0.000 E+000 \\
0.000 E+000\end{array}$ & $\begin{array}{l}0 \\
0 \\
0\end{array}$ & $\begin{array}{l}\mathbf{0} \\
\mathbf{0} \\
\mathbf{0}\end{array}$ & $\begin{array}{l}\mathbf{Y} \\
\mathbf{Y} \\
\mathbf{Y}\end{array}$ & $\begin{array}{l}\mathbf{Y} \\
\mathbf{Y}\end{array}$ & $\begin{array}{l}\mathbf{N} \\
\mathbf{N}\end{array}$ \\
\hline
\end{tabular}

Notation in the Peak Information DLalog Box. Several features of the peak fitting software are not necessary for the KED and are not implemented in this software version. Additional information is in Appendix A: Peak Fitting.

Area Fixed to Pk. Not used in KED.

Area Suinmed with Pk. Not used in KED.

Used for Einergy. These peaks are used for the energy calibration.

Used for H-WIIM. These peuks are used for the fiull Widih Ilalf Maximum calibration.

Used for Shape. 'These peaks are used for the peak shape calibration if the appropriate parameter is set uncler the Peak lïtting Constunts (pption. 
Notation in the Peat Information Dialog Box (cont.)

The Used for Energy and Used for FWHM features yield the values required for the diagnostic tests. See the FWHM \& Centroids (Diagnostic Peaks) Option.

If peak fitting is being used (see the Miscellaneous Parameters Option), the Used for Energy, FWHM, or Shape parameters defer to the Energy, FWHM, or Shape parameter 3 FREE settings in the Peak Fitting Constants Option.

Addins or Deleting Peak. Peaks are added by typing at the end of the table; when the F10 key is pushed to accept all entries, the program will arrange the peaks in onder of ascending energy. Peaks can be deleted by typing zero $(0.0)$ for the peak energy. It is impontant that the information in this option be consistent with the Peak Fitting Regions Option.

The region of interest constants depend on which transmission source in the Geneva mechanism is being used. Different peak fitting regions are required for each source. See the Appendix A: Peak Fitting for more information. When the Peak Fitring Regions Option is selected, the following dialog box will be shown:

\section{Edlt Peak Fitting Regions for:}

Blank source

Se-75 source

Co-57 source

Return to Edit Menu

The user selects the type of spectra corresponding to the parameters (o) be edited and presses enter. The following dialog bx)x uppears when the ${ }^{75}$ Se source is selected: 
Peak Fitting Regions

(cont.)

Fitling Region Information ( ${ }^{75}$ Se source)

\begin{tabular}{|c|c|c|c|c|c|c|c|}
\hline $\begin{array}{l}\text { Region } \\
\text { Numb-z }\end{array}$ & $\begin{array}{l}\text { IFitting } \\
\text { Low E }\end{array}$ & $\begin{array}{l}\text { Rangel } \\
\text { Hiph }\end{array}$ & $\begin{array}{l}\text { (Backg } \\
\text { H }\end{array}$ & d & 13 & $M$ & $\begin{array}{l}\text { Bkgu } \\
\text { Chunnels }\end{array}$ \\
\hline $\begin{array}{l}1 \\
2 \\
3 \\
4\end{array}$ & $\begin{array}{l}86.9 \\
119.7 \\
134.0 \\
277.0\end{array}$ & $\begin{array}{l}89.3 \\
123.7 \\
138.0 \\
282.0\end{array}$ & $\begin{array}{l}86.3 \\
119.0 \\
133.5 \\
276.5\end{array}$ & $\begin{array}{l}86.3 \\
119.0 \\
133.5 \\
276.5\end{array}$ & $\begin{array}{l}89.4 \\
124 . \\
138.5 \\
282.5\end{array}$ & $\begin{array}{l}89.4 \\
124 . \\
138.5 \\
282.5\end{array}$ & $\begin{array}{l}5 \\
5 \\
5 \\
5\end{array}$ \\
\hline
\end{tabular}

The parameters are explained in the Appendix. Thiey are

- The boundaries of the peak region for each gamma ray,

- The positions of the background regions around each gamma ray.

- The number of points in each background region, and

- The type of background function used to fit the continuum undti the gamma ray peak.

Notation Used in the Peak Fitting Regions Dialog Box. All region data are stored in the parameter file in energy units so that they are independent of the system energy calibration. One must enter all four background regions, but they need not be unique or independent. For example the same background region may be entered twice or two background regions can overlap. If they overlap, the duplicated points are used only once in the background fitting. If two identical regions are entered, only one set of points is used in the fitting, that is, they are not double weighted. The number of points per background region is the same for each region. The actual number used in the fitting in any given area of the spectrum can be adjusted by overlapping the regions or placing two regions adjacent to each other.

The types of background functions are related to the TERMS parameter as follows. 
Notation Used in the Peak Fitting Regions Dialog Box (conL)

TERMS Type of Bkg Function

$1 \quad$ Horizontal (zero slope) straight line

2 Straight line with slope and intercept

3 Sloping straight line with step function

4 Parabola with step function

$5 \quad$ Step function with zero slope

Regions are analyzed in the order they are listed.

Adding or Deleting Regions. Kegions can be added at the end of the table; when the FIO key is pushed to accept all the entries, the program will arrange the regions in ascending order by energies. Regions can be deleted by zeroing the low energy. It is important that the information in this option be consistent with the information in the Peak Information Option.

Moving Between Cells. Use thr up and down arrows to change between rows. Use the tab and left arrow keys to change between cells.

Please note that the peak fitting is disabled in this application.

Peak Fltting Constants

This option allows the operator to change the peak-shape-titting constants used in the analysis. Detailed dextiption of the peak-shape constants can be found in Appendix $A$. The printout for the Fitting Constants Option is shown below: 


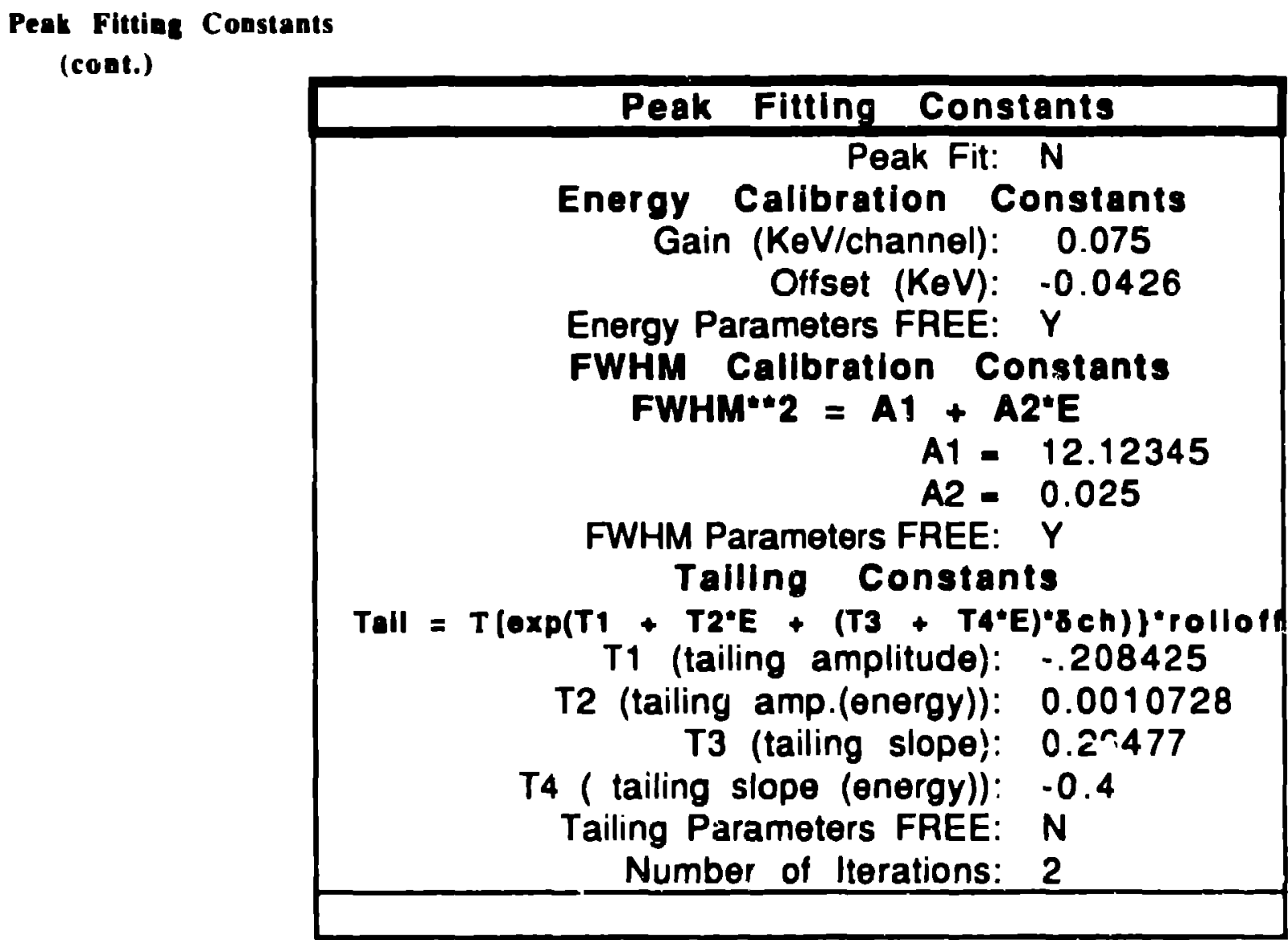

In the KED program, the peak shape determination should be performed during the ${ }^{75}$ Se portion of the straight-through run. Plea: " note that the units are inconsistent in this application. The units for the FWHM constants are channels, not cnergy in keV. If any of these parameters are set FREF, then vach of the spectrum types under the Peak Information Uption must specify which peaks are used for the parameter fit. The initial determination of these parameters is not a trivial exercise. The Peak Area Option in the RI:ANALYSIS menu may or may nox te useful for those who attempt this exercise. Plecase nute that the peak fit ting is disabled in this application.

Peak tile. This parameter indicates whether peak filting or simple summation is used (1) generate the uet peatk areas. All of the gatmma rays in this application are well resolved. leak titling will yicld lower yuality results than the 
PWHM \& Centroidy

\section{Peak Fit (cont.)}

summation method. The measurement precision will be smaller for the summation method. In addition, the setup and maintenance of the peak fitting parameters is not easy. We recommend setting this parmeter to No. Please note that the peak fitting is disabled in this application. No is the only possible response.

Nomber of Iteration in Pit. If peak fitting is used, the number of iteracions can be restricted. The iteration involves adjusting the background under the peak(s) by looking at the residual from the fit, then repeating the fitting process.

Other applications have suggested that no benefits are found after two or three iterations.

In each spectrum, specified peaks are checked for resolution, position, and intensity. These diagnostic checks are specified with this option. A printout of the diagnostic peak dialog box is shown below:

EWHM centrolds (Diugnostlc Paks)

Transmission
Source
Blank
Se-75
Se-' j
Se-75
C. $-5 \%$
Co-57

Peak

Energy

B8.036

08.036

121.110

136.090

88.036

122.060

\section{Centroid Limit}

(Channel $+/-$ Tolerance)

1157.1

1157.1

1629.8

1842.5

1157.1

1644.6
2.0

3.0

2.0

3. 0

2.0

3.0

FWH limit
(Channels)
9.4
9.4
9.9
10.1
9.4
10.4

Desired

pracision (h)

0.5

0.2

0.2

0.2

0.2

0.2

The centroid limit (position) check is a (wo-sidad cest because the spectra can drift in either direction. The limits on tive peak centroid must be fairly tight when using the region-of -interest summarion method of deternine the peak areus because in the peak fitting, the progrum detennines the energy calibration for each spectrum. So if the peak centrnid liss changed by several channels, the resulting peak area would still be correct.

'The I.WIIM (resolutoon) test is an upper limit. 'The limits on the I.WIIM are detennined by meusuring the I.WIIM ut low. counting rales and muliplying hy a fik'tor of 1.1 . 


\section{FWHM \& Centroids}

(cont.)

Operator Paswords

Stablizer Settings
The limits on the peak centroid and FWHM are printed in the medium and long printout options.

Operator password privileges are divided into two levels.

Level 1. The first level allows the operator to change between the full menu (requires the operator's name) and the short menu (no restriction).

Level 2 The second level allows the operator to select the Edit Parameter Option. With level two privilege, one can change the calibration constants, as well as the passwords that control access to the calibration constants. The Level 2 capability allows the facility to limit access to critical features of the KED software.

The controls of the stabilizer are set with this option. Note that each transmission source condition sen!rires different gain-stabilizer parameters. The stabilizer manual describes the parameters.

Stenbilierer Seuings

Huclupound Se-75 Co-57

(inin

Peak ('hennel:

Wulow Wudth:

Kunge: Ten) Surve:

Irak (hannel:

Winchew Wulth:

Runge:

Sime:

l'wt: |

\begin{tabular}{|c|c|c|}
\hline $\begin{array}{l}389.3 \\
11 \\
0.5(x) \\
\text { (X) }\end{array}$ & $\begin{array}{l}369.3 \\
17 \\
0.5 \times 0 \\
0 n\end{array}$ & $\begin{array}{l}1857 \\
11 \\
(0.5 x) \\
(2 \pi\end{array}$ \\
\hline $\begin{array}{l}11.57 \\
11 \\
0.5(x) \\
(1)\end{array}$ & $\begin{array}{l}11.57 \\
11 \\
0.5(x) \\
(\mathrm{ln})\end{array}$ & $\begin{array}{l}11.57 \\
11 \\
0.5 x) \\
(2 \pi)\end{array}$ \\
\hline
\end{tabular}

Hand Kere:

$\mathbf{w}(x)$ 
Callbration Cosstants In this option, the calibration constants can be changed The calibration constant dialog box is shown below.

\begin{tabular}{|c|c|c|c|}
\hline \multicolumn{4}{|c|}{ Calibration Constants } \\
\hline $\begin{array}{l}\text { Simple Method: } \\
\text { Extrapoluion Method: } \\
\text { Calibration Dere: }\end{array}$ & $\begin{array}{l}6.1234 \\
6.4321 \\
92.11 .30 \\
10\end{array}$ & $\begin{array}{l} \pm \\
\pm\end{array}$ & $\begin{array}{l}.0012 \\
.0021\end{array}$ \\
\hline
\end{tabular}

The number of measurements per standard is chosen from a list that appears when the F2 button is pressed. The replicate measurements are checked for consistency.

Asany Test Criterlon

Meanurement ('uatrul

Mensurenent control Backgruand a Sirnight. I'hrough
The Awron bubble test for each assay has two parameters as explained in the appendix. The dialog box is shown below.

\section{Assoy Test Crikrion}

Two Messurement Test (sigma):

Three Mcosurement Test (sigma):

Andysis method to test:
3.18

1.95

Simple

Please note that the user must select whicii result is tested. We recommend that the simple result be used.

When the measurement control paraineters are selected irum the edit menu, a choice must he inude with the following dia$\log (x) x$ :

Edie Meisureineme Control for:

Hackground \& Siruight-'Through

Bias \& Precision

Retum to lidit Menu

lior both of these neasurement types, there is a maximum tinte allowed before like meesurement type must be iepealed successfully. When this time is exceeded and the check has nex been perfonmed, ull assay will noll le pemitted. If the 


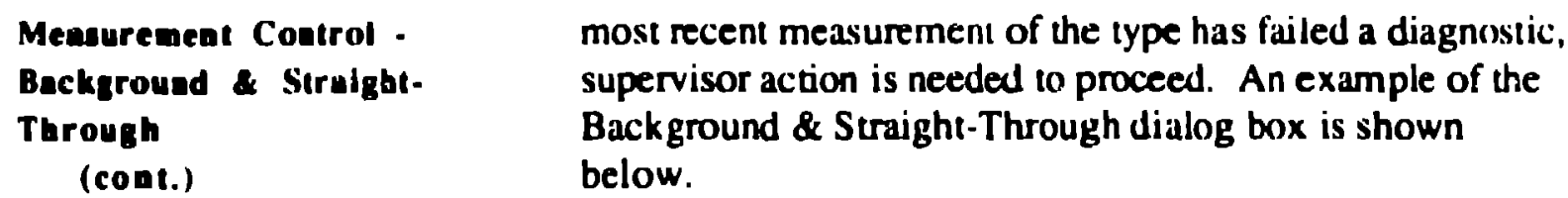

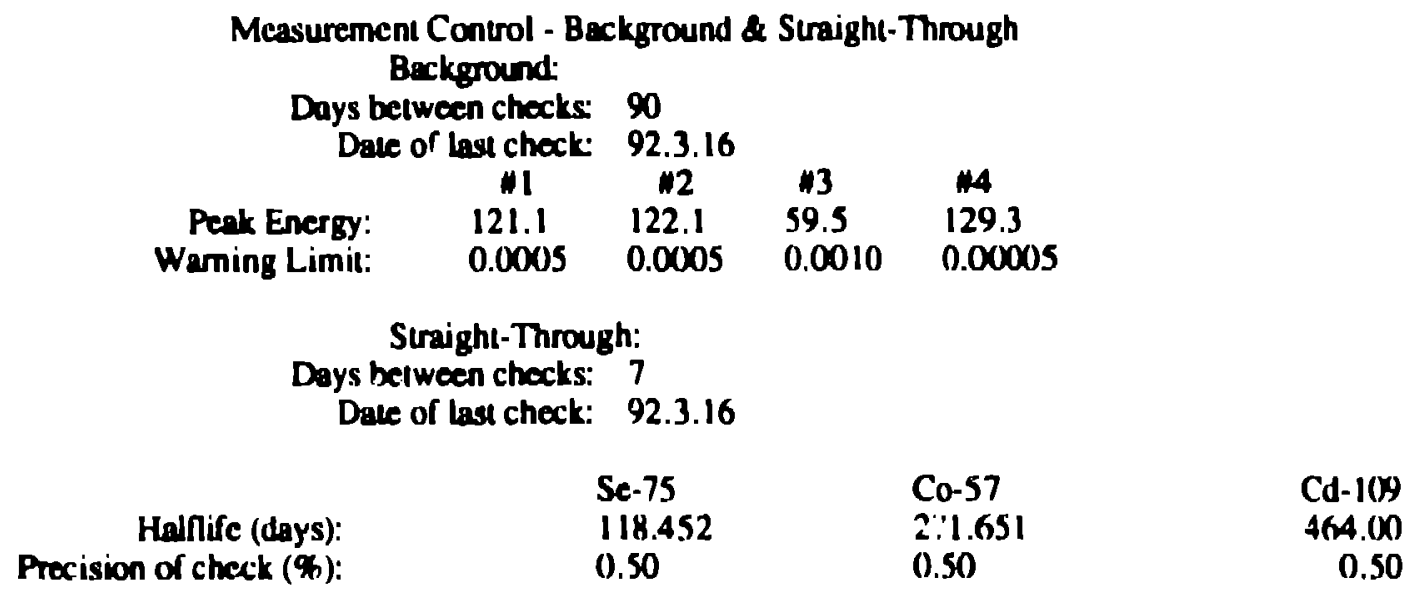

Four peak regions, specified by energy, can be checked in the background spectra. If the normalized counts exceed the specified value, a warning is printed.

The program compares each background or straight-through measurement with the preceding measurement of the sume type. If the change in gamma-ray intensity is nox consistent with the predicted half-life decaly, the operator is warned.

Fior each of these meusurement types, there is a maximum time allowed hefore the measurement type must be repeated successfully. When this time is excealed and the check has nos been performed, an assay will not be pemitted. If the inost recerit measurement of one of these types failed the diagnostic tests, then supervisory action is required (o) 

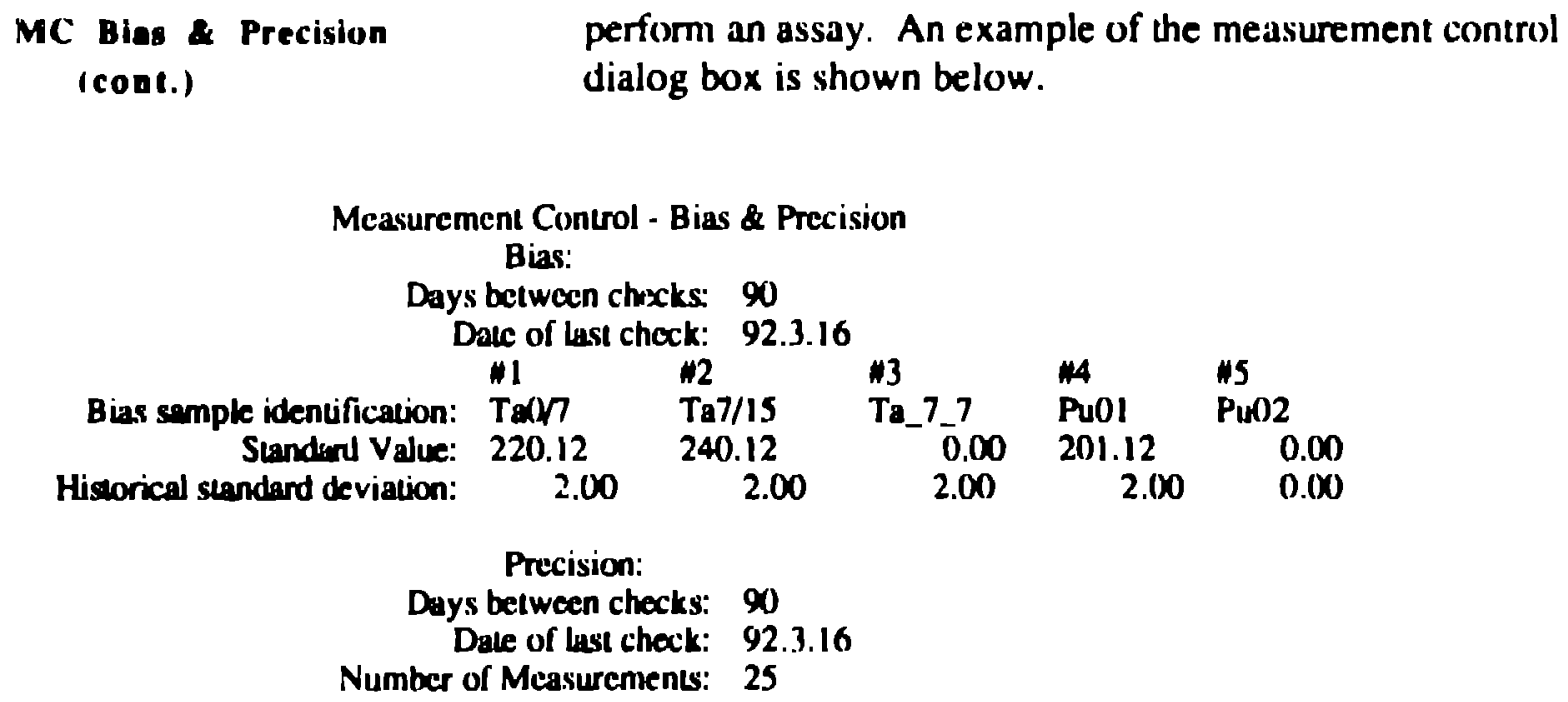

PRINT PARAME'THES
The operator may s ie up to five different standand identifications and values for the $\mathrm{MC}-\mathrm{Bias}$ Option. When the $\mathrm{MC}$ Bias Measurement Option is exercised, the sample ID will be chosen from this list.

The number of measurements for an MC-Precision Option can be selected from the list seen when the $F 2$ bution is pressed. A larger number of measurements yields a more precise estimate of the standard deviation of the measurements, consequently the test limits are tighter for that case.

This option allows the operator (o) prine the paramelers used in the program. The prograus can either print all the purameters or it can fint different parameter groupings. The following dialog box will be shown when this option is selecied: 
PRINT PARAMETERS

(cont.)

All of Then

KED Paramoter File

\begin{tabular}{l} 
Print Whlch Parameters? \\
\hline Peak Information \\
\hline Peak Fitting Regions \\
\hline Peak Fitting Constants \\
\hline FWHM \& Centroids \\
\hline Operator Passwords \\
\hline Stabilizer Settings \\
\hline Calibration Constants \\
\hline Assay Test Criterion \\
\hline Measurement Control \\
\hline Count Times \\
\hline Miscellaneous Constants \\
\hline All of them \\
\hline Return to the Main Menu \\
\hline
\end{tabular}

The operation of these options is similar to the Fdit Parameter Options, except that the output will be printed instead of allowing the operator to change the parumeters.

This uption allows the operator in print all the parameters used in the KED program, except for the operubor pass. words. The user may ulso choxose to print a subset of the parumeter file.

\begin{tabular}{|c|c|c|c|c|c|c|c|c|}
\hline \multirow[b]{2}{*}{$\begin{array}{l}\text { Pk } \\
\text { No }\end{array}$} & \multirow[b]{2}{*}{$\begin{array}{l}\text { leotope } \\
\text { Neme }\end{array}$} & \multirow[b]{2}{*}{$\begin{array}{l}\text { Peak } \\
\text { Enorgy }\end{array}$} & \multicolumn{6}{|c|}{ Peek Informalion (Dackground) } \\
\hline & & & $\begin{array}{l}\text { Branching } \\
\text { Pallo }\end{array}$ & $\begin{array}{l}\text { Area } \\
\text { Fixed } \\
\text { IoPk }\end{array}$ & $\begin{array}{l}\text { Area } \\
\text { Summed } \\
\text { Wilh Pk }\end{array}$ & $\begin{array}{l}\text { Uand } \\
\text { For } \\
\text { Fineray }\end{array}$ & $\begin{array}{l}\text { Uhad } \\
\text { For } \\
\text { FWHIM }\end{array}$ & $\begin{array}{l}\text { Uhed } \\
\text { I or } \\
\text { Shpon }\end{array}$ \\
\hline 1 & Am.241 & 50595 & 0 OOOE $: 000$ & 00 & 0 & $\mathbf{N}$ & $\mathbf{N}$ & $N$ \\
\hline$?$ & Cd.100 & Bค. 036 & $0.000 \mathrm{E}, 000$ & 0 & 0 & $Y$ & $\mathbf{N}$ & $\mathbf{N}$ \\
\hline 3 & Se. 75 & 121115 & 0 OOOE +000 & o & 0 & $\mathbf{N}$ & $\mathbf{N}$ & $\mathbf{N}$ \\
\hline 4 & Co. 57 & 122.060 & 0 oool: $: 000$ & 0 & 0 & $\mathbf{N}$ & $\mathbf{N}$ & N \\
\hline b. & Pu 239 & 129290 & 0 O001 .000 & o & 0) & $\mathbf{N}$ & $\mathbf{N}$ & $\mathbf{N}$ \\
\hline H & Co:st & $136.4 / 1$ & o oout + und & n & 0 & $\mathbf{N}$ & $\mathbf{N}$ & $\mathbf{N}$ \\
\hline 1 & Sn $/ !$ & $21952 \mathrm{H}$ & 00001,000 & 00 & 0 & $\mathbf{N}$ & $\mathbf{N}$ & $\mathbf{N}$ \\
\hline
\end{tabular}


All of Then

(cuat.)

Peak Information (So-i, Source)

Pk leotope Paak Branching Area Area Uned Unod Used

No Name Enorgy Ratio Fixed Summed For For For

Io Pl. With Ek Ennegy FWHM Shan

1 Cd-100 $88.036 \quad 0.000 E+000 \quad 0 \quad 0$

$\begin{array}{llllll}2 & 50.75 & 121.115 & 0.000 E+000 & 0 & 0\end{array}$

$\begin{array}{llllll}3 & 50.75 & 136.000 & 0.000 E+000 & 0 & 0\end{array}$

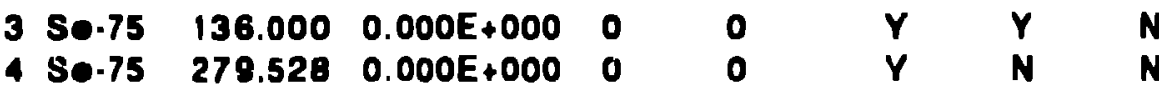

Peak Inlormation (Co.57 Source)

\begin{tabular}{|c|c|c|c|c|c|c|c|c|}
\hline Pk & $\begin{array}{l}\text { leotopo } \\
\text { Namp }\end{array}$ & $\begin{array}{l}\text { Peak } \\
\text { Encroy }\end{array}$ & $\begin{array}{l}\text { Branching } \\
\text { Patio }\end{array}$ & $\begin{array}{l}\text { Area } \\
\text { Fixed } \\
\text { To Pk }\end{array}$ & $\begin{array}{l}\text { Area } \\
\text { Summod } \\
\text { With Pk }\end{array}$ & $\begin{array}{l}\text { Unad } \\
\text { For } \\
\text { Enaray }\end{array}$ & $\begin{array}{l}\text { Uned } \\
\text { For } \\
\text { FWHM }\end{array}$ & $\begin{array}{l}\text { Uned } \\
\text { For } \\
\text { Shono? }\end{array}$ \\
\hline & $\begin{array}{l}\text { Cd-109 } \\
\text { Co-57 } \\
\text { Co-57 }\end{array}$ & $\begin{array}{r}88.036 \\
122.060 \\
138.471\end{array}$ & $\begin{array}{l}0.000 E+00 \\
0.000 E+00 \\
0.000 E+00\end{array}$ & $\begin{array}{ll}10 & 0 \\
10 & 0 \\
10 & 0\end{array}$ & $\begin{array}{l}0 \\
0 \\
0\end{array}$ & $\begin{array}{l}Y \\
Y \\
Y\end{array}$ & $\begin{array}{l}Y \\
Y \\
N\end{array}$ & $\begin{array}{l}\mathbf{N} \\
\mathbf{N} \\
\mathbf{N}\end{array}$ \\
\hline
\end{tabular}

FIIIing Reglon Information (Background)

\begin{tabular}{|c|c|c|c|c|c|c|c|c|}
\hline $\begin{array}{l}\text { Pegion } \\
\text { Numbint }\end{array}$ & $\begin{array}{l}\text { lFining } \\
\text { Lory }\end{array}$ & $\begin{array}{l}\text { Rangol } \\
\text { Hiah E }\end{array}$ & (Backo & $\begin{array}{l}\text { ound } \\
12\end{array}$ & 13 & 14. & $\begin{array}{l}\text { Bkgd } \\
\text { Chronole }\end{array}$ & $\begin{array}{l}\text { Bkod } \\
\text { Inrmn }\end{array}$ \\
\hline 1 & 57.5 & 61.5 & 57.0 & 57.0 & 62.0 & 62.0 & 5 & 5 \\
\hline 2 & 86.0 & 80.3 & 86.3 & 86.3 & 80.4 & 89.4 & 5 & 5 \\
\hline 3 & 119.7 & 123.7 & 110.0 & 110.0 & 124.0 & 124.0 & 5 & 5 \\
\hline 4 & 128.1 & 130.4 & 127.6 & 127.6 & 130.5 & 130.5 & 5 & 5 \\
\hline 5 & 134.0 & 138.0 & 133.5 & 133.5 & 138.5 & 138.5 & 5 & 5 \\
\hline 6. & 277.0 & 282.0 & 276.5 & 276.5 & 282.5 & 282.5 & 5 & 5 \\
\hline
\end{tabular}

Filling Resion Intormallon ( 75 Se source)

\begin{tabular}{|c|c|c|c|c|c|c|c|}
\hline Region & FFifing & Pange| & |Backg & und & & 1 & Bhod likgd \\
\hline Number & LOWE & Hiah E & $\mu$ & 22 & 13 & 14 & Channals Lerm: \\
\hline 1 & 86.8 & 80.3 & 86.3 & 86.3 & 80.4 & 89.4 & 5 \\
\hline $\mathbf{a}$ & 1197 & 123.1 & 1100 & 110.0 & 124. & 124. & 5 \\
\hline 3 & 1340 & 138.0 & 1335 & 1335 & 1385 & 1385 & 5 \\
\hline 4 & 2170 & 2820 & : 16.5 & ?/A 5 & 2825 & 2825 & $\mathbf{5}$ \\
\hline
\end{tabular}

Finling Rogion Inlurmallon (5/Co source)

\begin{tabular}{|c|c|c|c|c|c|c|c|}
\hline Hegion & If ilfing & Hange| & |lHacikgr & & & 1 & Phogd Ikngd \\
\hline Numbre: & Lawt & llight & 11. & 12 & 13 & 14 & 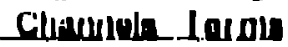 \\
\hline 1 & HA & 00.3 & HE :I & AH : 1 & BH 4 & BOA & 5 $\quad 3$ \\
\hline ?? & 110.1 & 1:3:1 & 1100 & 1190 & 124 & 124 & ! \\
\hline $\mathbf{a}$ & $1: 140$ & 1380 & 1:1:1: & 1335 & $133 \mathrm{~S}$ & 1.395 & ו \\
\hline
\end{tabular}


All of Then

(cont.)

Peak Fitting Constants

Ealibration Constants

Energy Parameters Frea:

$\mathrm{KoV}$

FWHM Calibration Constants

$F W H M{ }^{* 2} 2=A 1+A 2 \cdot E+A 3 / E$

a1: 25.6178 a2: 0.028649 a3: -9976.6563

FWHM Parameters Free: $Y$

Tailing Constants

T1 (talling amplitude): -3.90650

T2 (talling energy): 0.0150908

T3 (tailing slope): 0.34008

T4 (Gaussian Roll-off): -0.40000

Talling Parameters Free: $Y$

FWHM \& Centrolds (Dlagnostlc Peaks)

Transmissio
Source
Blank
Se.75
Se -75
Se -75
Co 57
Co.57

Peak Centroid Limit

Ene.gy

88.036

88.036

121.110

136.000

88.036

122.060

Gain

Foek C imned:

Window Width:

Ranoa:

Stule:

Zaro

Puak Cherinat:

Window Whith:

Pryxu:

Slate: (Channel + + - Tolerance)

$\begin{array}{ll}1157.1 & 2.0 \\ 1157.1 & 3.0 \\ 1629.8 & 2.0 \\ 1842.5 & 3.0 \\ 11571 & 2.0 \\ 1644.6 & 3.0\end{array}$

Slabilizor Seltings

Background

FWHM IImll

(Channels)

9.4

9.4

9.9

10.1

9.4

10.4

3893
11
0.500
OfI

1157

11

0.500

(1)

Porl: 1

So-75
3893

17

0.500

on
1157
11
0.500
O)

Co 57

$$
\begin{aligned}
& 1857 \\
& 11 \\
& 0.500 \\
& \text { On }
\end{aligned}
$$

$$
\begin{aligned}
& 1157 \\
& 11 \\
& 0.500 \\
& \text { In }
\end{aligned}
$$

Hinat Hulu: $\quad 300 \quad$ Frilly: Nory 
All of Them

(cont.)

\title{
Calibration Constants
}

Simple Mathod:

Extrapslation Method:

Calibration Date:

Number of measurements per standard:

$\begin{array}{lll}6.1234 & \pm & .0012 \\ 6.4321 & \pm 0021 \\ 92.1130 & & \\ 10 & \end{array}$

\section{Assay Teit Criterion}

Two Measurement Test (sigma):

Three Measurement Tesı (sigma):

3.18

Analysis method to test:

1.95

Simple

Measurement Control - Background Straight-Through

Background:

Days between cherks: 90

Date of last chieck: 32.3 .16

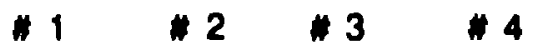

Peak Energy: $\quad \begin{array}{lllll}121.1 & 122.1 & 59.5 & 129.3\end{array}$

Warning Limit: $\quad 0.00050 .00050 .00100 .00005$

Straight-Through:

Days between checks: 7

Date of last check: 92.3.16

\author{
Se.75 Co.57 \\ 118.452 \\ 0.5 \\ 271.651 \\ 0.5 \\ Halflife (days): \\ Precision of check (\%):

\section{Measurement Control - Bias \& Precision} \\ Blas: \\ Days between checks: 9 u \\ Dale of last check: 92.3.16

\section{$\begin{array}{lllllll}* & 1 & 2 & 4 & 4\end{array}$} \\ Bias sample identilication: Ta0/7 Ta7/15 Taxxx Pu01 Pu02 \\ Slandard Value: $220.12 \quad 240.12 \quad 201.12$ \\ Historical standard deviation: 2.22. \\ $\begin{aligned} \text { Warning Limil: } & 2.0 r \\ \text { Error Limil: } & 4.00\end{aligned}$ \\ Procision: \\ Days bolween checks 90 \\ Dalu of last chock: $92.3,16$ \\ Number of Mosasuroments: 15
}

Cd. 109

464.00

0.50 
All of Them

(cont.)

\section{Count Times in seconds}

$\begin{array}{lllll}\text { Measurement Type } & \begin{array}{l}\text { Number of } \\ \text { Measurements }\end{array} & \text { No Source } & \text { C0-57 } & \text { Se-75 } \\ \text { Assay } & 2 & & 500 & 500 \\ \text { Background } & 1 & 300 & & \\ \text { Straight-Through } & 1 & & 2000 & 2000 \\ \text { MC.Bias } & 1 & & 300 & 300 \\ \text { MC.Precision } & 15 & & 500 & 500 \\ \text { Calibrate } & 10 & & 100 & 100\end{array}$

Miscellantous Constants

Instrument Title: Tokai-mura K-Edge Densitometer

Print Level: Normal

Write Data to Disk: N

Automatic Background: Daily Hour: 22:00

Automatic Straight-Through: Weokly Hour: 23:59

Peak Fit: $N$

Number of llerations in Fit: 2

\section{Write Data 10 Disk:Directory}

LIST CHANGF HISTORY
This option allows the operator to print the history of changes made on the KED system. It keeps a history of the changes made to the parameter file and which measurement control runs are performed on the system.

liach enury lists the date and time and the comment the operator entered. A hard copy can be obtained by ardjusting the displaty and then using the [print screen] button. 
GENERAL

Source Spectra
To see the MCA spectral display, one must exit the KED software. This can be accomplished in two ways.

Method 1 requires that the user start Windows 3 and the S100 software before starting the KED software. Then the user can collapse the display to an icon. This releases the $S$ 100 board so that the KED progran can attach to it. When at the DOS prompt, the user can start the KED program as normal, collapse the KED program to an icon, and then toggle between KF.D and the S-100 display icons. Once the Windows pack nge is started, the user can toggle into and out of Windows 3 by typing ctrl-alt. This type of exit to DOS will not detach the $S-100$ board. If the user then runs KED, eventually the system will stop because of a conflict between the two pieces of software competing for the S-100 board.

Method 2 requires the user to run either the S-100 software under windows or the KED software. The user performs an EXIT Option of the first program before starting the other one.

In any event, typing "WIN" to a DOS prompt will stan Windows 3.0. Then the user artivates the S-100 button with the mouse to start the $S-100$ software.

Spectra from the three radioactive sources are in the next three figures. The ${ }^{1109} \mathrm{Cd}$ is the rate-loss source and the 88.036-keV gamma ray is expected to be present in every spectrum. The ${ }^{75} \mathrm{Se}$ and ${ }^{57} \mathrm{Co}$ are the two transmission sources.

Please note that lead shields can fluoresce at 72,8, 74.7. 84.4 , and $84.9 \mathrm{keV}$, while tungsten can fluoresce at $58 .()$. 59. $3,6,7.2$, and 69.1 keV. Some ${ }^{1(x)}$ Cd sources are contaminated with $113 \mathrm{~m} \mathrm{Cd}$, which has a ganma ray at $26.3 .7 \mathrm{keV}$. 


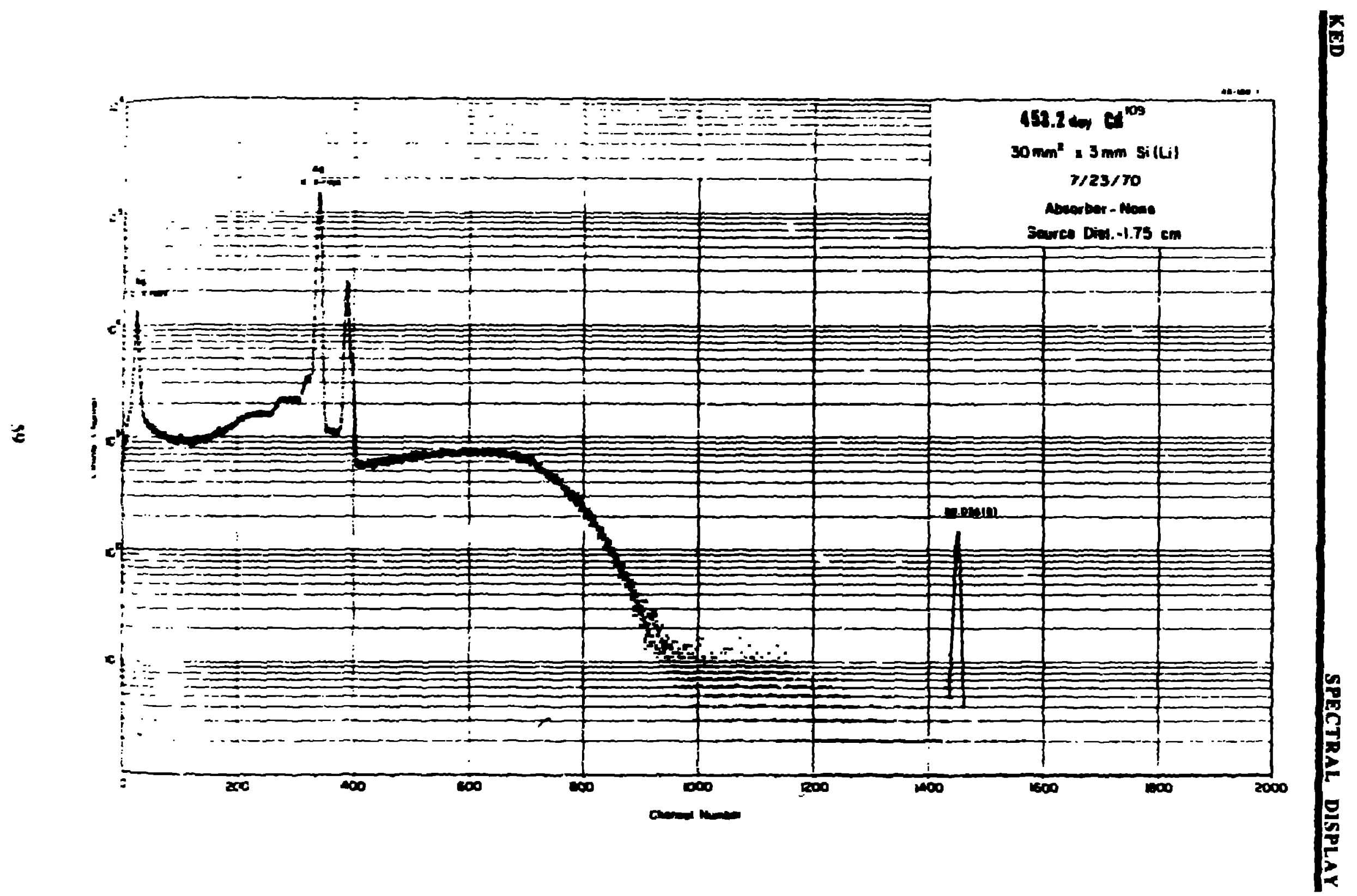




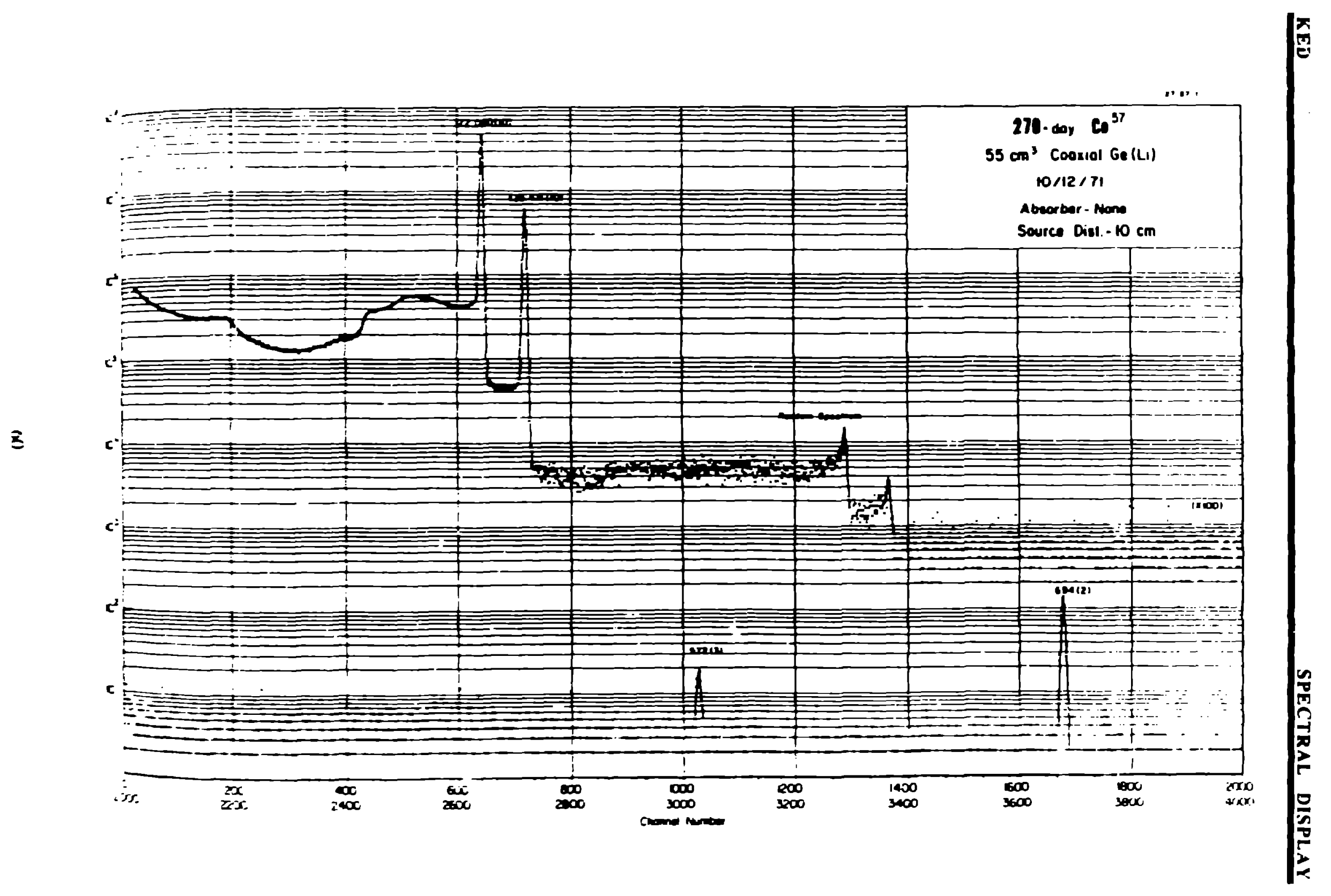




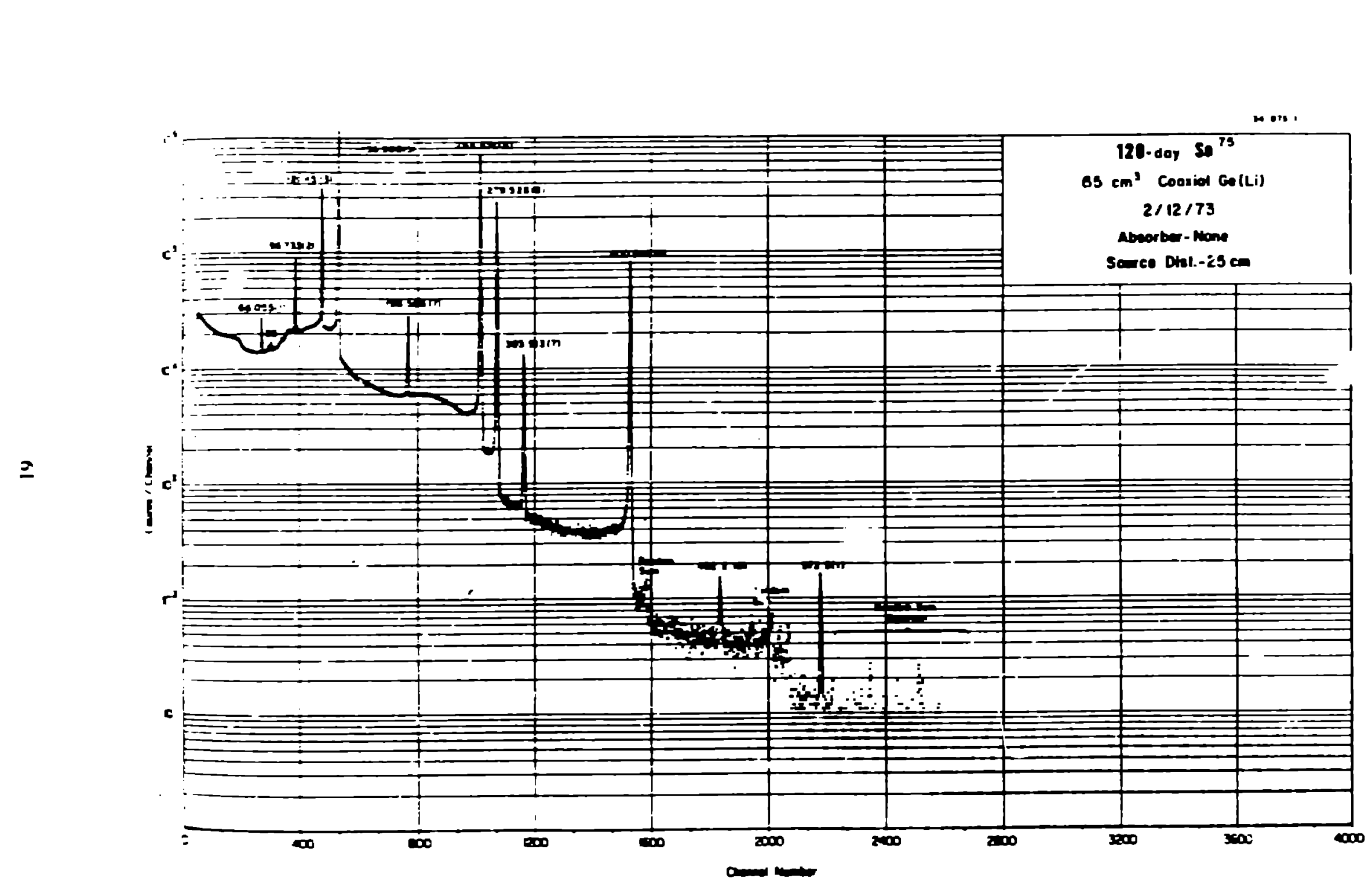


GENERAL

ANALYSIS ALGORITHMS OF THE KED SOFTWARE

Peak Region Summation

Background Determination
In the appendix, you will leam about

- Analysis physics of KED software,

- Amplifier gain and ADC zero adjustment,

- Calibration,

- FEIR determination, and

- Trouble shooting.

We recommend the use of the ROI summation method over peak fitting for applications that have gamma-ray peaks that are isolated by energy. The net peak area determination has a smaller uncertainty and it is simpler to implem:ent. The determination of the tail portion of the peak shape parameters is difficult to perform and quite se. ive to which peaks are selected.

The net peak area is determined by subtracting the background from the measured counts, channel-by-channel. The net counts are summed over the region of interest to obtain a result.

Four background regicus can be specified. Each region is the same width. Each region is soecified by the staning channel. If the user prefers to u two background regions, the first and second regions should be identical and the third and fourth regions should be identicial.

A choice between five functions to fit the background continuum is offered by the terms parameter: 
Background Determiantion (cont.)

Eneray Calibratton

rWHM Defermination

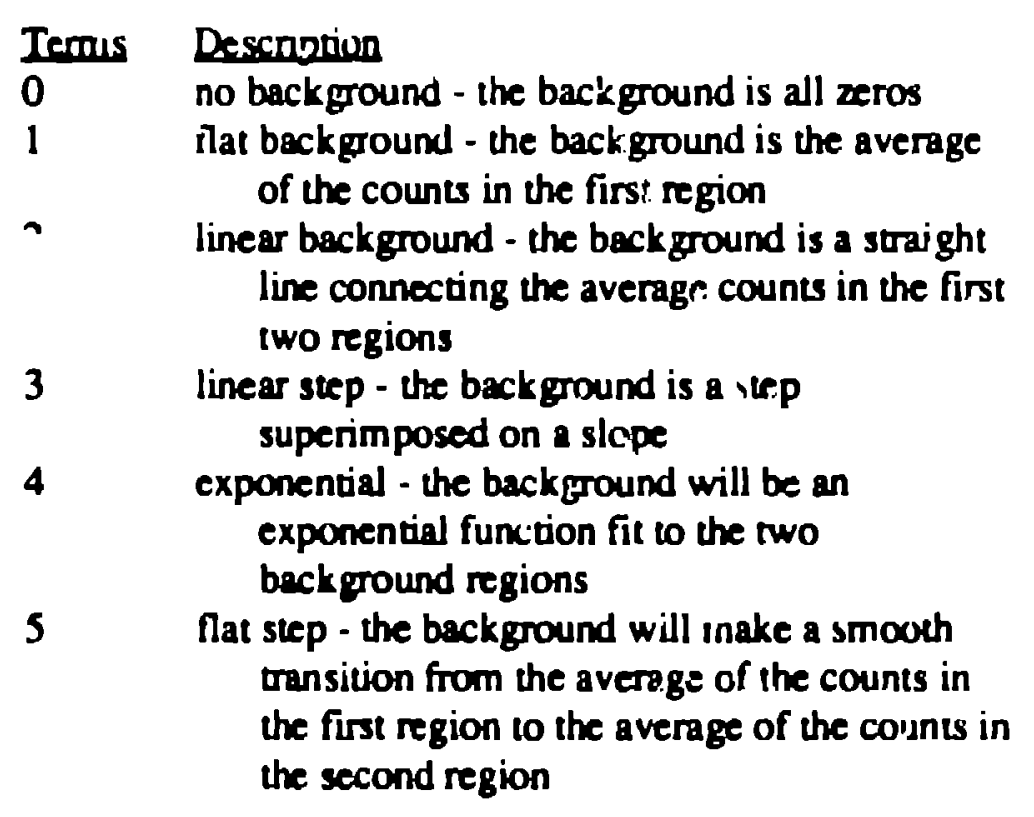

The choice of background region is more important for the fiting of multiple peaks that overlap. The KED was delivered with terms set to five.

Energy calibration is performed for every spectrım. Peuk centroids for all peaks in the energy cusibration list are needed to carry out the segment-by-segment linear energy calibration. In addition, the centroids of specified peaks are compared to dizgnostic limits for each spectoum type. The peak centrixds are found by fitting a quadratic in channel number (o) the net counts. The fitting range is five channels wide, centered on the channel where the default energy culibration predicts the peak will be. The encrgy calibration is then ussu:ared to be linear between each pair of energy calibration peaks in the list.

The PWHM's of specified peaks are comparod (1) diagnostic litnits for each spectoum type. The detennination of the I.WIIM is maxde by fitting a quidritic in channel number II) the logituthm of the net counts The fitting range is frum (1).75 - IIT on the lower energy side of me: centrovid io 
FWHM Deterwination (cont.)

\section{K-EDGE DENSITOMETRY}

0.25 - HT on the higher energy side of the centroid, where $\mathrm{HT}$ is the height of the peak shape.

The net peak areas, resolutions (FWHM), and centroids are calculated from the raw data in the same way for all gammaray instruments. The algorithms have been carefully checked and should nut be modified withcut careful consideration and rigorous testing to ensure no possibility of an error. The measured net peak areas from the five different data acquisitions follow some conventions. $B$ represents peak area results from the rackground measurement, $A_{0}$ represents results from a straight-through measurement with no sample present, and $A$ represents results from an assay, MC, auto cycle, or calibration measurement with a sample. The background measurement is one acquisition with $I_{i}$, transmission source (blank), all other measurements are based on two acquisitions with the selenium and cobalt sources. The value in parentheses is the gannma-ray energy associated with the peak area, and the letter indicates which source was in place.

The measured net peak areas from the five different data acquisitions are

from the hackground:

$B(88)$

$B(121)$

$B(122)$

$B(136)$

f::m the cobalt source, straight-through (no sample):

$$
A_{0}(88, C)
$$$$
A_{0}(122, \mathrm{C})
$$

from the selenium source, straight-Ihrough (no sample):

$$
\begin{aligned}
& A_{0}(88, S) \\
& A_{0}(121,5) \\
& A_{(0}(136,5)
\end{aligned}
$$

from the cobult source, sample measurement:

$$
\begin{aligned}
& A\left(8 K, C^{\prime}\right) \\
& A(122,()
\end{aligned}
$$

from the selenium source, sample measurement:

$$
\begin{aligned}
& A(88, S) \\
& A(121, S) \\
& A(1,3(1, S) .
\end{aligned}
$$




\section{K-EDGE DENSITOMETRY} (cont.)
Notes: a net peak area corresponding to the 88-keV gamma ray from the ${ }^{1109} \mathrm{Cd}$ rate-loss source is obtained in each acquisition and the five different values must not be mixed up. There is a $136-\mathrm{keV}$ gamma ray from both ${ }^{57} \mathrm{Co}$ and ${ }^{75} \mathrm{Se}$; we use the net peak area from the ${ }^{75} \mathrm{Se}$.

Two methods are used in this instrument to calculate the plutonium concentration from the measured net peak areas. The simple method was implemented in 1979 in Tokaj I. It works quite well, but has a small bias if there are large quantities of other SNM present. For example, $100 \mathrm{~g} / 1$ of uranium gives the same result as $-1.5 \mathrm{~g} /$ of plutonium. The extrapolation method avoids that bias for a small increase in the measurement uncertainty. However, the samples at the Tokai plant are believed to never have significant quantities of high-atomic-number impurities. In the Simple Method, each net peak area is nor inalized by the corresponding rateloss-source net peak area:

$$
\begin{aligned}
& \text { that is } B(122, n)=\frac{B(122)}{B(88)} \\
& \text { or } A_{1}(122, C, n)=\frac{A_{1}(122, C)}{A_{1}(88, C)} \\
& \text { or } A(121, S, n)=\frac{A(121, S)}{A(88, S)}
\end{aligned}
$$

No background subtraction is made for the densitometry measurement. Several reasons support this:

(1) The gammu rays used for assay do not come from the sumble.

(2) The detector in tightly collimated and well shickled. During an assay, mosi of the giumma-ray signal cone:. from the trunsmission soures through the sanple, not from the simmple.

(1) No sumple is present for the background measurement. Any significant comtamination of fire sample cell would be deiecied with die buck ground limil test. 


\section{K-EDGE DFNSITOMETRY} (cont.)
Three transmissions are computed, $T(121), T(122)$, and $T(136)$. Each transmission :s computed in the form given explicitly for $121 \mathrm{keV}$ :

$$
\begin{aligned}
& T(121)=\frac{A(121)}{A_{0}(121)} \\
& =\frac{A(121, S)}{\frac{A(88, S)}{A_{0}(121, S)}}
\end{aligned}
$$

The relative uncertainty in the transmission at $121 \mathrm{keV}$ is

$$
\begin{aligned}
\frac{\sigma^{2}[T(121)]}{T^{2}(121)} & =\frac{\sigma^{2}[A(121, S)]}{A^{2}(121, S)}+\frac{\sigma^{2}[A(88, S)]}{A^{2}(88, S)} \\
& +\frac{\sigma^{2}\left[A_{0}(121, S)\right]}{A_{0}^{2}(121, S)}+\frac{\sigma^{2}\left[A_{0}(88, S)\right]}{A_{4}^{2}(88, S)}
\end{aligned}
$$

where $\alpha(x)$ is the absolute uncertainty (I sigma) in $x$. This can also be written as

$$
\begin{aligned}
\sigma_{r}^{2}[I(121) \mid= & \sigma_{r}^{2}|A(121, S)|+\sigma_{r}^{2}|A(88, S)| \\
& +\sigma_{r}^{2}\left|A_{1}(121, S)\right|+\sigma_{r}^{2}\left|A_{1}(88, S)\right| .
\end{aligned}
$$

where $\sigma_{1}(1)=\frac{\sigma(x)}{1}$

lior the special case of un MC' Irecision mensurement, the sime stranght through doun is used for ench result. 'I7r straight through diten shoulel be treated as a comsiame in the crror estimite. Therefore the following expression is valiol. 


\section{K-EDGE DFNSITOMETRY}

(cont.)

$$
\sigma_{r}^{2}[T(121)]=\sigma_{r}^{2}[A(121, S)]+\sigma_{r}^{2}[A(88, S)] .
$$

A half-life correction is made to correct for the elapsed time between the straight-through measurement and the assay.

$C F($ half life $)=\exp (\lambda \cdot e t)$ where

$\lambda=$ the decay constant for the isotope involved

$$
\begin{aligned}
= & \frac{\ln (2)}{\text { half }-\operatorname{life}(\text { isotope), }} \\
t & =\text { elapsed time }
\end{aligned}
$$

The units in this application will be days for half-life and elapsed time. Three are half-lives invulved: one for ${ }^{109}$ ( $\mathrm{Cd}$, one for ${ }^{75} \mathrm{Se}$, and one for ${ }^{57} \mathrm{Co}$. The ${ }^{75} \mathrm{Se}$ transmission values will be cormcted by the ratio of the ${ }^{75} \mathrm{Se}$ to ${ }^{10 \%} \mathrm{Cd}$ corrections.

$$
\begin{aligned}
& \left(F(T 121)-\frac{\exp |\lambda(S e) \cdot e t|}{\exp \mid \lambda(C d) \cdot e t]}\right. \\
& =\exp \left\{\mid \lambda(\text { Se })-\lambda\left(C^{\circ} d\right) \mid \cdot \rho t\right\} \\
& \left(\%(T i, 36)=\frac{\exp [\lambda(\text { Se) } \cdot \operatorname{es}]}{\exp \mid \lambda((\mathrm{C}) \cdot \operatorname{er}]}\right.
\end{aligned}
$$

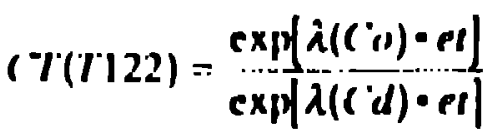

$$
\begin{aligned}
& \exp \left\{\mid \lambda\left(c^{\prime}(0)-\lambda\left(c^{\prime} d\right)\right] \cdot c t\right\}
\end{aligned}
$$

Therefore the half lite conrected values, $r$, are: 


\section{K-HDGE DENSITOMETRY}

(cont.)

$$
T^{\prime}(121)=T(121) \cdot C F(T 121)
$$

and similarly for $T(122)$ and $T(136)$. The relative uncertainty in the transmissions is unchanged by this correction. The absolute uncertainty is

$$
\left.\sigma\left[T^{\prime}(121)\right]=\sigma T(121)\right] \cdot C F(T 121)
$$

and similarly for $\sigma\left[T^{\prime}(122)\right]$ and $\sigma\left[T^{\prime}(136) \mid\right.$.

The simple result for the densitometry measureinent is calculuted from the two transmissions $T^{\prime \prime}(121)$ and $T^{\prime \prime}(122)$ :

$$
\begin{aligned}
& R=\frac{T^{\prime}(122)}{T^{\prime}} \frac{(121)}{k}, \\
& \text { concentrution }=\frac{-\ln (R)}{k},
\end{aligned}
$$

where $k$ is the culibration corstiunt. The relative uncertainty in the simple med/uxd result is calculated from the relutive uncertuinties in the two trunsmissions:

$$
\begin{aligned}
& \frac{\sigma^{2}(K)}{R^{2}}=\left\{\frac{\sigma^{2}\left[T^{\prime}(121)\right]}{T^{2}(121)}+\frac{\sigma^{2}\left[T^{\prime}(122)\right]}{T^{2}(122)}\right\} \\
& \frac{\sigma^{2}(\text { concentration) }}{\text { concentration }}=\frac{\sigma^{2}(k)}{|k \ln (k)|^{2}}+\frac{\sigma^{2}(k)}{k^{2}}
\end{aligned}
$$

In the culibration oppion, invert the equntion and use fie ckelandal centcrentration: 


\section{K-FDGF DENSITOMPTRY}

(cont.)

$$
\begin{aligned}
& k=\frac{\ln R}{\text { concentration }} \\
& \frac{\sigma^{2}(k)}{k^{2}}=\frac{\sigma^{2}(R)}{\{R[\ln (R)]\}^{2}}+\frac{\sigma^{2}(\text { concentration })}{\text { concentration }} .
\end{aligned}
$$

EXTRAPOLATION TO THE EDCE:

$\ln (-\ln (T))$ vs. $\ln (E)$

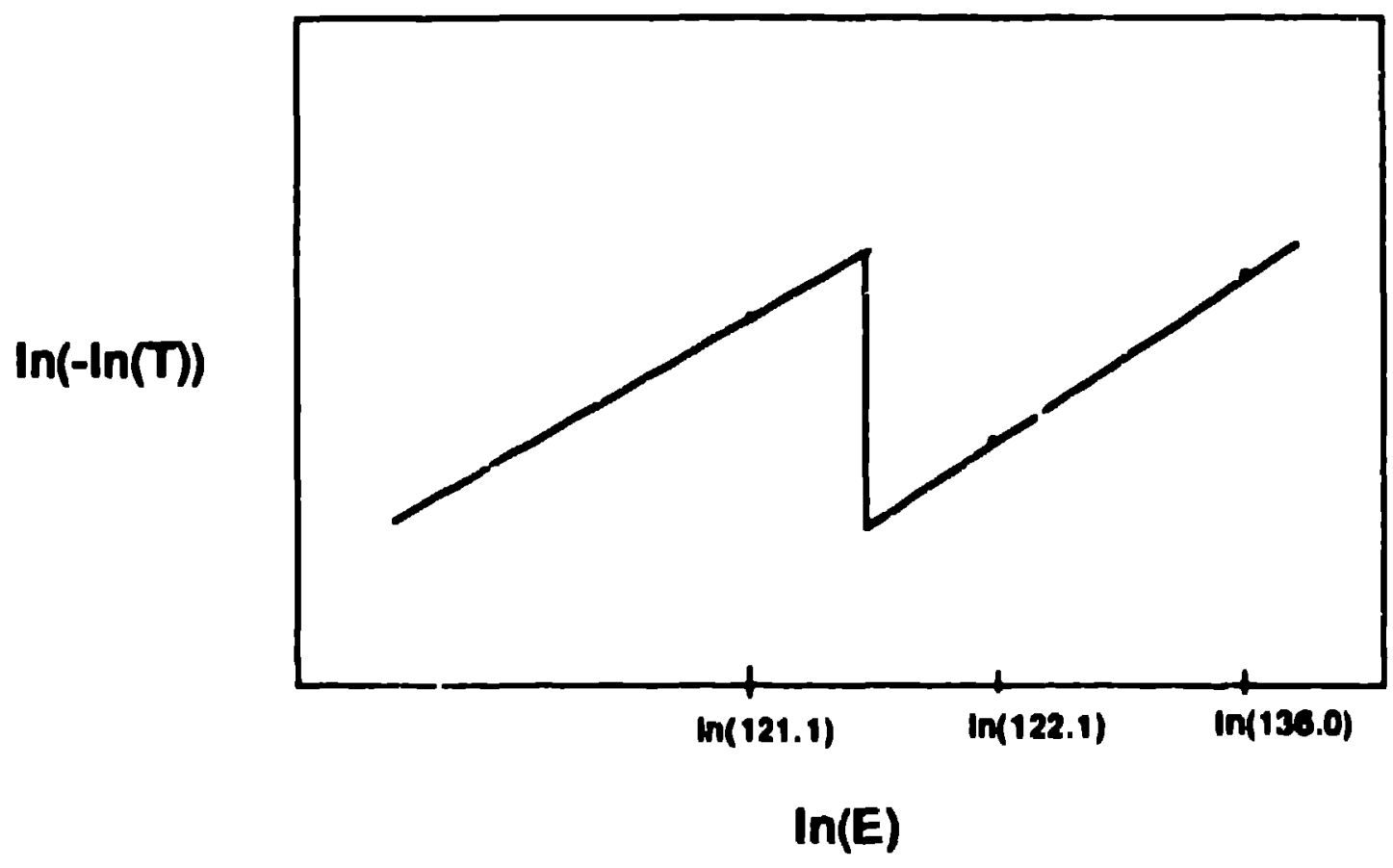

In this method, the transmissions abuve and below the $\mathrm{K}$ edge are extrapslated (t) the edge energy at $121.7 \mathrm{keV}$. The extri|x $)$ lation is very ne 'rrly linear in $\ln |-\ln (T)|$ v:s $\ln (t:)$ spuce. The (wo transmissions abuve the edge. $T^{\prime \prime}(122)$ and I'(1.36), are used (1) ex(rapollate (1) $T_{\text {a1 }}$ (21.7). where the a denotes the vilise athove the edge.

$\ln \left|\ln \left(I_{11}\right)\right| \because\left(\cdot \ln |\ln | I^{\prime}(\mid 22)||+||(1) \ln |\ln | I^{\prime}(\mid)(1) \mid\right)$ 
EXTRAPOLATION TO THE ED(iE (cont.)

$$
\begin{aligned}
& \text { where } C=\frac{\ln (121.795)-\ln (136.00)}{\ln (122.06)-\ln (136.00)} \\
& =1.0200978 \\
& \text { and } 1-C=-0.0200978
\end{aligned}
$$

The formula for the uncerainty in $T_{a}$ is

$$
\begin{aligned}
& \sigma_{r}^{2}\left(T_{a}\right)= \\
& \frac{\sigma^{2}\left(T_{a}\right)}{T_{a}^{2}}=\ln ^{2}\left(T_{a}\right)\left\{\frac{C^{2} \sigma_{r}^{2}\left[T^{\prime}(122)\right]}{\ln ^{2}\left[T^{\prime}(122)\right]}+\frac{(1-C)^{2} \sigma_{r}^{2}\left[T^{\prime}(136)\right]}{\ln ^{2}\left[T^{\prime}(136)\right]}\right\} \\
& \text { where } \sigma_{r}(x)=\frac{\sigma(x)}{x} .
\end{aligned}
$$

The slope determined above the edge is used below the edye with the transmission determined below the edge, $T^{\prime}(121)$, (1) determine $T_{b}(121.7)$. The slope is actually different, but the hias this assumption introduces is very small.

$$
\begin{aligned}
& \left.\ln \left|-\ln \left(T_{b}\right)\right|=I\right)\left(\ln \left\{-\ln \left[T^{\prime}(122)\right]\right\}-\ln \left\{-\ln \left[T^{\prime}(1.36) \mid\right\}\right)\right. \\
& +\ln \left\{-\ln \left\{T^{\prime}(121)\right]\right\} \\
& \text { where } U=\frac{\ln (121.79 .5)-\ln (121.11 .5)}{\ln (122 .(6)-\ln (1.36 .(10))} \\
& =-0.051772 .57
\end{aligned}
$$

The finmula for the uncerianty in $T_{h}$, is 
EXTRAPOLATION TO THF. E.DGE

(cont.)

$$
\begin{aligned}
\sigma_{r}^{2}\left(T_{b}\right)=\frac{\sigma^{2}\left(T_{b}\right)}{T_{b}^{2}}=\ln ^{2}\left(T_{b}\right)\{ & \left\{\frac{D^{2} \sigma_{r}^{2}\left[T^{\prime}(122)\right]}{\ln ^{2}\left[T^{\prime}(122)\right]}\right. \\
& \left.+\frac{D^{2} \sigma_{r}^{2}}{\ln ^{2}\left[T^{\prime}(136)\right]}+\frac{\sigma_{r}^{2}\left[T^{\prime}(121)\right]}{\ln ^{2}\left[T^{\prime}(121)\right]}\right\}
\end{aligned}
$$

The extrapolated result is

concentration $1=\frac{-\ln \left[\frac{T_{a}(121.7)}{T_{b}(121.7)}\right]}{k !}$

where $k l$ is the calibration constant. Note that the two calibration constants $k 1$ and $k$ are different. We will ignore the small correlation between $T_{a}$ and $T_{b}$ that is a consequence of using the sarne slope; therefore the uncertainty in concentrationl is

$$
\begin{aligned}
& R I=\frac{T_{a}(121.7)}{T_{b}(121.7)} \\
& \frac{\sigma^{2}(R 1)}{R l^{2}}=\frac{\sigma^{2}\left[T_{a}(121.7)\right]}{T_{a}^{2}(121.7)}+\frac{\sigma^{2}\left[T_{b}(121.7) \mid\right.}{T_{b}^{2}(121.7)} \\
& \frac{\sigma^{2} \text { (concentration) }}{\text { concentration }{ }^{2}}=\frac{\sigma^{2}(R 1)}{|R 1 \cdot \ln (R I)|^{2}}+\frac{\sigma^{2}(k 1)}{k !^{2}}
\end{aligned}
$$

In the calibraticm option use 
EXTRAPOLATION TO THE FDGE (cont.)

$$
\begin{aligned}
& k 1=\frac{-\ln \left[\frac{T_{a}(121.7)}{T_{b}(121.7)}\right]}{\text { concentration } 1} \\
& \frac{\sigma^{2}(k 1)}{(k 1)^{2}}=\frac{\sigma^{2}(R 1)}{[R 1 \cdot \ln (R l)]^{2}}+\frac{\sigma^{2} \text { (concentration) }}{\text { concentration }^{2}}
\end{aligned}
$$

For the special case with no sample, the transmission should be 1.00000 . The uncertainty in the counting statistics can cause the transmission to be slightly different from 1.00000 . If the transmission is greater than 1.0, then it is not possible to perform $\ln (-\ln (T))$, where $T=$ transmission. If any of the three transmission values $T 121, T 122$, or $T 136$ exceed 1.0 , then we extrapolate in $\ln (T)$ vs $\ln (E)$ space.

$$
-\ln \left(T_{a}\right)=C\left\{-\ln \left[T^{\prime}(122)\right]\right\}+(1-C)\left\{-\ln \left[T^{\prime}(136)\right]\right\}
$$

where $C$ is defined above. The formula for the uncertainty in $T_{a}$ is

$$
\begin{aligned}
& \sigma_{r}^{2}\left(T_{u}\right)=C^{2} \sigma_{r}^{2}\left[T^{\prime}(122)\right]+\left(1-C^{\prime}\right)^{2} \sigma_{r}^{2}\left[T^{\prime}(136) \mid\right. \\
& \left.-\ln \left(T_{h}\right)=D\left\{-\operatorname{Ir}:\left|T^{\prime}(122)\right|+\ln \mid T^{\prime}(1.36)\right]\right\}-\ln \left[T^{\prime}(121)\right]
\end{aligned}
$$

where $D$ is defined above. The formula for the uncenainty in $T_{b}$ is

$$
\begin{gathered}
\sigma_{r}^{2}\left(I_{b}\right)=D^{2} \sigma_{r}^{2}\left|I^{\prime}(122)\right|+I^{2} \sigma_{r}^{2}\left[T^{\prime}(1.36) \mid\right. \\
+\sigma_{r}^{2}\left|T^{\prime}(121)\right|
\end{gathered}
$$


Tantalua Foll

Rate-lous Source Cusiderations
The use of a tantalum foil in both transmission measurements (121.1 and $122.1 \mathrm{keV}$ ) will result in an answer very close to zero. However, placing a tantalum foil into one of the transmission measurements or two foils of different thicknesses into the two transmission measurements will give a nonzero result. This allows a verification of the KED instrument without using plutonium. In fact, if the foil is stable and it is measured precisely, this test of the KED is quite rigorous.

The 88 -keV gamma ray from the ${ }^{109} \mathrm{Cd}$ rate-loss source is analyzed in each spectrum. The 88-keV net peak area is used to normalize all other net peak areas obtained from that spectrum. Consequently, the uncertainty in the 88-keV net peak area affects the uncertainty of every normalized net peak area and subsequently all calculations using the net peak areas. The 88-keV count rate should be greater than 5r.O counts/s to allow reasonable measurement precision in the K-edge densitometer.

The rate-loss source should be filtered to reduce the lowenergy $x$-rays. Without filtering, these $x$-rayis can contribute to pileup peak $\mathrm{a}$ and bias the net peak area determination of the peaks used for the assay. Filters can be chosen so that the count rate in the 88-keV net pesk area will be approximately 1000 counts/s and the total count rate will be less than twice the $88-\mathrm{kcV}$ count rate. By selecting between copper. brass, tin, and cadmium as a filter material and changing the thickness between 0.15 and $2.0 \mathrm{~mm}$, the user can optimize the 88-keV net peak arest and almost eliminate the low energy $x$ ray peaks.

The ${ }^{10 \%} \mathrm{Cd}$ source and tie filters will have (o) be adjusteal annually to preserve adec iate meisurement precision. A new ${ }^{1(19} \mathrm{Cd}$ rate-loss source will be required every 4-5 years as the source has a 453-day half-life. To achieve adexpuate: measurement precision, we silggest that a new ${ }^{l(1)} \mathrm{Co}$ rate loss source be specified to have $1(x)-2(X) \mu C \mathrm{C}$ of activity. 
AARON'S BUBBLE TEST FOR A SSA YS
There has been some experience with bubbles in the densitometer samples. Therefore two measurements of each sample are compared. If they agree, the a verage is accepted. If they do not agree, the sample is mixed and measured a third time. We will assume the measurement uncertainty is the same for all measurements in this comparison. This test was developed by Aaron Goldman and Erwin Kuhn.

first result is $\mathrm{X} 1 \pm \mathrm{Sl}$ (from simple method)

second result is $X 2 \pm S 2$ (from simple method)

average of results is $\mathrm{x}=(X 1+X 2) / 2$

test parameter is $\mathrm{Zl}=(|\mathrm{X} 1-\mathrm{X} 2|) / \mathrm{S} 1$

if $\mathrm{Zl}<3.18$, then average result is accepted answer $=\mathrm{x} \pm(\mathrm{S} 1 / 1.414)$ end of assay!

The final output will contain the following information: each measurement result the test result whether the test passec the average result

if $\mathrm{ZI} \geq 3.18$, then prompt operator to:

please remove sample. check sample for bubbles, place sample into assay position perform third measurement third result is $X 3 \pm S 3$ (from simple method) average of results is now $x=(X 1+X 2+X 3) / 3$

the value farthest from $\triangle$ is $x$ * test parameter is:

$Z 2=(\mid x-x+1) / S I$

if $Z 2<1.95$ then accept all three answers (note $Z 1.1>3.18$ ) answer $=\mathrm{x} \pm(\mathrm{S} 1 / 1.732)$ cnd of assay!

The final output will contain the following infonmation: ciach measurerient result the test result whether the tesi passed the averige result

if $1.95<7.2<3.18$, then reject $x^{*}$ answer $=\left(X_{1}+X_{i+1}\right) / 2 \pm(S / / 1.414)$ end of assaly

The final sutput will contain the folkowing isformation: eikch mealsurement result the lest result 
AARON'S BUBBLE TEST FOR ASSAYS

(cont.) whietier the test passed

the average result

if $\mathbf{Z 2}>3.18$, sample is out of control must perform DA on this sample

The final output will contain the following information: each measurement result the test result whether the test passed the average result

Please make the two test values, 3.18 and 1.95, parameters the operator can change in the long paraneter change.

The MC-Precision test requires the acquisition of multiple measurement results. The average and standard deviation of the sample are then computed. The chi-square/degree of freedom, or the reduced chi-square is

$$
\chi^{2}=\frac{(\text { std dev of sample })^{2}}{(\text { Est. std dev })^{2}}
$$

The value of the chi-square/degree of freedom is tested against waming limits at $95 \%$ confidence and action limits at $99 \%$ confidence. These limits are fixed in the software. 
Chi-Square Test

(cont.)
Number of degrees of measurements freedom
95\% confidence

$$
\chi^{2} 0.025 \quad \chi^{2} 0.975
$$

0.12

0.17

0.21

0.24

0.27

0.30

0.40

0.48

0.52

0.56

0.61

0.67

0.76
2.79

2.57

2.41

2.29

2.19

2.11

1.87

1.71

1.64

1.57

1.48

1.39

1.27
99\% confidence

\begin{tabular}{cc}
$\chi^{2} 0.005$ & $\chi^{2} 0.595$ \\
\hline 0.05 & 3.72 \\
0.08 & 3.35 \\
0.11 & 3.09 \\
0.14 & 2.90 \\
0.17 & 2.75 \\
0.19 & 2.62 \\
0.29 & 2.24 \\
0.37 & 2.00 \\
0.41 & 1.90 \\
0.46 & 1.79 \\
0.52 & 1.67 \\
0.59 & 1.53 \\
0.70 & 1.36
\end{tabular}

Failure of the waming limit will cause a waming to be printed for every succeoding measurement type, until the MC-Precision Option is successfully passed. Failure of the action limit will cause the system to not allow assays until the MC-Precision Option is successfully passed or a warming limit level is achieved. This test may be avoided by selecting a nonpositive time for the repetition rate. 


\section{INTRODUCTION}

DATA ACQUISITICON

P.(IT DATA
It might seem desirable to have calibration solutions spanning the measurement range of the instrument $(5-500 \mathrm{~g} /$ ). However, it is generally impractical to do so. Below abou! $100 \mathrm{~g} / \mathrm{h}$ the statistical precision becomes poor enough to require excessively lonc running times to obtain a meaningful calibration precision ( $0.1 \%$ RSD). A bove $400 \mathrm{~g} /$ there can be problems with keeping the plutonium in solution. The user should also note that extensive evaluations exist in the literature; not every facet of the instrument's performance requires frequent repetition.

The physics of the measurement does not require the calibration materials to span the range of the instrument for every calibration attempt. Indeed, a single point does provide a good calibration if the concentration of the standard is known accurately. It is recommended that a minimum of two solutions of diffierent concentration be used to calibrate. This can provide a quality check on the accuracy of the concentration claimed for the standar. :.

The user should be aware of the potential for correlations if a straight-through or background measurement is used for more than one calibration measurement of one or more standardy. A better calibration can often be ubtained with niore measurements and more standurds.

Make a new background measurement.

Before meusuring the standards, make a straighr-through measurement. Count for at least $2(\mathrm{XX})$ is for ench transmission source. We suggest that the user attuin measurement uncertainties of approximately (0.1\% for each of the nonnulizod net peak aneas af 122.1 and $121.1 \mathrm{keV}$. The fixed times in the purameter file may have (o) le changeal (o) nllow this.

Acyuire data from each culibration molution stumblard. Use the Culibration (p)tion unxer the long menu. 'The Calibrition) ( ppoi mo will regurst inpur of the plutonium conkentration.

Plolling lle dutu coun illusirate if there are correlations or

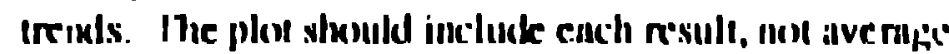
results. 
PLOT DATA

(cont.)
The autocycle runs under the Calibration option produce an average value for the calit ration constant. This result should be independent of sampie, soncentration, or operator.

Outliers $\mathbf{n}+\mathbf{y}$ indicate an incorrest standard value for the claimed concentration, a t-anscription error, or variability in sumple-vial dimensions. 


\section{CALIBRATION HISTORY}

Date:

Operator:

Comment:

\begin{tabular}{|l|l|l|l|}
\hline Concentraion & \pm & $\begin{array}{l}\text { Number of } \\
\text { measurements }\end{array}$ & $\begin{array}{l}\text { Calibraion } \\
\text { Consuant }\end{array}$ \\
\hline & & & \\
\hline & & & \\
\hline & & & \\
\hline & & & \\
\hline & & & \\
\hline & & & \\
\hline & & & \\
\hline & & & \\
\hline
\end{tabular}




\section{Calibration history}

(cont.)

Date:

Operator:

Comment:

\begin{tabular}{|l|l|l|l|}
\hline Concentration & \pm & $\begin{array}{l}\text { Number of } \\
\text { measurements }\end{array}$ & $\begin{array}{l}\text { Calibration } \\
\text { Constant }\end{array}$ \\
\hline & & & \\
\hline & & & \\
\hline & & & \\
\hline & & & \\
\hline & & & \\
\hline & & & \\
\hline & & & \\
\hline & & & \\
\hline
\end{tabular}




\section{CALIBRATION HISTORY}

(cont.)

Da!e:

Operator:

Comment:

\begin{tabular}{|l|l|l|l|}
\hline Concentraion & \pm & $\begin{array}{l}\text { Number of } \\
\text { measurements }\end{array}$ & $\begin{array}{l}\text { Calibracion } \\
\text { Constint }\end{array}$ \\
\hline & & & \\
\hline & & & \\
\hline & & & \\
\hline & & & \\
\hline & & & \\
\hline & & & \\
\hline & & & \\
\hline & & & \\
\hline
\end{tabular}


INTRODUCTION

MULTICHANNEL ANALYZER

\section{COMPUTHR}

DIIITAL. STABILIZKKR
In this appendix, we list additional information about error messuges, problems solved during development, and (maybe) other useful hints.

The MCA can be set with intemal jumpers to multiple addresses. This system assumes the factory default. If the computer has problems finding the MCA, the software will offer the choice to switch to the second address. This is not used in the K-edge software.

If the communications between the MCA and computer have a problem, reset both by turning off the power. If the communications problem occurs twice, a hardware failure is indicated

The computer sometimes locks up; the symptom is that the keyboard will not respond to any command (such as NUM LOCK).

The computer can be sometime: be unlocked bv pushing the CIRL, ALT, and DEL keys simultancously. If this does nol unlock the computer, then push the computer front punel switch io turn the power off. Wait 10 s after turning the power off to allow the disk drive to stop. 'Then tum the power (ON and wait for the operuting system to get sturted.

If a problen is suspectued witl, the stabilizer, check the swilch sellings and coniputer iriterfice cable. Be sure the musumai/remuste switch is ses 10 remote.

'The ('anberru 82.32 stubilizer can lock up. In this condition, it does nol ialjust the gain antl /ero. It s'(xes not respond (1) uny tront panel bumons. 'luning its power off and then :n will reset it. Inis can be done by pulling it $5 \mathrm{~cm}$ oul of the NIM bin and then pushing it back in, without turneng the NIM hin off.

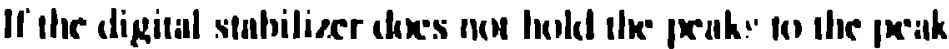
chumels, the stabiliser may mon le working. This is usually

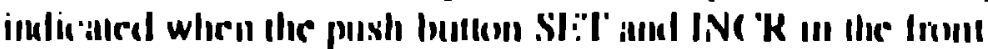

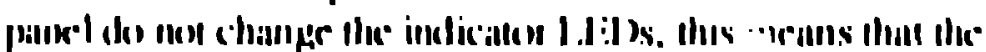


digital stabilizer

(cont.)

GHNEVA MRC'HANISM

MF:ASIIRE:D STANIIARI

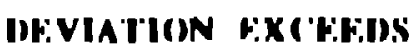

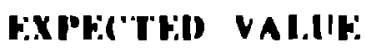

stabilizer is locked up. To unlock it, remove the unit from the NIM bin momentarily. This should unlock the unit.

The initial adjustment of the system gain and zero to place the gamma-ruy peaks into the desired channcls is difficult. After the initial adjusment, the system should not require a change unless the detector, ADC, or amplifier is changed. In that case, we suggest that the operator manually set the ${ }^{75}$ Se source into position using the source control interface chassis. Then turn the stabilizer switch on the front panel to manual mode and tum the zero and gain switches to off. Acquire a spectrum using the Canberra MCA program. Adjust the amplifier gain to fix the 279.528-keV peak in channel 3893. Adjust the ADC zero to fix the 88.036-keV peak in channel 1157. Repeat the gain and zero adjustment until the two peaks are within two channels of the correct channels. Tum the stabilizer switch from manual to remote (this will override the gain and zero switches). Check the first KED measurement to verify that the centroids pass the diagnostic test3. If they do not, repeat this procedure.

The KFD program can be used with no communication to the Geneva mechanism interface. Start the program with the additionul command, $-\mathbf{C}$, in the subdirectory Vok ai.

\section{c:YsokaisKKD) -(ifreturn)}

The (ienevu mechanism interface can be used in a stand. alone mode. See the Diagnostic Soft ware se:tuon in the Troubleshuxuting appendix for a ckescription of the test pro). primm liT.

Ihis prohlem call have several caluses.

(1) During the initial testing in 1979, the system showed an umblerlying instillilaty of (0.2\%.

(2) If a Iransmussiom source is lexuse in its hoblder, the

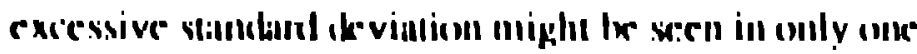
(If the mallsmission values. 
MEASURED STANDARJ

DEVIATION EXCEEDS

EXPECTED VALUE

(cont.)

CORRFLATEd RESUlts

THMPERATURE FFHFCTS ON DFNSITY

DIACENOSTIC SORTWARF
(3) The uncertainty in the actual standard deviation of $n$ results depends on $n$. If $n<25$, perhaps try again with a larger value.

$$
\sigma(\sigma) \frac{1}{\operatorname{sqt}[2(n-1)]}
$$

(4) Perhaps the sarnple : 3 changing. Bubbles or precipitation in the liquid can cause results to vary.

The use of a sir :le straight-through measurement for several sample assays is :ommon practice. Note that this results in correlated values for those results that share the same straight-through measurement. If the uncertainty in the straight-through measurement contributes half of the uncertainty in the assay, a plot of the resuits shows interesting bias trends. This "problem" seems to be rediscovered by each new user. We recommend the use of very long straight-through measurements.

The K-edge densitometer does not measure the sample temperuture. 'Therefore a correction fir the effects of temperature is not performed. A measurement of a sample with a temperature much greater than roxun temperature might uppear on be bissed if the result is uppiied to tanks at rxm temperature. If this situation is encountered, the operator must correct for the censity variation because of temperature differences.

Some specialized test progriuns have heen huilt lin testing specilic features used in the large Kl:D) program.

(1) (il' is a program to) test the parallel intertiuce on lise Transmission Source (ieneva Mechanism. 'I'o use it. first exit the main program Klil). Then swikh (1) the subline'tory voknivest and type $\boldsymbol{R t}$. 
Synopsis. gt $[-123|[-\mathrm{m}]|-\mathrm{a}][-1[$ position $]] \mid-\mathrm{p}[$ position $] \mid$

Description. Gt provides the user with a way to control the Geneva Mechanism. The Computer/Manual toggle on the Geneva Mechanism must be in the Computer position to enable computer control.

A FC may have up to three parallel ports installed. Generally, one of these is connected to a printer. The Geneva Mechanism cont ects to the PC through one of the available parallel ports (LPT1, LPT2, or LFT3). The user tells gt which port to use by selecting one of the port options: -1 for LPT 1, -2 for LPT2, or -3 for LPT3. If none of the ports are specified, LPTI is used by default.

The Geneva Mechanism motor can be controlled directly by the - $m$ option. Whell selected, this option will tum on the motor immediately. The motor will continue running until the user hits any key. The position lights can be activated to track the motor while it is ruıning by using the -a option together with the -m option.

The Geneva Mechanism position lights may be controlled directly by the -l option. An explicit position (1, 3, or 5) may be selected using position. If no position is specified. position 1 is used by defuult. When selected, this option will tum on the light immediately. The light will remain on until the user kits any key.

The Geneva Mechanism motor may be sent to a particular pesition using the poption. An explicil position (1, 3, or .5) may be selected using positi, n. If no position is specilied, position 1 is used by defiault. When selected, this option moves the motor to the selected position; the position lights track the motor as it moves. 
Examples.

gt - ?

gt

gt -2 -p3

gt -2 -m

gt -2 -m -a

st $-3-11$
Displays a usage message.

Using LPT: Geneva Mechanism moves to position 3 ( ${ }^{57}$ Co source).

Using LPT2 Geneva Mechanism moves to position 5 (blank source).

Using LPT2 turns on motor (until user hits a key, stopping inotor).

Same as previous example but also turning on position lights as motor moves.

Using LPT 3 tum on light for position 1 ( 75 Se source) (until user hits a key turning the light off).

(2) PIO is a program to test the parallel VO ports. To use it, first exit the main program KED. Then .....

(3) DST is a program to iest the digital stabilizer communications. To use it, first exit the main progran KED. Then switch to the vokaivest subdirectory and type dist.

Synopsis. dst [-p[port]] [-b|baud]] [-eloln] [-g|z] [k|peak|| |-w|window|| |-r|range || |-s|state|| |-v].

Description. Dst provides the user with a way to control the Canberra 8232 Digital Stabilizer. The Remote/Manual toggle on the Digital Stabilizer must be in the Remote position to enable computer control.

The Digital Stabilizer connects to the PC through one of the available serial porns (COM1 or (COM2). Please note that this requires a custom cable between the Digital Subilizer and the PC. The user tells dist which port to use by selecting the $-p$ option. An explicit port ( 1 or 2 for COM 1 or COM2, respectively) may be selected using port. If no port is specitied. COMI is used by default. The baud rate is selected using the $\cdot b$ option. Baud rates of $3(x), 12(x), 24(x)$, and $(S(X)$ are supported. If no batud is specified $3(X)$ is used by defuult. The purity is selected using either the - - , o, or -n (options (o) choosese even, (xld, or ino parity, respectuvely. If no parity is selecencil, even is used hy deciualt. 
Description (cont.)

The user chooses to communicate with either the Gain or Zero controls of the Digital Stabilizer by selecting either the $-g$ or $-z$ option, respectively. If neither is spec:Iied, Gain is used by default.

Dst always gives the current settings of either the selected Gain or Zero. If the user chuoses to set one uf the sertings, dst will also read back the re::ised settings. The peak may be set using the $-k$ option. Possible peak values are 0 to 19999 . The window may be set using the $-w$ option. The range nuay be set using the $-r$ option. Possible range values are 0 (for Full), 1 (for Half), 2 (for Quarter), or 3 (for Eighth). The state may be set using the -s option. Possible stare values are 0 (for Off), 1 (for Hold), or 2 (for On).

Verbose detail of the serial communications between the Digital Stabilizer and the PC may be enabled using the $-v$ option. The option is primarily tor debugging purposes.

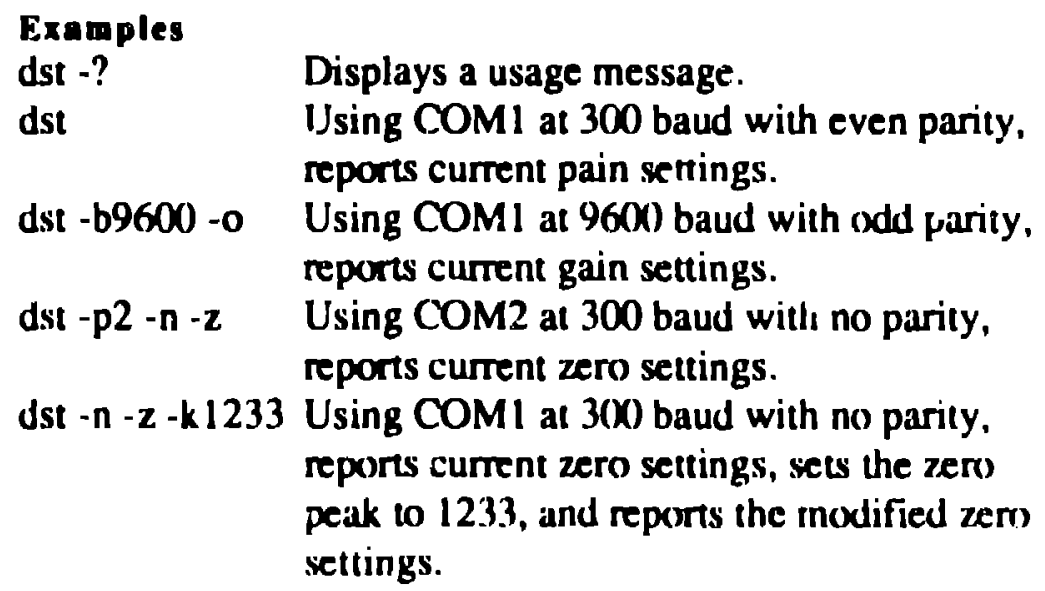

(4) T10)S - is a program to To use it, first exit the muin program KED. Then .....

(5) DB DUMP is a program to read and print the KI:I) database, KF: DB.DAT, which contains the back ground and suraight- through results. To use it, fir it 
Examples (cont.)

exit the main program . .ED. To send output to the printer use

c:ltokai>DB_DUMP KED_DB.DAT >PRN

The KED program can be started with some features disabled. If you do not want to use the interface to the Geneva mechanism, add the option $-G$ to the command line that starts the progran.

\section{c: tokai>KED -(G}

To override the diagnostic tests, which block certain actions after a test failure, add the option - $O$ to the command line that sturts the program:

(. Vokai>k' $7 \cdot 0$

We have attempted to make the error messages complete and self-explanatory. Please contact the safeguards assay group at Los Alamos if you need relp: Jim Sprinkle (50)5)-667-418I or Walt Hansen (505) 667-8818.

Two levels of erroriwaming messages are used in the KI:I) program. Blue messages are not us serious ay red messages. Some blue messages infonn the user that the program is busy, while some appear as warnings. A warning limit is chosen such that cxcusional false alams ixicur. A false alanm rate of 2-5\% is considered acceptable. Red messages indicate a more serious problem. Red messiges usually reçuire the user (o) perfionn a repair or adjustment. The limits for red messages are chosen wo that filse allann rates are kess (hanl 1 ). $5 \%$. 

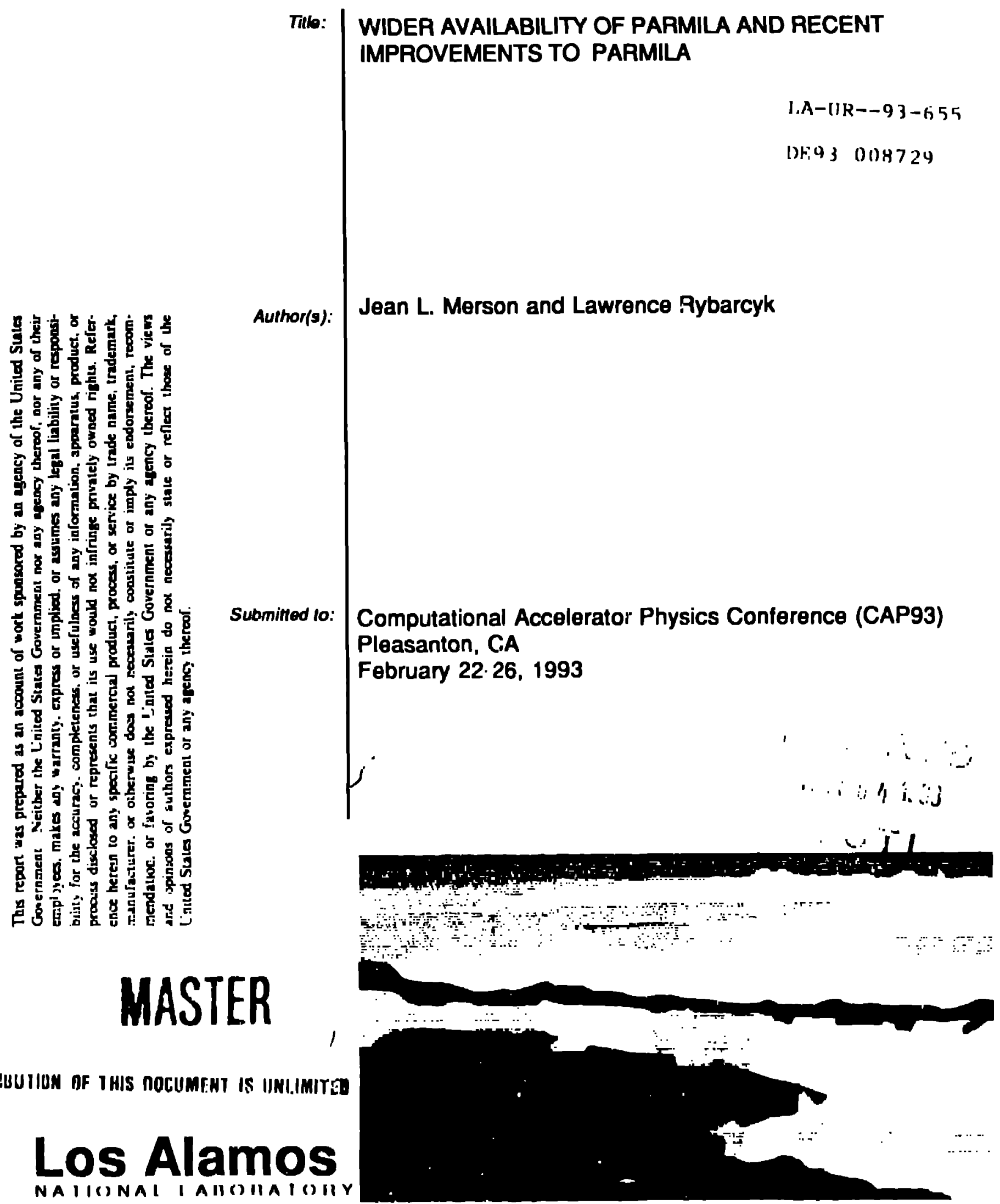

H!UUIION DF I HIS nOCUMF:HT IS INNI.IMITE.

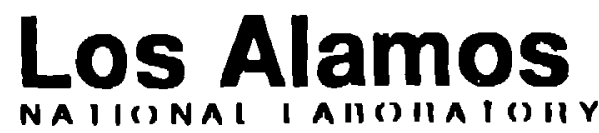

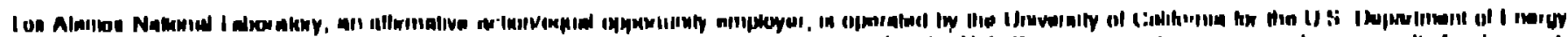

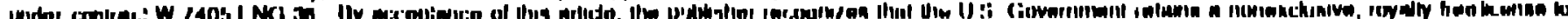

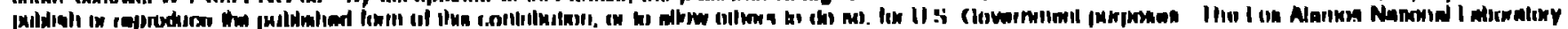

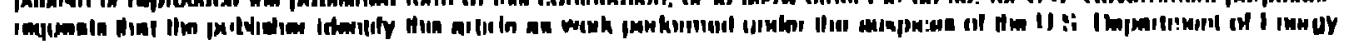




\title{
WIDER AVAILABILITY OF PARMILA AND RECENT IMPROVEMENTS TO PARMILA ${ }^{a}$
}

\author{
Jean L. Merson, AT-7 and Lawrence J. Rybarcyk, MP-6 \\ Los Alamos National Laboratory \\ P.O. Box 1663 \\ Los Alamos, NM 87545
}

\begin{abstract}
PARMIIA (Phase And Radial Motion in Ion Lincenr Accelerators) is a drifttube linac (I)'Tl,) ion-bean dynamics code. Over its long life, many versions linve developoed. 'I'lie Los Alamos Acceleralor Codo (iroup distributes a versıon, for which a manual' is isvailable. Inless otherwise spoceilied, all mentions

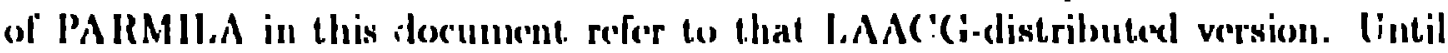
recently, this documented and distributed version functionerl only under ("ISSS. I!sers who wished to run onl a different operating system meded ho convert the

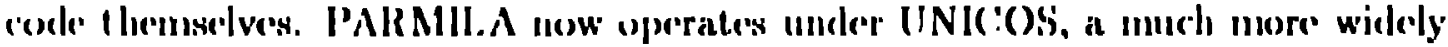
availablo ('RAY operating system, and under VAX/V'MSS. 'I'his paper describess

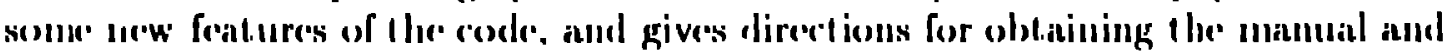
Hoe IINIC'(OS and V'MS' versions of the rode.

\section{IN"TR()I)I!("TI()N}

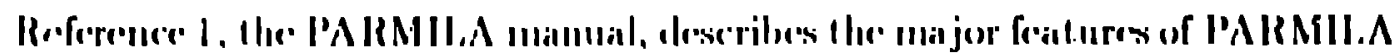

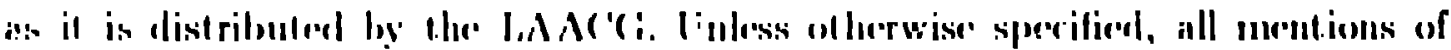

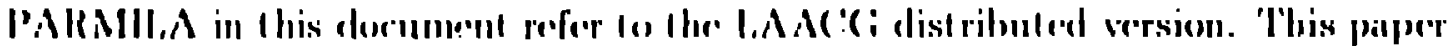

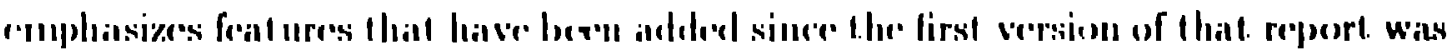

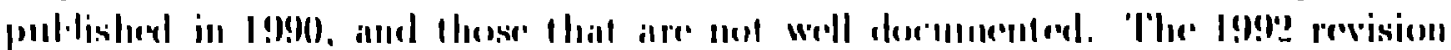

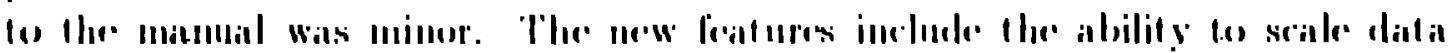

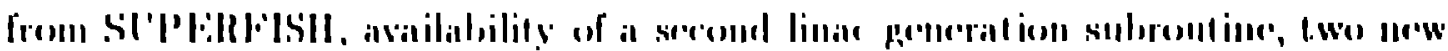

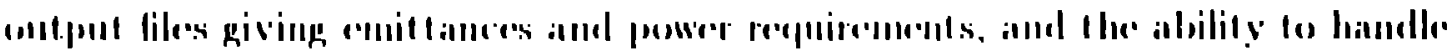
commine

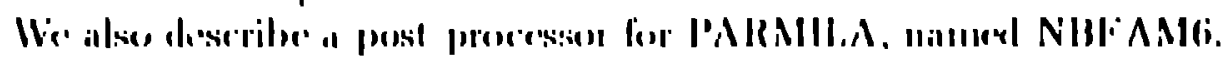

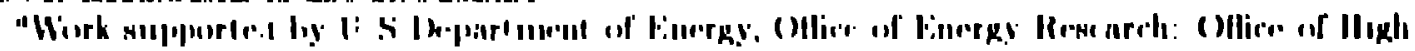

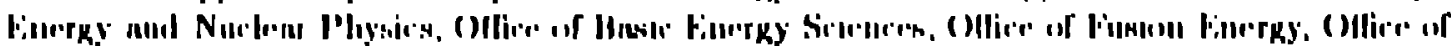

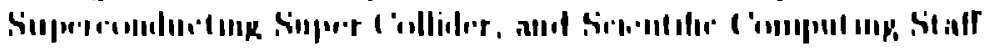




\section{SCALED SFDATA INFORMATION}

A table of information generated by running the cavity code SIIPFRFISII ${ }^{2.3}$ provides the basis for generating a linac. PARMIlLA now has the ability to scale information in an SFIJA'A table based on SL:PEIRFISII analysis of colls having one resonate frequency to a different design frecpuency. In order to utilize this feature, the user must specify the reference frepuency for which the SI!PliR lish runs we:e done, F!Rl:QREF. 'The fifth data element after the LINAC label is set equal to the value of l.RFQREF, in megahertz. 'The'n PARMIl],A multiplie.s each shunt impedance, $Z$, in the Sl'DSTA table by the square root of the ratio of the design frequency to the reference frequency. ('The design frecpuency is the' third data element following the LINA(: label, as describer in the manual.) If no value for FRLQRLE is given, PARMILA assumes it to be egual to the design frepuency. 'This scaling is done in the main program. and is independent of the linac generation routine selected for use (sere next section).

\section{CHOICE ()F ROUTINE TO GENERATE LINAC:}

PARMII.A now comlains two rontines that the user can select to generate the linac. 'The lwo routines have sosurwhal different capabilities, and even for the same input data, they generate slightly different linacs. 'The new routione, which

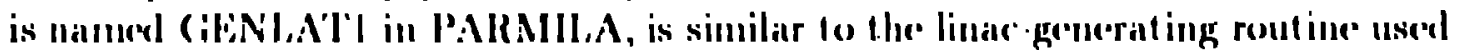
in the A'l'- I P' version of PARMIll. A. It is the routine that is called by default when all the cells for which S'Pl) $\mathrm{Al}^{\prime} \mathrm{A}$ information is provided are symmetrie.

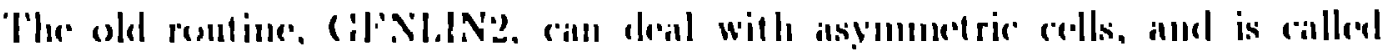

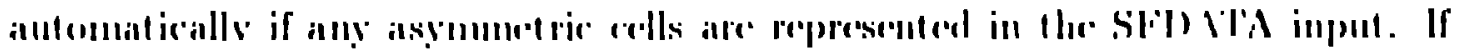

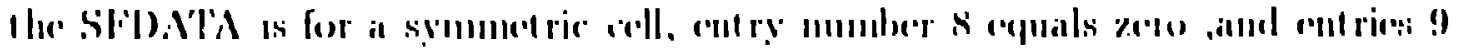

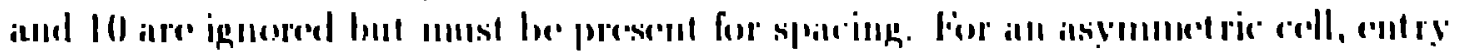

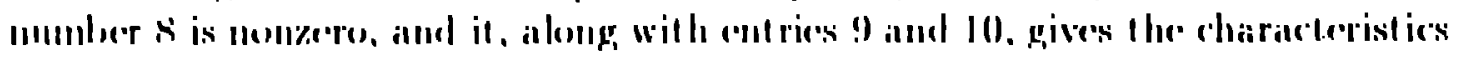

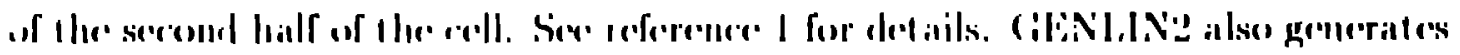

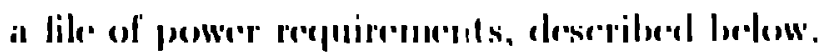

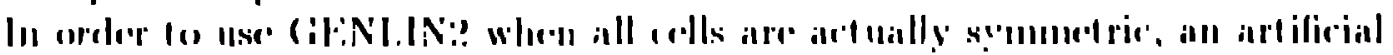

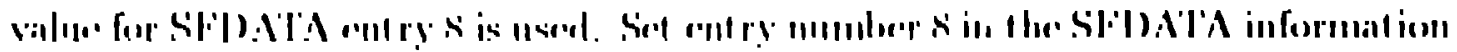

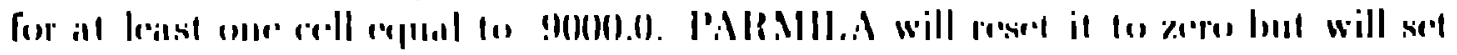

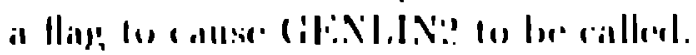

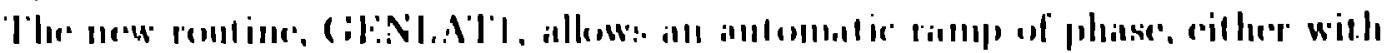

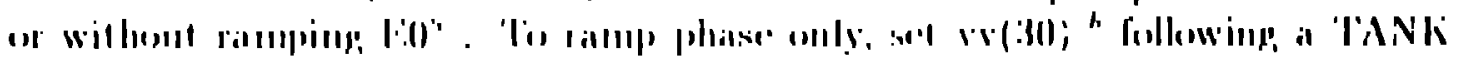

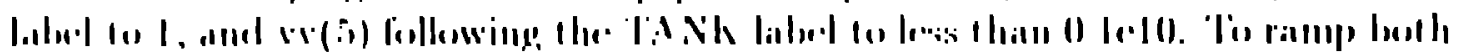
,

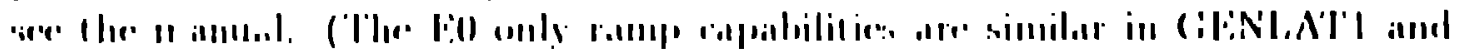

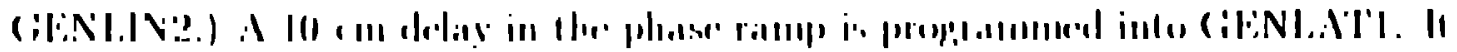

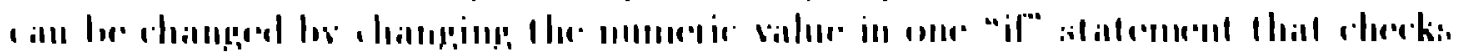

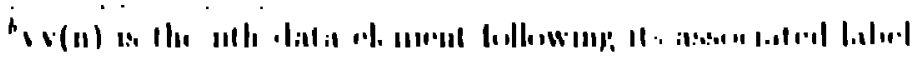


"(gnlen .le. 10.00)" and recompiling. Similarly, the phase linit can be changerl by changing the value assigned to SPMINV in the routine and recompiling. 'This assignment occurs immediately after the comment "generate linac".

\section{NEW OUTPUT FILES}

'Two additional output files not documented in the mamual are now available. The lile EMIITT contains 100\%, 90\%, and 1 ms emittances, as well as $a$ and 19 in the x-xprime, y-yprime and phase-energy phasse space planes at each cell, and the number of particles that have not been lost to that point. The file is written by subroutine EMI'l'.

POW:ILE contains the power reguirement in megawatts for each ceit and the cumulative power reguirement to that cell in the tank. It is written by sulbroutine (iENIIN2.

\section{C.OMMENTS}

Data on a line that starts with a ('OM:MEN'T label will now be ignored. 'This permits comments to be included in input filess.

\section{P'()S'T-PIR()('ESS()R}

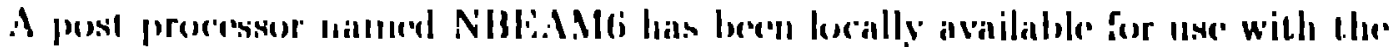

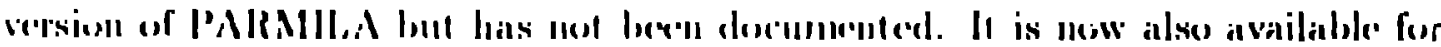

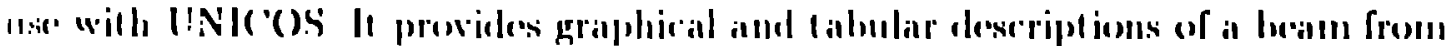

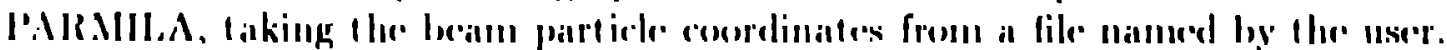

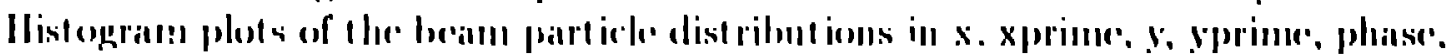

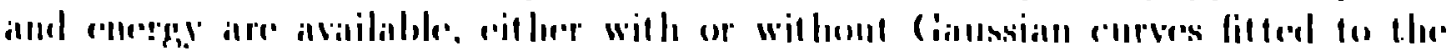

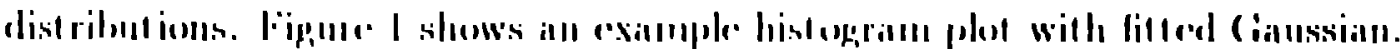

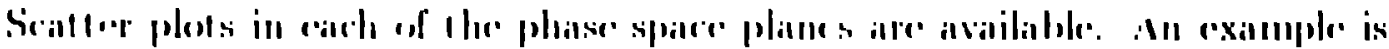

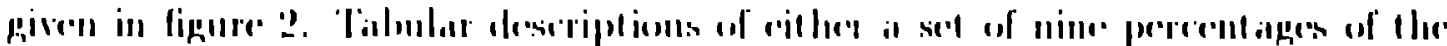

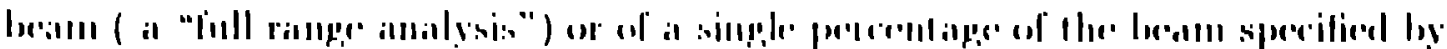

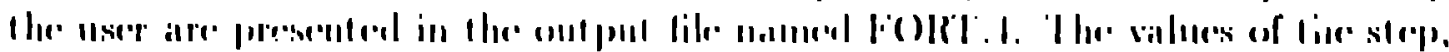

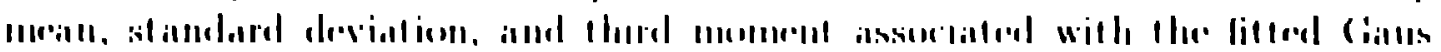

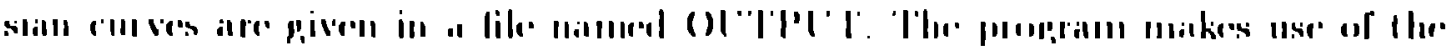

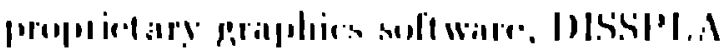

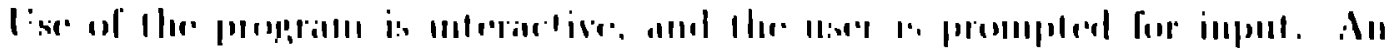

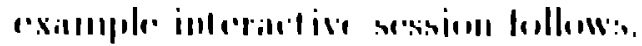




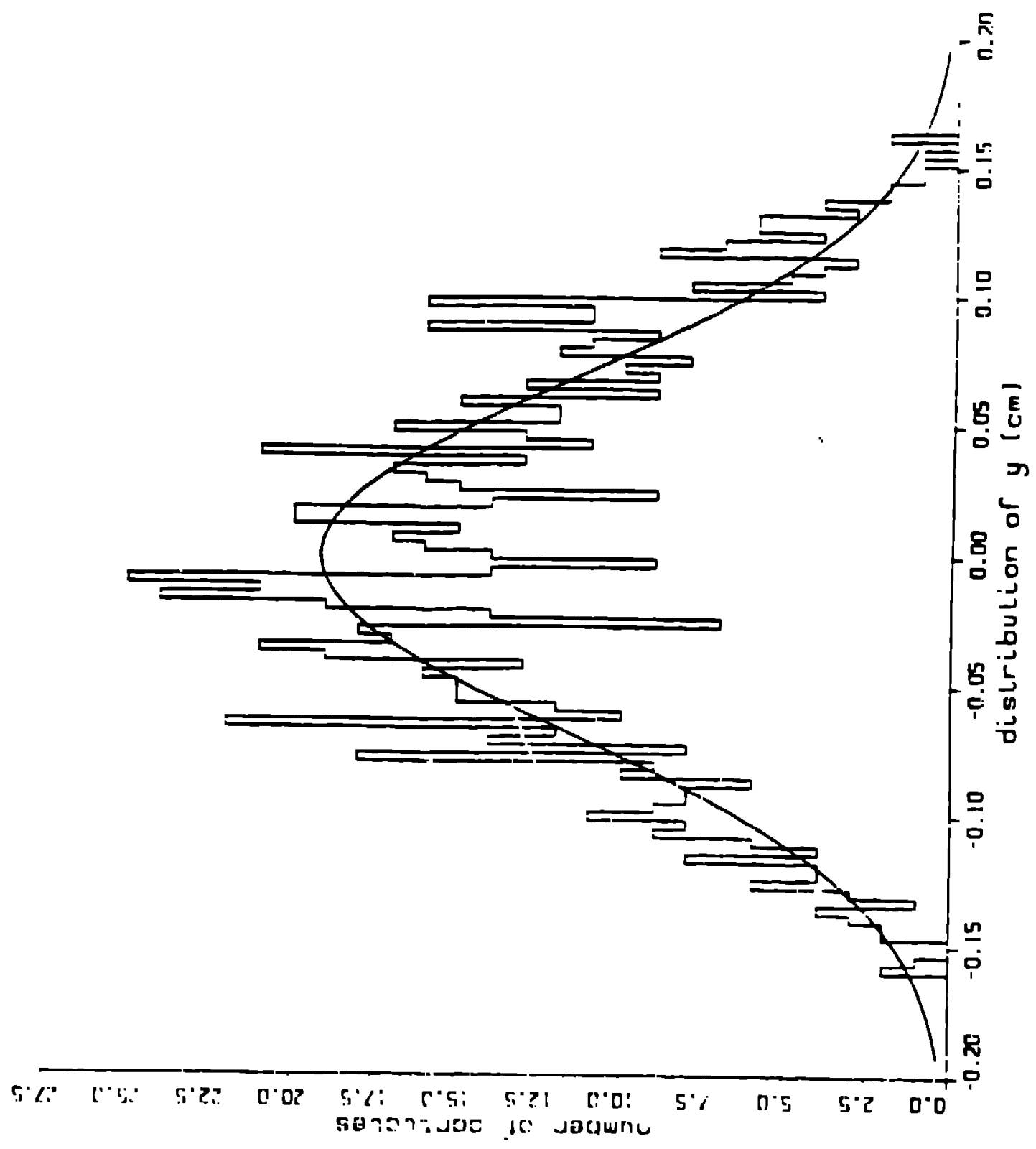

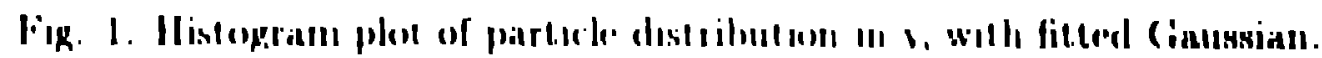




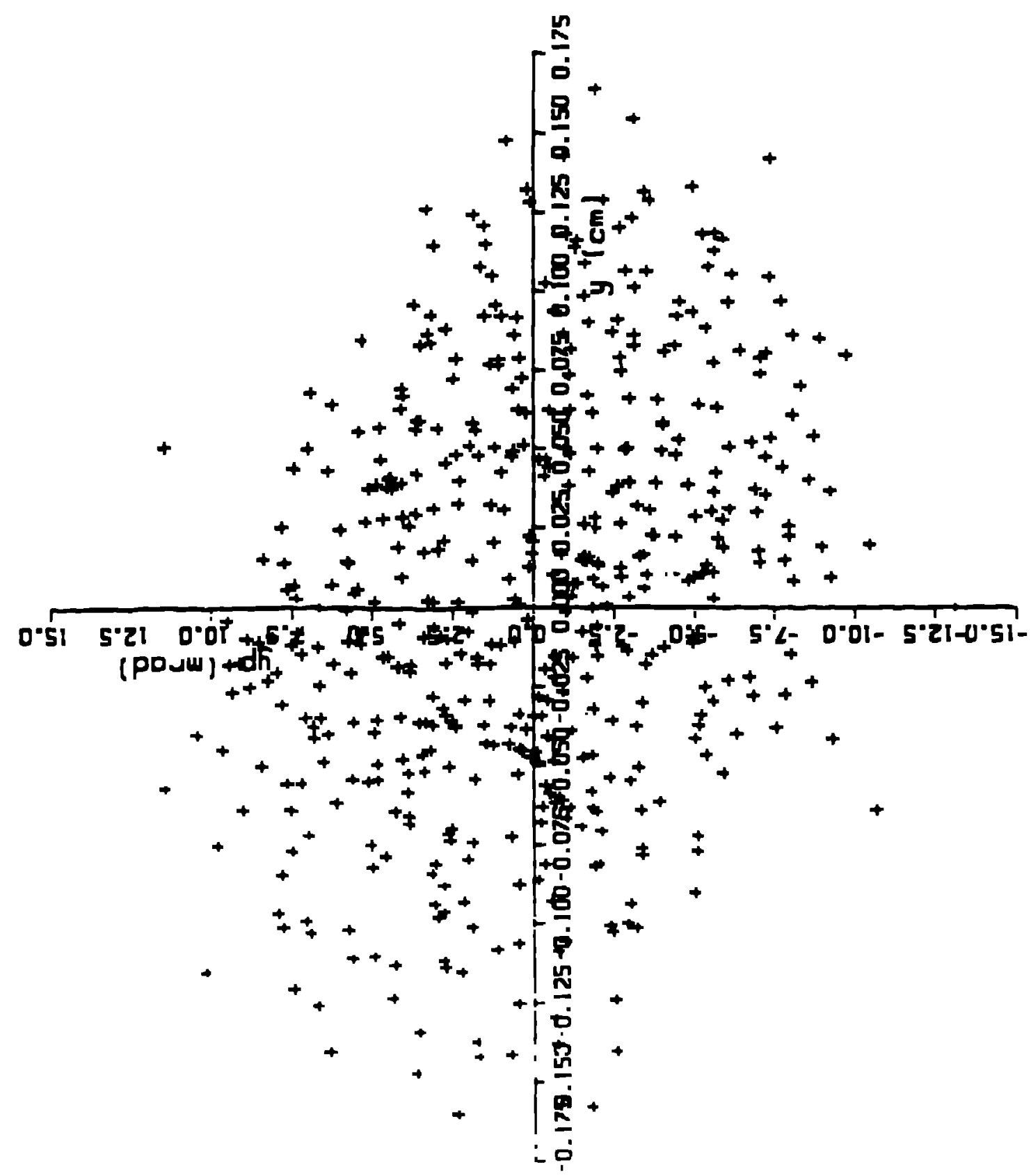

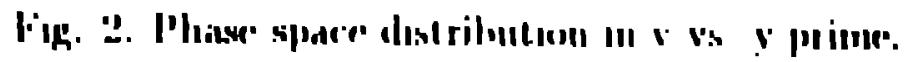




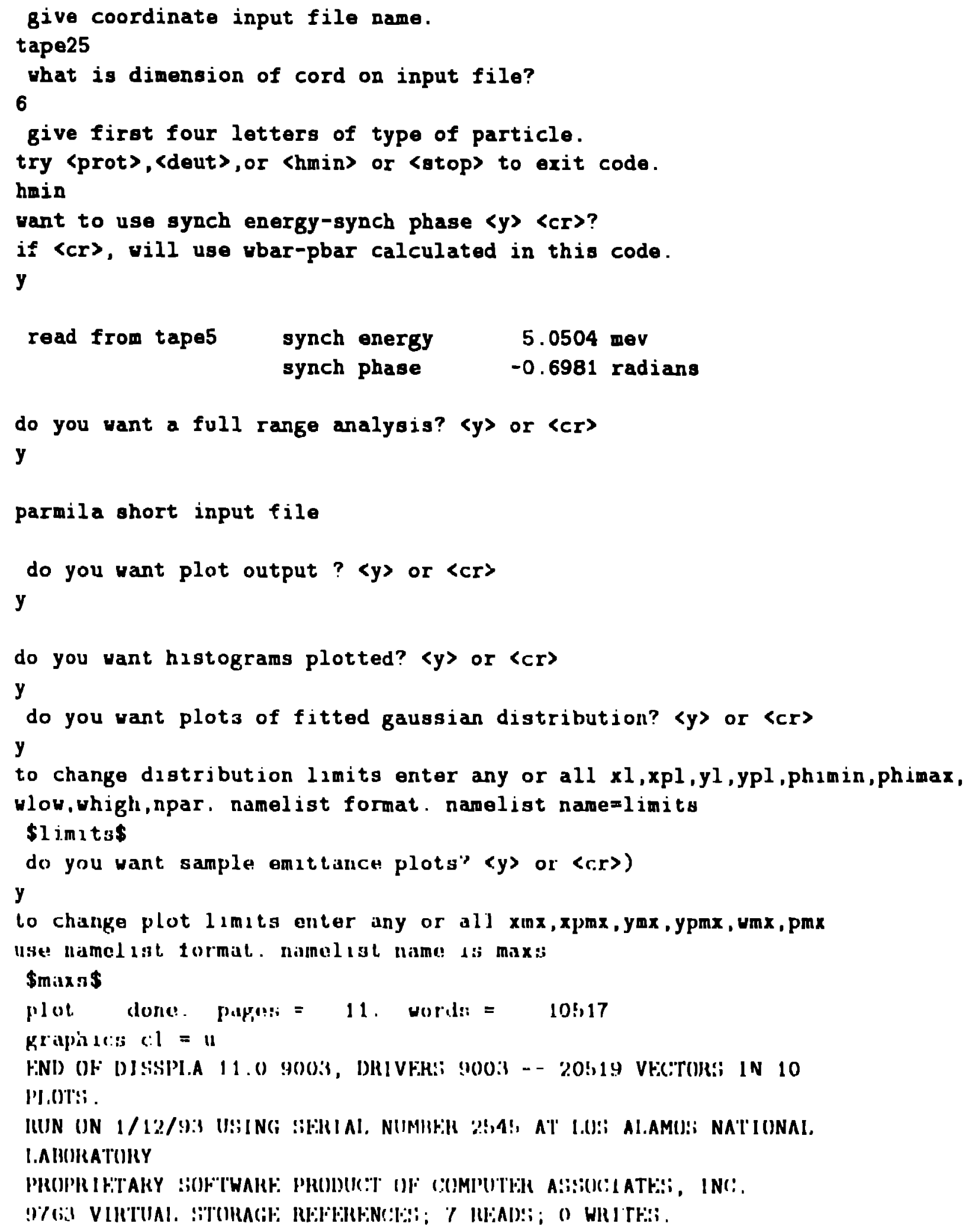




\section{CONCLUSIONS}

The manual, the UNIC:OS version of PARMILA, or the VAX/VMS version can be obtained by sending a request to The Los Alamos Accelerator ('ocle (iroup by one of the means given below.

Mail request to:

Los Alamos Arcelerator Ciode Ciroup (LA AC'(i)

Mail Stop IIs:J

Los Alamos National laboratory

I.os Alamos, New Mexico sit5.15

I'SSI

Phone:

$(50.5) 6(37-9131$

I'-Miail:

latacgulanl.gov

Please include the following information with your recpuest: code and/or documentation reyuested, your name, orgatization, address, phone mumber, fax numher, and li-mail address, and the computer and operating syste'm on which you intend to use the program.

I'he LAAC ( is restricted in its dealings with persons from countries on the

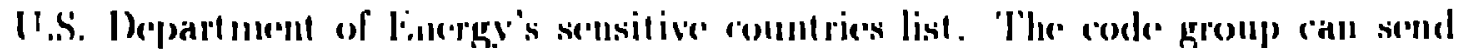
such persons documentiation, but lhey must repulest software from lhe binergy

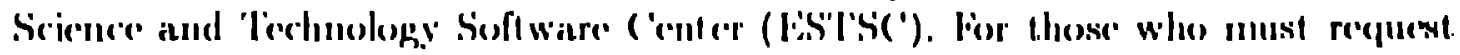
sofeware from the bo'l's(', the center call be reached as follows:

Plone: (615) $576(6 \cdot 2606)$

Fix: $\quad(6.15) 5 \pi(i 28(i)$

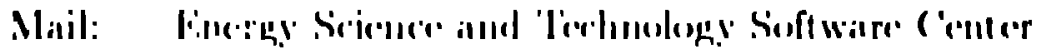

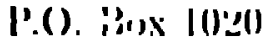

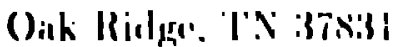

I'Sil

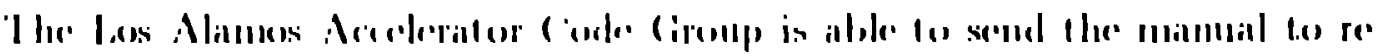
questors in sensilove comblries.

\section{References}

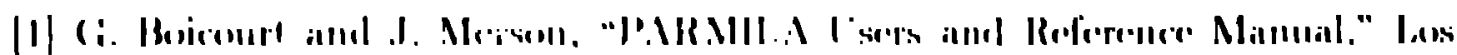

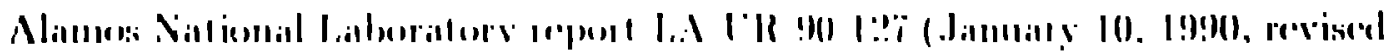

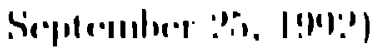

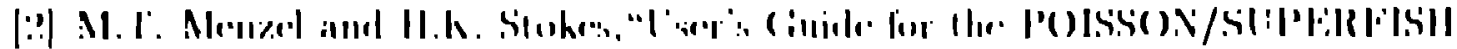

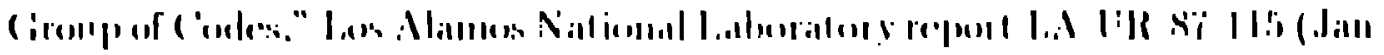
niary $(n) i i)$ 
[:3] Los Alamos Arcelerator ('ode (iroup. "POLSSON/SLPERFISII Reference" Manual," Los Alamos National Laboratory report LA-I!R-si-126 (January 1987)

[1] Thomas P'. Wangler, private communication, October 1991

[5] Cieorge H. Neuschacfer, private communication, Decentber 21, 1992 